\title{
Protein Prosthesis: 1,5-Disubstituted[1,2,3]Triazoles as cis-Peptide Bond Surrogates
}

\author{
Annie Tam, Ulrich Arnold, Matthew B. Soellner, Ronald T. Raines*
}

Departments of Chemistry and Biochemistry, University of Wisconsin, Madison, Wisconsin 53706, and Department of Biochemistry and Biotechnology, Martin-Luther University, 06099 Halle, Germany

\begin{tabular}{|c|c|c|c|}
\hline Page & Contents & Page & Contents \\
\hline S1 & Table of Contents & S46 & ${ }^{13} \mathrm{C}$ NMR Spectrum of Compound 14 \\
\hline S2-S14 & Experimental Procedures & S47 & ${ }^{1} \mathrm{H}$ NMR Spectrum of Compound 15 \\
\hline S14 & References & S48 & ${ }^{13} \mathrm{C}$ NMR Spectrum of Compound 15 \\
\hline S15 & Tables S-1 and S-2: Molecular Masses & S49 & ${ }^{1} \mathrm{H}$ NMR Spectrum of Compound 22 \\
\hline S16 & Table S-3: Crystal Data for 12 & S50 & ${ }^{13} \mathrm{C}$ NMR Spectrum of Compound 22 \\
\hline S17 & Table S-4: Atomic Coordinates for 12 & S51 & ${ }^{1} \mathrm{H}$ NMR Spectrum of Compound 23 \\
\hline S18-S19 & Table S-5: Bond Lengths and Angles for 12 & S52 & ${ }^{13} \mathrm{C}$ NMR Spectrum of Compound 23 \\
\hline S20 & Table S-6: Displacement Parameters for 12 & S53 & ${ }^{1} \mathrm{H}$ NMR Spectrum of Compound $\mathbf{2 4}$ \\
\hline S21 & Table S-7: Hydrogen Parameters for 12 & S54 & ${ }^{13} \mathrm{C}$ NMR Spectrum of Compound 24 \\
\hline S22 & Table S-8: Torsion Angles for 12 & S55 & ${ }^{1} \mathrm{H}$ NMR Spectrum of Compound 25 \\
\hline S23 & Table S-9: Hydrogen Bonds for 12 & S56 & ${ }^{13} \mathrm{C}$ NMR Spectrum of Compound 25 \\
\hline S24 & Figures S-1 and S-2: Chiral HPLC Traces & S57 & ${ }^{1} \mathrm{H}$ NMR Spectrum of Compound $\mathbf{2 6}$ \\
\hline S25 & Figures S-3 and S-4: CD Spectroscopy & S58 & ${ }^{13} \mathrm{C}$ NMR Spectrum of Compound $\mathbf{2 6}$ \\
\hline S26 & Figure S-5: ORTEP Diagram of 12 & S59 & ${ }^{1} \mathrm{H}$ NMR Spectrum of Compound 27 \\
\hline S27 & ${ }^{1} \mathrm{H}$ NMR Spectrum of Compound 1 & S60 & ${ }^{13} \mathrm{C}$ NMR Spectrum of Compound 27 \\
\hline S28 & ${ }^{13} \mathrm{C}$ NMR Spectrum of Compound 1 & S61 & ${ }^{1} \mathrm{H}$ NMR Spectrum of Compound 28 \\
\hline S29 & ${ }^{1} \mathrm{H}$ NMR Spectrum of Compound 2 & S62 & ${ }^{13} \mathrm{C}$ NMR Spectrum of Compound $\mathbf{2 8}$ \\
\hline S30 & ${ }^{13} \mathrm{C}$ NMR Spectrum of Compound 2 & S63 & ${ }^{1} \mathrm{H}$ NMR Spectrum of Compound 29 \\
\hline S31 & ${ }^{1} \mathrm{H}$ NMR Spectrum of Compound 4 & S64 & ${ }^{13} \mathrm{C}$ NMR Spectrum of Compound 29 \\
\hline S32 & ${ }^{13} \mathrm{C}$ NMR Spectrum of Compound 4 & S65 & ${ }^{1} \mathrm{H}$ NMR Spectrum of Compound $\mathbf{3 0}$ \\
\hline S33 & ${ }^{1} \mathrm{H}$ NMR Spectrum of Compound 8 & S66 & ${ }^{13} \mathrm{C}$ NMR Spectrum of Compound $\mathbf{3 0}$ \\
\hline S34 & ${ }^{13} \mathrm{C}$ NMR Spectrum of Compound 8 & S67 & ${ }^{1} \mathrm{H}$ NMR Spectrum of Compound 31 \\
\hline S35 & ${ }^{1} \mathrm{H}$ NMR Spectrum of Compound 9 & S68 & ${ }^{13} \mathrm{C}$ NMR Spectrum of Compound 31 \\
\hline S36 & ${ }^{13} \mathrm{C}$ NMR Spectrum of Compound 9 & S69 & ${ }^{1} \mathrm{H}$ NMR Spectrum of Compound 32 \\
\hline S37 & ${ }^{1} \mathrm{H}$ NMR Spectrum of Compound 10 & S70 & ${ }^{13} \mathrm{C}$ NMR Spectrum of Compound 32 \\
\hline S38 & ${ }^{13} \mathrm{C}$ NMR Spectrum of Compound 10 & S71 & ${ }^{1} \mathrm{H}$ NMR Spectrum of Compound 33 \\
\hline S39 & ${ }^{1} \mathrm{H}$ NMR Spectrum of Compound 11 & S72 & ${ }^{13} \mathrm{C}$ NMR Spectrum of Compound 33 \\
\hline S40 & ${ }^{13} \mathrm{C}$ NMR Spectrum of Compound 11 & S73 & ${ }^{1} \mathrm{H}$ NMR Spectrum of Compound 34 \\
\hline S41 & ${ }^{1} \mathrm{H}$ NMR Spectrum of Compound 12 & S74 & ${ }^{13} \mathrm{C}$ NMR Spectrum of Compound 34 \\
\hline S42 & ${ }^{13} \mathrm{C}$ NMR Spectrum of Compound 12 & S75 & ${ }^{1} \mathrm{H}$ NMR Spectrum of Compound 35 \\
\hline S43 & ${ }^{1} \mathrm{H}$ NMR Spectrum of Compound 13 & S76 & ${ }^{13} \mathrm{C}$ NMR Spectrum of Compound 35 \\
\hline S44 & ${ }^{13} \mathrm{C}$ NMR Spectrum of Compound 13 & S77 & ${ }^{1} \mathrm{H}$ NMR Spectrum of Compound $\mathbf{3 6}$ \\
\hline S45 & ${ }^{1} \mathrm{H}$ NMR Spectrum of Compound 14 & S78 & ${ }^{13} \mathrm{C}$ NMR Spectrum of Compound 36 \\
\hline
\end{tabular}


General Experimental. Reagent chemicals were obtained from commercial suppliers, and reagent grade solvents were used without further purification. Anhydrous THF, DMF, and $\mathrm{CH}_{2} \mathrm{Cl}_{2}$ were from a CYCLE-TAINER ${ }^{\circledR}$ solvent delivery system (Baker). Procedures were performed at room temperature $\left(\sim 23{ }^{\circ} \mathrm{C}\right)$ unless indicated otherwise. Reactions were monitored by thin-layer chromatography with visualization by UV light or staining with $\mathrm{KMnO}_{4}$, ninhydrin, or $\mathrm{I}_{2}$. Compound purification was carried out with flash chromatography on silica gel, which had a mesh of $230-400$ (ASTM) and a pore size of $60 \AA$. The removal of solvents and other volatile materials "under reduced pressure" refers to the use of a rotary evaporator at water-aspirator pressure ( $<20$ torr) and a water bath of $<40{ }^{\circ} \mathrm{C}$.

Instrumentation. NMR spectra were acquired at ambient temperature with a Bruker DMX400 Avance spectrometer $\left({ }^{1} \mathrm{H}, 400 \mathrm{MHz} ;{ }^{13} \mathrm{C}, 100.6 \mathrm{MHz}\right)$ or Bruker Avance DMX-500 spectrometer $\left({ }^{1} \mathrm{H}, 500 \mathrm{MHz} ;{ }^{13} \mathrm{C}, 125.7 \mathrm{MHz}\right)$ at the National Magnetic Resonance Facility at Madison (NMRFAM). Carbon-13 spectra were proton-decoupled.

Mass spectrometry was performed with a Micromass LCT (electrospray ionization, ESI) in the Mass Spectrometry Facility in the Department of Chemistry, UW-Madison, or a Reflex Bruker-Franzen mass spectrometer (matrix-assisted laser desorption-time-of-flight, MALDITOF) at Martin-Luther University.

General Procedure to Generate Weinreb Amide. The $N$-protected amino acid (1.0 mmol) and HOBT $(1.0 \mathrm{mmol})$ was dissolved in anhydrous DMF $(8 \mathrm{~mL})$, and DIC $(1.0 \mathrm{mmol})$ was added. The resulting solution was stirred for $20 \mathrm{~min}$. $N, O$-Dimethylhydroxylamine hydrochloride $(1.0 \mathrm{mmol})$ was added, followed by DIEA $(1.0 \mathrm{mmol})$. The resulting solution was stirred for $8 \mathrm{~h}$. Solvent was removed under reduced pressure, and the crude oil was purified by flash chromatography to give the desired Weinreb amide.

General Procedure to Generate $\boldsymbol{N}$-Protected Aminoalkyne. ${ }^{1}$ The Weinreb amide (1 mmol) was dissolved in anhydrous $\mathrm{CH}_{2} \mathrm{Cl}_{2}(8 \mathrm{~mL})$, and the resulting solution was cooled to $-78{ }^{\circ} \mathrm{C}$ with a dry ice/acetone bath. Diisobutylaluminum hydride $\left(1.2 \mathrm{mmol}, 1 \mathrm{M}\right.$ in $\left.\mathrm{CH}_{2} \mathrm{Cl}_{2}\right)$ was added dropwise, and the resulting mixture was stirred at $-78^{\circ} \mathrm{C}$ for $40 \mathrm{~min}$. Excess hydride was quenched by the addition of anhydrous $\mathrm{MeOH}(2 \mathrm{~mL})$, and the resulting solution was warmed to $0{ }^{\circ} \mathrm{C}$ with an ice/water bath. Potassium carbonate $(2 \mathrm{mmol})$ and the Bestmann-Ohira reagent ${ }^{2}$ $(1.2 \mathrm{mmol})$ was added to the reaction mixture. The resulting solution was stirred at RT for $8 \mathrm{~h}$. The solvents were removed under reduced pressure, and the crude residue was dissolved in EtOAc $(10 \mathrm{~mL})$ and water $(10 \mathrm{~mL})$. The layers were partitioned, and the organic extracts were washed with brine and dried over anhydrous $\mathrm{MgSO}_{4}(\mathrm{~s})$. The solvent was removed under reduced pressure, and the crude residue was purified by flash chromatography to give the desired alkyne.

Azide 1. (2S)-2-Azido-1-propionic acid was synthesized from L-alanine according to the procedure of Lundquist and Pelletier. ${ }^{3}$ (2S)-2-Azido-1-propionic acid (1.66 g, $14.4 \mathrm{mmol}$ ) was dissolved in anhydrous $\mathrm{CH}_{2} \mathrm{Cl}_{2}(91 \mathrm{~mL})$ and cooled to $-78^{\circ} \mathrm{C}$ with a dry ice/acetone bath. Isobutylene $(46 \mathrm{~mL})$ was condensed with a cold finger $\left(-78^{\circ} \mathrm{C}\right)$ in a separate flask and poured into the reaction mixture. Concentrated $\mathrm{H}_{2} \mathrm{SO}_{4}$ ( 2 drops) was added to the resulting mixture, and the reaction flask was sealed with a rubber septa and allowed to slowly warm to room temperature. (CAUTION: Rubber septa may expand as the temperature reaches room temperature. Proper shielding should be used.) The reaction mixture was allowed to stir at room temperature for $72 \mathrm{~h}$, after which the reaction was vented carefully with a needle. Saturated $\mathrm{NaHCO}_{3}$ was added, and the organic layer was separated and washed with brine. The organic extracts were dried over anhydrous $\mathrm{MgSO}_{4}(\mathrm{~s})$ and filtered, and the filtrate was concentrated to yield a colorless oil that was purified by flash chromatography (silica gel, 1:1 ethyl 
acetate/hexanes) to give azide 1 as a colorless oil in $81 \%$ yield. Spectral data. ${ }^{1} \mathrm{H}$ NMR $\left(\mathrm{CDCl}_{3}\right.$, $400 \mathrm{MHz}) \delta 3.79(\mathrm{q}, J=7.1 \mathrm{~Hz}, 1 \mathrm{H}), 1.50(\mathrm{~s}, 9 \mathrm{H}), 1.43(\mathrm{~d}, J=7.0 \mathrm{~Hz}, 3 \mathrm{H}) \mathrm{ppm} ;{ }^{13} \mathrm{C}$ NMR $\left(\mathrm{CDCl}_{3}, 100.6 \mathrm{MHz}\right) \delta 170.38,82.90,28.21,16.97 \mathrm{ppm} ; \mathrm{MS}$ (ESI) $m / z 194.0898\left(\mathrm{MNa}^{+}\right.$ $\left.\left[\mathrm{C}_{7} \mathrm{H}_{13} \mathrm{~N}_{3} \mathrm{O}_{2} \mathrm{Na}^{+}\right]=194.0905\right)$.

Azide 2. (2S)-2-Azido-1-propionic acid was synthesized from L-alanine according to the procedure of Lundquist and Pelletier. ${ }^{3}$ (2S)-2-Azido-1-propionic acid (2.0 g, $\left.17.3 \mathrm{mmol}\right)$ was dissolved in $\mathrm{MeOH}(105 \mathrm{~mL})$, and the resulting solution was cooled to $0{ }^{\circ} \mathrm{C}$ with an ice/water bath. Cesium carbonate $(2.83 \mathrm{~g}, 8.69 \mathrm{mmol})$ was dissolved in water $(68 \mathrm{~mL})$, and the resulting solution was cooled to $0{ }^{\circ} \mathrm{C}$ with an ice/water bath. The cesium carbonate solution was added to the solution of azide, and the resulting reaction mixture was stirred for $5 \mathrm{~min}$. Solvent was removed under reduced pressure as an azeotrope with toluene to give the cesium salt of (2S)-2azido-1-propionic acid as a colorless oil. This oil was dissolved in DMF $(130 \mathrm{~mL})$, and the resulting solution was cooled to $0{ }^{\circ} \mathrm{C}$ with an ice/water bath. Benzyl bromide $(2.06 \mathrm{~mL}$, $17.3 \mathrm{mmol}$ ) was added to the reaction mixture, and the resulting solution was allowed to slowly warm to RT and stirred overnight. Solvent was removed under reduced pressure. The resulting residue was dissolved in $\mathrm{CH}_{2} \mathrm{Cl}_{2}$, and the insoluble white salt was filtered. The filtrate was concentrated under reduced pressure, and the crude residue was purified by flash chromatography (silica gel, 1:1 ethyl acetate/hexanes) to give azide $\mathbf{2}$ as colorless oil in $73 \%$ yield. Spectral data. ${ }^{1} \mathrm{H}$ NMR $\left(\mathrm{CDCl}_{3}, 400 \mathrm{MHz}\right) \delta 7.38-7.36(\mathrm{~m}, 5 \mathrm{H}), 3.98(\mathrm{q}, J=7.2 \mathrm{~Hz}, 1 \mathrm{H})$, $1.48(\mathrm{~d}, J=7.0 \mathrm{~Hz}, 3 \mathrm{H}) \mathrm{ppm} ;{ }^{13} \mathrm{C} \mathrm{NMR}\left(\mathrm{CDCl}_{3}, 100.6 \mathrm{MHz}\right) \delta 171.05,135.28,128.87,128.79$, 128.53, 67.65, 57.53, 16.95 ppm; MS (ESI) $m / z 228.0747\left(\mathrm{MNa}^{+}\left[\mathrm{C}_{10} \mathrm{H}_{11} \mathrm{~N}_{3} \mathrm{O}_{2} \mathrm{Na}^{+}\right]=228.0749\right)$.

Alkyne 3. Alkyne 3 was synthesized according to reports published previously. ${ }^{4}$ Spectral data. Spectral data were as reported previously. ${ }^{4}$

Alkyne 4. Compound $22(638 \mathrm{mg}, 1.39 \mathrm{mmol})$ was reacted according to the general procedure. The crude residue was purified by flash chromatography (silica gel, 1:4:15 ethyl acetate/hexanes $/ \mathrm{CH}_{2} \mathrm{Cl}_{2}$ ) to give alkyne $\mathbf{4}$ as a white solid in $29 \%$ yield. Spectral data. ${ }^{1} \mathrm{H}$ NMR $\left(\mathrm{CDCl}_{3}, 500 \mathrm{MHz}\right) \delta 7.30-7.22(\mathrm{~m}, 15 \mathrm{H}), 6.88(\mathrm{bs}, 1 \mathrm{H}), 6.03(\mathrm{~d}, J=5.9 \mathrm{~Hz}, 1 \mathrm{H}), 4.73-4.66(\mathrm{~m}$, $1 \mathrm{H}), 2.71-2.62(\mathrm{~m}, 2 \mathrm{H}), 2.35(\mathrm{~s}, 1 \mathrm{H}), 1.40(\mathrm{~s}, 9 \mathrm{H}) \mathrm{ppm} ;{ }^{13} \mathrm{C} \mathrm{NMR}\left(\mathrm{CDCl}_{3}, 125 \mathrm{MHz}\right) \delta 169.26$, $155.10,144.34,128.86,128.19,127.35,82.85,80.08,71.58,71.03,41.78,40.05,28.46$ ppm; MS (ESI) $m / z$ 477.2159 $\left(\mathrm{MNa}^{+}\left[\mathrm{C}_{29} \mathrm{H}_{30} \mathrm{~N}_{2} \mathrm{O}_{3} \mathrm{Na}^{+}\right]=477.2154\right)$.

Alkyne 5. Commercially-available Boc-L-alaninal (100 $\mathrm{mg}, 0.58 \mathrm{mmol})$ was reacted according to the general procedure. The crude residue was purified by flash chromatography (silica gel, $\mathrm{CH}_{2} \mathrm{Cl}_{2}$ ) to give alkyne $\mathbf{5}$ as an white solid in $33 \%$ yield. Spectral data. Spectral data were as reported previously. ${ }^{5}$

Alkyne 6. Boc-L-phenylalaninal $(497 \mathrm{mg}, 2.0 \mathrm{mmol}$ ) was reacted according to the general procedure. The crude residue was purified by flash chromatography (silica gel, $30 \% \mathrm{v} / \mathrm{v}$ hexanes in $\mathrm{CH}_{2} \mathrm{Cl}_{2}$ ) to give alkyne $\mathbf{6}$ as a white solid in $32 \%$ yield. Spectral data. Spectral data were as reported previously. ${ }^{5}$

Alkyne 7. $N$-(tert-Butoxycarbony)-L-valine $\quad N^{\prime}$-methoxy- $N^{\prime}$-methylamide (447 $\mathrm{mg}$, $2.22 \mathrm{mmol}$ ) was reacted according to the general procedure. The crude residue was purified by flash chromatography (silica gel, 30\% v/v hexanes in $\mathrm{CH}_{2} \mathrm{Cl}_{2}$ ) to give alkyne 7 as a white solid in $48 \%$ yield. Spectral data. Spectral data were as reported previously. ${ }^{5}$

Alkyne 8. Alkyne $7(100 \mathrm{mg}, 0.51 \mathrm{mmol})$ was dissolved in $4 \mathrm{~N} \mathrm{HCl}$ in dioxane $(5 \mathrm{~mL})$ and cooled to $0{ }^{\circ} \mathrm{C}$ with an ice/water bath. The reaction was completed in $1 \mathrm{~h}$ as judged by TLC, and solvent was removed under reduced pressure to yield a crude white solid. The solid was dissolved in DMF ( $5 \mathrm{~mL})$. Fmoc-OSu (174 $\mathrm{mg}, 0.52 \mathrm{mmol})$ was added to the resulting solution, 
followed by DIEA (176 $\mu \mathrm{L}, 1.0 \mathrm{mmol})$. The resulting mixture was stirred for $8 \mathrm{~h}$. Solvent was removed under reduced pressure, and the residue was dissolved in $\mathrm{CH}_{2} \mathrm{Cl}_{2}(10 \mathrm{~mL})$ and washed with $0.1 \mathrm{~N} \mathrm{HCl}$ and brine. The organic extracts were dried over anhydrous $\mathrm{MgSO}_{4}(\mathrm{~s})$, and concentrated. The crude residue was purified by flash chromatography (silica gel, $50 \% \mathrm{v} / \mathrm{v}$ EtOAc in hexanes) to give alkyne 8 as a white solid in $57 \%$ yield. Spectral data. ${ }^{1} \mathrm{H}$ NMR $\left(\mathrm{CDCl}_{3}, 400 \mathrm{MHz}\right) \delta 7.78(\mathrm{~d}, J=7.5 \mathrm{~Hz}, 2 \mathrm{H}), 7.60(\mathrm{~d}, J=7.0 \mathrm{~Hz}, 2 \mathrm{H}), 7.41(\mathrm{t}, J=7.1 \mathrm{~Hz}, 2 \mathrm{H})$, 7.35-7.26 (m, 2H), 4.94 (bs, 1H), 4.45-4.37 (m, 3H), 4.23 (t, $J=7.8 \mathrm{~Hz}, 1 \mathrm{H}), 2.29$ (d, $J=$ $2.4 \mathrm{~Hz}, 1 \mathrm{H}), 1.93(\mathrm{sep}, J=6.5 \mathrm{~Hz}, 1 \mathrm{H}), 1.00(\mathrm{~d}, J=6.8 \mathrm{~Hz}, 6 \mathrm{H}) \mathrm{ppm} ;{ }^{13} \mathrm{C} \mathrm{NMR}\left(\mathrm{CDCl}_{3}, 100.6\right.$ MHz) $\delta 155.78,144.01,141.53,128.34,127.92,125.22,120.20,81.83,72.42,67.09,49.38$, 47.42, 33.02, 18.90, 17.76 ppm; MS (ESI) $m / z 342.1456\left(\mathrm{MNa}^{+}\left[\mathrm{C}_{21} \mathrm{H}_{21} \mathrm{NO}_{2} \mathrm{Na}^{+}\right]=342.1470\right)$.

Triazole 9. Azide 1 (110 mg, $0.64 \mathrm{mmol})$ and alkyne 3 (100 mg, $0.64 \mathrm{mmol})$ were dissolved in degassed toluene $(4 \mathrm{~mL})$ under an inert atmosphere of $\operatorname{Ar}(\mathrm{g})$. Chloro(1,5cyclooctadiene)(pentamethylcyclopentadienyl)ruthenium (II) $(9.8 \mathrm{mg}, 0.026 \mathrm{mmol})$ was added to the mixture, and the resulting solution was stirred for $12 \mathrm{~h}$. The solvent was removed under reduced pressure, and the crude residue was purified by flash chromatography (silica gel, $2 \% \mathrm{v} / \mathrm{v}$ $\mathrm{MeOH}$ in $\mathrm{CH}_{2} \mathrm{Cl}_{2}$ ) to give triazole 9 as a yellow oil in $45 \%$ yield. Spectral data. ${ }^{1} \mathrm{H}$ NMR $\left(\mathrm{CDCl}_{3}, 400 \mathrm{MHz}\right) \delta 7.60(\mathrm{~s}, 1 \mathrm{H}), 5.27(\mathrm{q}, J=6.5 \mathrm{~Hz}, 1 \mathrm{H}), 5.11(\mathrm{bs}, 1 \mathrm{H}), 4.48-4.32(\mathrm{~m}, 2 \mathrm{H})$, $1.90(\mathrm{~d}, J=7.4 \mathrm{~Hz}, 3 \mathrm{H}), 1.45(\mathrm{~s}, 9 \mathrm{H}), 1.43(\mathrm{~s}, 9 \mathrm{H}) \mathrm{ppm} ;{ }^{13} \mathrm{C} \mathrm{NMR}\left(\mathrm{CDCl}_{3}, 100.6 \mathrm{MHz}\right) \delta$ $168.31,155.73,135.10,133.54,83.54,80.54,57.24,33.47,28.47,27.97,16.96$ ppm; MS (ESI) $m / z 327.2028\left(\mathrm{MH}^{+}\left[\mathrm{C}_{15} \mathrm{H}_{26} \mathrm{~N}_{4} \mathrm{O}_{4} \mathrm{H}^{+}\right]=327.2032\right)$.

Triazole 10. Azide 1 (414 g, $2.2 \mathrm{mmol})$ and alkyne $4(1 \mathrm{~g}, 2.2 \mathrm{mmol})$ were dissolved in anhydrous 1,4-dioxane $(15 \mathrm{~mL})$ under an inert atmosphere of $\operatorname{Ar}(\mathrm{g})$. Chloro(1,5cyclooctadiene)(pentamethylcyclopentadienyl)ruthenium (II) $(33 \mathrm{mg}, 88 \mu \mathrm{mol})$ was added, and the resulting solution was heated to $60{ }^{\circ} \mathrm{C}$ with an oil bath and stirred for $12 \mathrm{~h}$. The solvent was removed under reduced pressure, and the crude residue was purified by flash chromatography (silica gel, 50:20:30 v/v/v $\mathrm{CH}_{2} \mathrm{Cl}_{2}$ :EtOAc:hexanes) to give triazole 10 as a white solid in $62 \%$ yield as a mixture diastereomers. Spectral data. ${ }^{1} \mathrm{H}$ NMR $\left(\mathrm{CDCl}_{3}, 400 \mathrm{MHz}\right) \delta 7.51(\mathrm{~s}, 1 \mathrm{H})$, $7.24-7.22(\mathrm{~m}, 9 \mathrm{H}), 7.06(\mathrm{~d}, J=6.9 \mathrm{~Hz}, 6 \mathrm{H}), 7.00(\mathrm{~s}, 1 \mathrm{H}), 5.76(\mathrm{bs}, 1 \mathrm{H}), 5.30(\mathrm{q}, J=7.8 \mathrm{~Hz}, 1 \mathrm{H})$, $5.08(\mathrm{q}, J=6.3 \mathrm{~Hz}, 1 \mathrm{H}), 3.12-2.78(\mathrm{~m}, 2 \mathrm{H}), 1.77(\mathrm{~d}, J=7.3 \mathrm{~Hz}, 3 \mathrm{H}), 1.40(\mathrm{~s}, 9 \mathrm{H}), 1.38(\mathrm{~s}, 9 \mathrm{H})$ ppm; ${ }^{13} \mathrm{C}$ NMR $\left(\mathrm{CDCl}_{3}, 100.6 \mathrm{MHz}\right) \delta 171.36,168.72,155.00,144.31,138.13,132.66,128.71$, $128.16,127.27,83.22,80.34,70.92,57.47,42.67,41.37,28.46,27.99,17.17 \mathrm{ppm}$; MS (ESI) $\mathrm{m} / \mathrm{z}$ $648.3146\left(\mathrm{MNa}^{+}\left[\mathrm{C}_{36} \mathrm{H}_{43} \mathrm{~N}_{5} \mathrm{O}_{5} \mathrm{Na}^{+}\right]=648.3162\right)$.

Triazole 11. Azide $2(784 \mathrm{mg}, 3.19 \mathrm{mmol})$ and alkyne $4(1.45 \mathrm{~g}, 3.19 \mathrm{mmol})$ was dissolved in anhydrous 1,4-dioxane $(22 \mathrm{~mL})$ under an inert atmosphere of $\operatorname{Ar}(\mathrm{g})$. Chloro(1,5cyclooctadiene)(pentamethylcyclopentadienyl)ruthenium (II) $(48 \mathrm{mg}, 0.13 \mathrm{mmol}$ ) was added, and the resulting solution was heated to $60^{\circ} \mathrm{C}$ with an oil bath and stirred for $12 \mathrm{~h}$. The solvent was removed under reduced pressure, and the crude residue was purified by flash chromatography (silica gel, 50:20:30 v/v/v $\mathrm{CH}_{2} \mathrm{Cl}_{2}$ :EtOAc:hexanes) to give triazole 11 as a white solid in $55 \%$ yield as a mixture diastereomers. Spectral data. ${ }^{1} \mathrm{H}$ NMR $\left(\mathrm{CDCl}_{3}, 400 \mathrm{MHz}\right) \delta$ $7.44(\mathrm{~s}, 1 \mathrm{H}), 7.30-7.16(\mathrm{~m}, 14 \mathrm{H}), 7.05(\mathrm{~d}, J=7.0 \mathrm{~Hz}, 6 \mathrm{H}), 5.83(\mathrm{~d}, J=8.9 \mathrm{~Hz}, 1 \mathrm{H}), 5.53(\mathrm{q}, J=$ $6.3 \mathrm{~Hz}, 1 \mathrm{H}), 5.13-5.05(\mathrm{~m}, 3 \mathrm{H}), 2.97-2.68(\mathrm{~m}, 2 \mathrm{H}), 1.75(\mathrm{~d}, J=7.3 \mathrm{~Hz}, 3 \mathrm{H}), 1.32(\mathrm{~s}, 9 \mathrm{H}) \mathrm{ppm}$; ${ }^{13} \mathrm{C}$ NMR $\left(\mathrm{CDCl}_{3}, 100.6 \mathrm{MHz}\right) \delta 169.52,168.56,155.02,144.27,138.65,135.10,132.25$, $128.69,128.68,128.52,128.16,128.05,127.17,80.18,70.82,67.74,56.61,42.11,41.31,28.35$, 17.33 ppm; MS (ESI) $m / z 682.3002\left(\mathrm{MNa}^{+}\left[\mathrm{C}_{16} \mathrm{H}_{28} \mathrm{~N}_{4} \mathrm{O}_{4} \mathrm{Na}^{+}\right]=682.3005\right)$.

Triazole 12. Azide $1(101 \mathrm{mg}, 0.59 \mathrm{mmol})$ and alkyne $5(100 \mathrm{mg}, 0.59 \mathrm{mmol})$ were dissolved in degassed toluene $(4 \mathrm{~mL})$ under an inert atmosphere of $\operatorname{Ar}(\mathrm{g})$. Chloro(1,5- 
cyclooctadiene)(pentamethylcyclopentadienyl)ruthenium (II) (9 $\mathrm{mg}, 0.024 \mathrm{mmol}$ ) was added, and the resulting solution was stirred for $12 \mathrm{~h}$. The solvent was removed under reduced pressure, and the crude residue was purified by flash chromatography (silica gel, $2 \% \mathrm{v} / \mathrm{v} \mathrm{MeOH}$ in $\left.\mathrm{CH}_{2} \mathrm{Cl}_{2}\right)$ to give triazole 12 as an off-white solid in $67 \%$ yield. Spectral data. ${ }^{1} \mathrm{H} \mathrm{NMR}\left(\mathrm{CDCl}_{3}\right.$, $400 \mathrm{MHz}) \delta 7.59(\mathrm{~s}, 1 \mathrm{H}), 5.12(\mathrm{q}, J=7.4 \mathrm{~Hz}, 1 \mathrm{H}), 4.96-4.91(\mathrm{~m}, 1 \mathrm{H}), 4.67-4.65(\mathrm{~m}, 1 \mathrm{H}), 1.92$ $(\mathrm{d}, J=7.4 \mathrm{~Hz}, 3 \mathrm{H}), 1.60(\mathrm{~d}, J=6.8 \mathrm{~Hz}, 3 \mathrm{H}), 1.45(\mathrm{~s}, 9 \mathrm{H}), 1.43(\mathrm{~s}, 9 \mathrm{H}) \mathrm{ppm} ;{ }^{13} \mathrm{C} \mathrm{NMR}\left(\mathrm{CDCl}_{3}\right.$, $100.6 \mathrm{MHz}) \delta 168.41,155.00,138.56,131.86,83.27,80.68,56.98,40.72,28.55,28.08,20.62$, 17.63 ppm; MS (ESI) $m / z 363.2025\left(\mathrm{MNa}^{+}\left[\mathrm{C}_{16} \mathrm{H}_{28} \mathrm{~N}_{4} \mathrm{O}_{4} \mathrm{Na}^{+}\right]=363.2008\right)$.

Triazole 13. Azide 1 (158 mg, $0.72 \mathrm{mmol})$ and alkyne $6(172 \mathrm{mg}, 0.70 \mathrm{mmol})$ were dissolved in anhydrous 1,4-dioxane $(7 \mathrm{~mL})$ under an inert atmosphere of $\operatorname{Ar}(\mathrm{g})$. Chloro(1,5cyclooctadiene)(pentamethylcyclopentadienyl)ruthenium (II) (11 $\mathrm{mg}, 0.03 \mathrm{mmol}$ ) was added, and the resulting solution was stirred for $12 \mathrm{~h}$. The solvent was removed under reduced pressure, and the crude residue was purified by flash chromatography (silica gel, 2:3:5 v/v/v ethyl acetate:hexanes: $\mathrm{CH}_{2} \mathrm{Cl}_{2}$ ) to give triazole 13 as an white solid in $90 \%$ yield. Spectral data. ${ }^{1} \mathrm{H}$ NMR $\left(\mathrm{CDCl}_{3}, 500 \mathrm{MHz}\right) \delta 7.64(\mathrm{~s}, 1 \mathrm{H}), 7.29-7.14(\mathrm{~m}, 5 \mathrm{H}), 5.07$ (bs, 1H), 4.95-4.84 (m, 2H), 3.23-3.12 (m, 2H), $1.72(\mathrm{~d}, J=5.5 \mathrm{~Hz}, 3 \mathrm{H}), 1.40(\mathrm{~s}, 9 \mathrm{H}), 1.34(\mathrm{~s}, 9 \mathrm{H}) \mathrm{ppm} ;{ }^{13} \mathrm{C} \mathrm{NMR}\left(\mathrm{CDCl}_{3}\right.$, $125 \mathrm{MHz}) \delta 168.13,154.95,137.97,136.28,131.73,129.50,128.79,127.21,83.08,80.46$, 56.84, 46.57, 41.75, 28.35, 27.92, $17.21 \mathrm{ppm}$; MS (ESI) $m / z$ 439.2317 $\left(\mathrm{MNa}^{+}\left[\mathrm{C}_{22} \mathrm{H}_{32} \mathrm{~N}_{4} \mathrm{O}_{4} \mathrm{Na}^{+}\right]\right.$ $=439.2321)$.

Triazole 14. Azide 1 (77 $\mathrm{mg}, 0.45 \mathrm{mmol})$ and alkyne 7 (89 $\mathrm{mg}, 0.45 \mathrm{mmol}$ ) were dissolved in degassed toluene $(3.8 \mathrm{~mL})$ under an inert atmosphere of $\operatorname{Ar}(\mathrm{g})$. Chloro(1,5cyclooctadiene)(pentamethylcyclopentadienyl)ruthenium (II) (7 mg, $18 \mu \mathrm{mol}$ ) was added, and the resulting solution was stirred for $12 \mathrm{~h}$. The solvent was removed under reduced pressure, and the crude residue was purified by flash chromatography ( silica gel, $2 \% \mathrm{v} / \mathrm{v} \mathrm{MeOH}$ in $\mathrm{CH}_{2} \mathrm{Cl}_{2}$ ) to give triazole 14 as an off-white solid in $92 \%$ yield. Spectral data. ${ }^{1} \mathrm{H}$ NMR $\left(\mathrm{CDCl}_{3}, 500 \mathrm{MHz}\right) \delta$ $7.55(\mathrm{~s}, 1 \mathrm{H}), 5.15(\mathrm{q}, J=6.8 \mathrm{~Hz}, 1 \mathrm{H}), 4.70(\mathrm{bs}, 1 \mathrm{H}), 4.62(\mathrm{~m}, 1 \mathrm{H}), 2.12(\mathrm{sep}, J=7.0 \mathrm{~Hz}, 1 \mathrm{H})$, $1.89(\mathrm{~d}, J=7.3 \mathrm{~Hz}, 3 \mathrm{H}), 1.43(\mathrm{~s}, 9 \mathrm{H}), 1.41(\mathrm{~s}, 9 \mathrm{H}), 1.05(\mathrm{~d}, J=6.7 \mathrm{~Hz}, 3 \mathrm{H}), 0.96(\mathrm{~d}, J=7.3 \mathrm{~Hz}$, 3H) $\mathrm{ppm} ;{ }^{13} \mathrm{C} \mathrm{NMR}\left(\mathrm{CDCl}_{3}, 125 \mathrm{MHz}\right) \delta 167.99,155.61,137.92,131.52,83.08,80.52,56.85$, 50.49, 33.06, 28.11, 27.99, 20.15, 18.49, 17.77 ppm; MS (ESI) $m / z ~ 369.2501 \quad\left(\mathrm{MH}^{+}\right.$ $\left.\left[\mathrm{C}_{18} \mathrm{H}_{32} \mathrm{~N}_{4} \mathrm{O}_{4} \mathrm{H}^{+}\right]=369.2502\right)$.

Triazole 15. Azide 1 (27 mg, $0.16 \mathrm{mmol})$ and alkyne 8 (50 $\mathrm{mg}, 0.16 \mathrm{mmol})$ were dissolved in degassed toluene $(1.0 \mathrm{~mL})$ under an inert atmosphere of $\operatorname{Ar}(\mathrm{g})$. Chloro(1,5cyclooctadiene)(pentamethylcyclopentadienyl)ruthenium (II) $(2.4 \mathrm{mg}, 6.3 \mu \mathrm{mol})$ was added, and the resulting solution was stirred for $12 \mathrm{~h}$. The solvent was removed under reduced pressure, and the crude residue was purified by flash chromatography (silica gel, $2 \% \mathrm{v} / \mathrm{v} \mathrm{MeOH}$ in $\mathrm{CH}_{2} \mathrm{Cl}_{2}$ ) to give triazole 15 as an off-white solid in 91\% yield. Spectral data. ${ }^{1} \mathrm{H} \mathrm{NMR}\left(\mathrm{CDCl}_{3}, 400 \mathrm{MHz}\right) \delta$ $7.75(\mathrm{~d}, J=7.5 \mathrm{~Hz}, 2 \mathrm{H}), 7.55$ (d, $J=7.3 \mathrm{~Hz}, 2 \mathrm{H}), 7.39$ (t, $J=5.9 \mathrm{~Hz}, 2 \mathrm{H}), 7.29$ (t, $J=7.0 \mathrm{~Hz}$, $2 \mathrm{H}), 5.23-5.16(\mathrm{~m}, 2 \mathrm{H}), 4.63-4.59(\mathrm{~m}, 2 \mathrm{H}), 4.26-4.19(\mathrm{~m}, 2 \mathrm{H}), 2.15(\mathrm{sep}, J=6.0 \mathrm{~Hz}, 1 \mathrm{H}), 1.89$ $(\mathrm{d}, J=7.5 \mathrm{~Hz}, 3 \mathrm{H}), 1.34(\mathrm{~s}, 9 \mathrm{H}), 0.99(\mathrm{~d}, J=6.0 \mathrm{~Hz}, 3 \mathrm{H}), 0.92(\mathrm{~d}, J=6.1 \mathrm{~Hz}, 3 \mathrm{H}) \mathrm{ppm} ;{ }^{13} \mathrm{C}$ NMR $\left(\mathrm{CDCl}_{3}, 100.6 \mathrm{MHz}\right) \delta 167.92,155.99,143.79,141.45,131.45,127.91,127.22,125.13$, $124.97,120.09,83.03,66.97,56.80,51.02,47.33,32.76,27.91,20.11,18.64,17.62$ ppm; MS (ESI) $m / z 513.2454\left(\mathrm{MNa}^{+}\left[\mathrm{C}_{28} \mathrm{H}_{34} \mathrm{~N}_{4} \mathrm{O}_{4} \mathrm{Na}^{+}\right]=513.2478\right)$. 

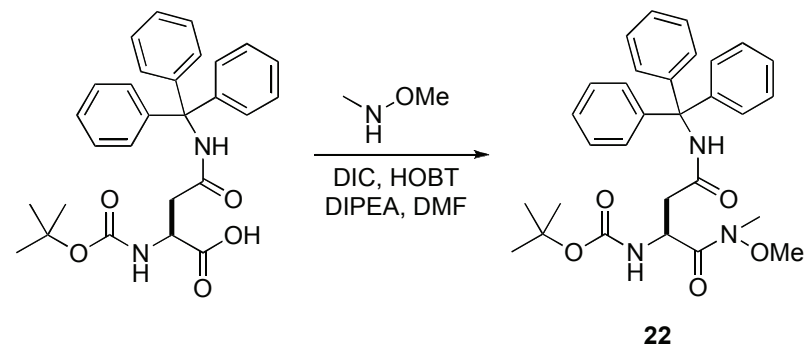

Compound 22. Boc-Asn(Trt)-OH $(5.0 \mathrm{~g}, 10.54 \mathrm{mmol})$ was reacted according to the general procedure. The crude residue was purified by flash chromatography (silica gel, $2 \% \mathrm{v} / \mathrm{v} \mathrm{MeOH}$ in $\left.\mathrm{CH}_{2} \mathrm{Cl}_{2}\right)$ to give compound 22 as a white solid in $93 \%$ yield. Spectral data. ${ }^{1} \mathrm{H}$ NMR $\left(\mathrm{CDCl}_{3}\right.$, $400 \mathrm{MHz}) \delta 7.29-7.20(\mathrm{~m}, 15 \mathrm{H}), 5.71-5.65(\mathrm{~m}, 1 \mathrm{H}), 5.00-4.92(\mathrm{~m}, 1 \mathrm{H}), 3.68(\mathrm{~s}, 3 \mathrm{H}), 3.12(\mathrm{~s}$, $3 \mathrm{H}), 2.78-2.59(\mathrm{~m}, 2 \mathrm{H}), 1.39$ (s, 9H) ppm; ${ }^{13} \mathrm{C} \mathrm{NMR}\left(\mathrm{CDCl}_{3}, 100.6 \mathrm{MHz}\right) \delta 168.52,155.51$, $144.75,128.96,128.09,127.11,80.21,70.84,61.79$, 48.64, 40.36, 28.52, 23.69 ppm; MS (ESI) $m / z 540.2499\left(\mathrm{MNa}^{+}\left[\mathrm{C}_{30} \mathrm{H}_{35} \mathrm{~N}_{3} \mathrm{O}_{5} \mathrm{Na}^{+}\right]=540.2474\right)$.

Scheme S1. Derivatization of triazoles 11 and 12 for solid-phase peptide synthesis.
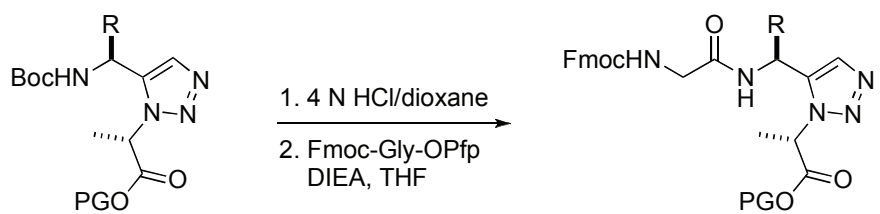

$11 \mathrm{R}=\mathrm{CH}_{2} \mathrm{CONH}_{2}(\mathrm{Trt}), \mathrm{PG}=\mathrm{Bn}$ $12 \mathrm{R}=\mathrm{CH}_{3}, \mathrm{PG}=t \mathrm{Bu}$

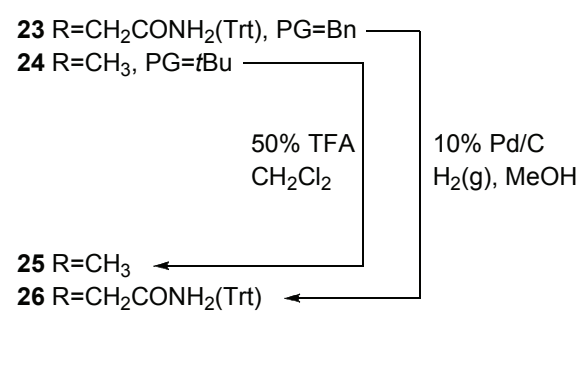

Triazole 23. Compound $11(272 \mathrm{mg}, 0.41 \mathrm{mmol})$ was dissolved in $4 \mathrm{~N} \mathrm{HCl}$ in dioxane $(6 \mathrm{~mL})$ and cooled to $0{ }^{\circ} \mathrm{C}$ with an ice/water bath. The reaction mixture was stirred until all the starting material was consumed $(1 \mathrm{~h})$, as judged by TLC. Solvent was removed under reduced pressure. In a separate round-bottom flask, FmocGlyOPfP $(210 \mathrm{mg}, 0.45 \mathrm{mmol})$ was dissolved in THF $(4.0 \mathrm{~mL})$. The crude residue from above was added, followed by DIEA (143 $\mu \mathrm{L}$, $0.82 \mathrm{mmol})$. The resulting reaction mixture was stirred for $12 \mathrm{~h}$. The solvent was removed under reduced pressure, and the crude residue was purified by flash chromatography (silica gel, $2 \% \mathrm{v} / \mathrm{v}$ $\mathrm{MeOH}$ in $\mathrm{CH}_{2} \mathrm{Cl}_{2}$ ) to give compound $\mathbf{2 3}$ as a white solid in $87 \%$ yield. Spectral data. ${ }^{1} \mathrm{H}$ NMR $\left(\mathrm{CDCl}_{3}, 400 \mathrm{MHz}\right) \delta 7.74(\mathrm{~d}, J=7.5 \mathrm{~Hz}, 2 \mathrm{H}), 7.51(\mathrm{~d}, J=6.5 \mathrm{~Hz}, 2 \mathrm{H}), 7.39(\mathrm{~s}, 1 \mathrm{H}), 7.37(\mathrm{t}, J=$ $6.5 \mathrm{~Hz}, 2 \mathrm{H}), 7.28-7.16(\mathrm{~m}, 16 \mathrm{H}), 7.05(\mathrm{~d}, J=7.0 \mathrm{~Hz}, 6 \mathrm{H}), 6.99(\mathrm{~s}, 1 \mathrm{H}), 5.48$ (q, $J=6.6 \mathrm{~Hz}, 1 \mathrm{H})$, $5.28-5.21(\mathrm{~m}, 1 \mathrm{H}), 5.05(\mathrm{~d}, J=3.8 \mathrm{~Hz}, 2 \mathrm{H}), 4.29-4.27(\mathrm{~m}, 2 \mathrm{H}), 4.12(\mathrm{t}, J=6.8 \mathrm{~Hz}, 1 \mathrm{H}), 3.50(\mathrm{~d}$, $J=4.5 \mathrm{~Hz}, 2 \mathrm{H}), 2.84(\mathrm{~d}, J=6.3 \mathrm{~Hz}, 2 \mathrm{H}), 1.80(\mathrm{~d}, J=7.2 \mathrm{~Hz}, 3 \mathrm{H}) \mathrm{ppm} ;{ }^{13} \mathrm{C} \mathrm{NMR}\left(\mathrm{CDCl}_{3}, 100.6\right.$ MHz) $\delta 169.68,168.73,168.49,156.67,144.22,143.93,141.47,138.10,135.07,132.28,128.84$, $128.74,128.24,128.19,127.94,127.40,127.28,125.26,125.22,120.17,71.09,67.99,67.30$, 
$56.89,47.18,44.17,40.66,40.33,17.35$ ppm; MS (ESI) $m / z 861.3368\left(\mathrm{MNa}^{+}\left[\mathrm{C}_{51} \mathrm{H}_{46} \mathrm{~N}_{6} \mathrm{O}_{6} \mathrm{Na}^{+}\right]\right.$ $=861.3377)$.

Triazole 24. Compound 12 (248 mg, $0.73 \mathrm{mmol})$ was dissolved in $30 \% \mathrm{v} / \mathrm{v}$ TFA in $\mathrm{CH}_{2} \mathrm{Cl}_{2}$ $(7 \mathrm{~mL})$ and cooled to $0{ }^{\circ} \mathrm{C}$ with an ice/water bath. The reaction mixture was stirred until all the starting material was consumed $(1 \mathrm{~h})$, as judged by TLC. The solvent was removed under reduced pressure, and excess TFA was removed as an azeotrope with toluene. In a separate round-bottom flask, FmocGlyOPfP $(371 \mathrm{mg}, 0.8 \mathrm{mmol})$ was dissolved in THF $(7 \mathrm{~mL})$. The crude residue from above was added, followed by DIEA $(279 \mu \mathrm{L}, 1.6 \mathrm{mmol})$. The resulting reaction mixture was stirred for $12 \mathrm{~h}$. Solvent was removed under reduced pressure, and the crude residue was purified by flash chromatography (silica gel, $2 \% \mathrm{v} / \mathrm{v} \mathrm{MeOH}$ in $\mathrm{CH}_{2} \mathrm{Cl}_{2}$ ) to give compound 24 as a white solid in $73 \%$ yield. Spectral data. ${ }^{1} \mathrm{H} \mathrm{NMR}\left(\mathrm{CDCl}_{3}, 400 \mathrm{MHz}\right) \delta 7.76(\mathrm{~d}, J=7.3$ $\mathrm{Hz}, 2 \mathrm{H}), 7.62(\mathrm{~s}, 1 \mathrm{H}), 7.57$ (d, $J=7.4 \mathrm{~Hz}, 2 \mathrm{H}), 7.40$ (t, $J=7.5 \mathrm{~Hz}, 2 \mathrm{H}), 7.30$ (t, $J=7.3 \mathrm{~Hz}, 2 \mathrm{H})$, $6.38(\mathrm{~d}, J=8.9 \mathrm{~Hz}, 1 \mathrm{H}), 5.45-5.38(\mathrm{~m}, 1 \mathrm{H}), 5.34(\mathrm{q}, J=6.5 \mathrm{~Hz}, 1 \mathrm{H}), 5.17(\mathrm{q}, J=7.3 \mathrm{~Hz}, 1 \mathrm{H})$, $4.40(\mathrm{~d}, J=5.2 \mathrm{~Hz}, 2 \mathrm{H}), 4.20(\mathrm{t}, J=6.8 \mathrm{~Hz}, 1 \mathrm{H}), 3.89-3.67(\mathrm{~m}, 2 \mathrm{H}), 1.89(\mathrm{~d}, J=7.2 \mathrm{~Hz}, 3 \mathrm{H})$, $1.60(\mathrm{~d}, J=6.8 \mathrm{~Hz}, 3 \mathrm{H}), 1.44(\mathrm{~s}, 9 \mathrm{H}) \mathrm{ppm} ;{ }^{13} \mathrm{C} \mathrm{NMR}\left(\mathrm{CDCl}_{3}, 100.6 \mathrm{MHz}\right) \delta 168.56,168.28$, $156.62,143.83,141.52,138.79,131.86,128.03,127.30,125.19,120.27,83.71,67.51,57.22$, 47.24, 44.59, 38.72, 28.04, 20.18, 17.78 ppm; MS (ESI) $m / z 542.2363\left(\mathrm{MNa}^{+}\left[\mathrm{C}_{28} \mathrm{H}_{33} \mathrm{~N}_{5} \mathrm{O}_{5} \mathrm{Na}^{+}\right]\right.$ $=542.2379$ ).

Triazole 25. Compound $24(347 \mathrm{mg}, 0.67 \mathrm{mmol})$ was dissolved in $50 \% \mathrm{v} / \mathrm{v}$ TFA in $\mathrm{CH}_{2} \mathrm{Cl}_{2}$ $(6 \mathrm{~mL})$. The reaction mixture was stirred until all the starting material was consumed $(2-3 \mathrm{~h})$, as judged by TLC. The solvent was removed under reduced pressure, and excess TFA was removed as an azeotrope with toluene to give compound $\mathbf{2 5}$ as a white solid in $73 \%$ yield. Spectral data. ${ }^{1} \mathrm{H}$ NMR (DMSO- $\left.d_{6}, 400 \mathrm{MHz}\right) \delta 8.32(\mathrm{~d}, J=8.5 \mathrm{~Hz}, 1 \mathrm{H}), 7.90(\mathrm{~d}, J=7.3 \mathrm{~Hz}, 2 \mathrm{H}), 7.72(\mathrm{~d}, J=$ $7.2 \mathrm{~Hz}, 2 \mathrm{H}), 7.69(\mathrm{~s}, 1 \mathrm{H}), 7.42(\mathrm{t}, J=7.7 \mathrm{~Hz}, 2 \mathrm{H}), 7.33(\mathrm{t}, J=7.5 \mathrm{~Hz}, 2 \mathrm{H}), 5.35(\mathrm{q}, J=7.5 \mathrm{~Hz}$, $1 \mathrm{H}), 5.22(\mathrm{q}, J=7.1 \mathrm{~Hz}, 1 \mathrm{H}), 4.28(\mathrm{~d}, J=5.8 \mathrm{~Hz}, 2 \mathrm{H}), 4.22(\mathrm{t}, J=6.5 \mathrm{~Hz}, 1 \mathrm{H}), 3.64-3.44(\mathrm{~m}$, $2 \mathrm{H}), 1.71(\mathrm{~d}, J=7.2 \mathrm{~Hz}, 3 \mathrm{H}), 1.41(\mathrm{~d}, J=6.7 \mathrm{~Hz}, 3 \mathrm{H}) \mathrm{ppm} ;{ }^{13} \mathrm{C} \mathrm{NMR}\left(\mathrm{CDCl}_{3}, 100.6 \mathrm{MHz}\right) \delta$ $168.56,168.28,156.62,143.83,141.52,138.79,131.86,128.03,127.30,125.19,120.27,66.85$, 56.08, 46.81, 43.22, 37.91, 18.90, 16.62 ppm; MS (ESI) $m / z 462.9\left(\mathrm{MH}^{-}\left[\mathrm{C}_{28} \mathrm{H}_{33} \mathrm{~N}_{5} \mathrm{O}_{5} \mathrm{H}^{-}\right]=\right.$ 462.2).

Triazole 26. A round-bottom flask containing compound 23 (289 $\mathrm{mg}, 0.34 \mathrm{mmol}$ ) was flushed with $\operatorname{Ar}(\mathrm{g})$. To the flask was added $10 \% \mathrm{w} / \mathrm{w} \mathrm{Pd} / \mathrm{C}(5 \mathrm{mg})$. MeOH $(3 \mathrm{~mL})$ was added to the $\operatorname{Ar}(\mathrm{g})-$ saturated flask, and the resulting suspension was stirred until all the starting material was consumed $(4 \mathrm{~h})$, as judged by TLC. The reaction suspension was diluted with $\mathrm{MeOH}$ $(5 \mathrm{~mL})$, filtered through a pad of Celite ${ }^{\circledR}$, and washed with $\mathrm{MeOH}(10 \mathrm{~mL})$. The filtrate was concentrated under reduced pressure to yield a crude oil, which was then purified by flash chromatography (silica gel, $15 \% \mathrm{v} / \mathrm{v} \mathrm{MeOH}$ in $\mathrm{CH}_{2} \mathrm{Cl}_{2}$ ) to give compound $\mathbf{2 6}$ as an off-white solid in $70 \%$ yield. Spectral data. ${ }^{1} \mathrm{H}$ NMR $\left(1: 1 \mathrm{CDCl}_{3} / \mathrm{CD}_{3} \mathrm{OD}, 400 \mathrm{MHz}\right) \delta 8.50(\mathrm{bs}, 1 \mathrm{H}), 7.73$ $(\mathrm{d}, J=7.4 \mathrm{~Hz}, 2 \mathrm{H}), 7.57(\mathrm{~d}, J=8.3 \mathrm{~Hz}, 2 \mathrm{H}), 7.54(\mathrm{~s}, 1 \mathrm{H}), 7.34(\mathrm{t}, J=7.5 \mathrm{~Hz}, 2 \mathrm{H}), 7.24(\mathrm{t}, J=$ $7.6 \mathrm{~Hz}, 2 \mathrm{H}), 7.19-7.11(\mathrm{~m}, 9 \mathrm{H}), 7.06(\mathrm{~d}, J=7.2 \mathrm{~Hz}, 6 \mathrm{H}), 5.47$ (t, $J=7.8 \mathrm{~Hz}, 1 \mathrm{H}), 5.01$ (q, $J=$ $6.8 \mathrm{~Hz}, 1 \mathrm{H}), 4.28(\mathrm{~d}, J=6.2 \mathrm{~Hz}, 2 \mathrm{H}), 4.12(\mathrm{t}, J=6.7 \mathrm{~Hz}, 1 \mathrm{H}), 3.64(\mathrm{~s}, 2 \mathrm{H}), 3.01-2.88(\mathrm{~m}, 2 \mathrm{H})$, $1.75(\mathrm{~d}, J=6.7 \mathrm{~Hz}, 3 \mathrm{H}) \mathrm{ppm} ;{ }^{13} \mathrm{C}$ NMR $\left(1: 1 \mathrm{CDCl}_{3} / \mathrm{CD}_{3} \mathrm{OD}, 100.6 \mathrm{MHz}\right) \delta 171.26,170.54$, $158.82,145.35,144.94,144.88,142.36,138.86,132.82,129.71,128.62,128.60,128.06,127.73$, $126.09,120.81,71.62,68.32,59.97,48.03,44.68,41.74,41.04,17.98 \mathrm{ppm}$; MS (ESI) $\mathrm{m} / z 771.3$ $\left(\mathrm{MNa}^{+}\left[\mathrm{C}_{44} \mathrm{H}_{40} \mathrm{~N}_{6} \mathrm{O}_{6} \mathrm{Na}^{+}\right]=771.8\right)$. 
Scheme S2. Cu(II)-mediated cycloaddition to 1,4-disubstituted triazoles.

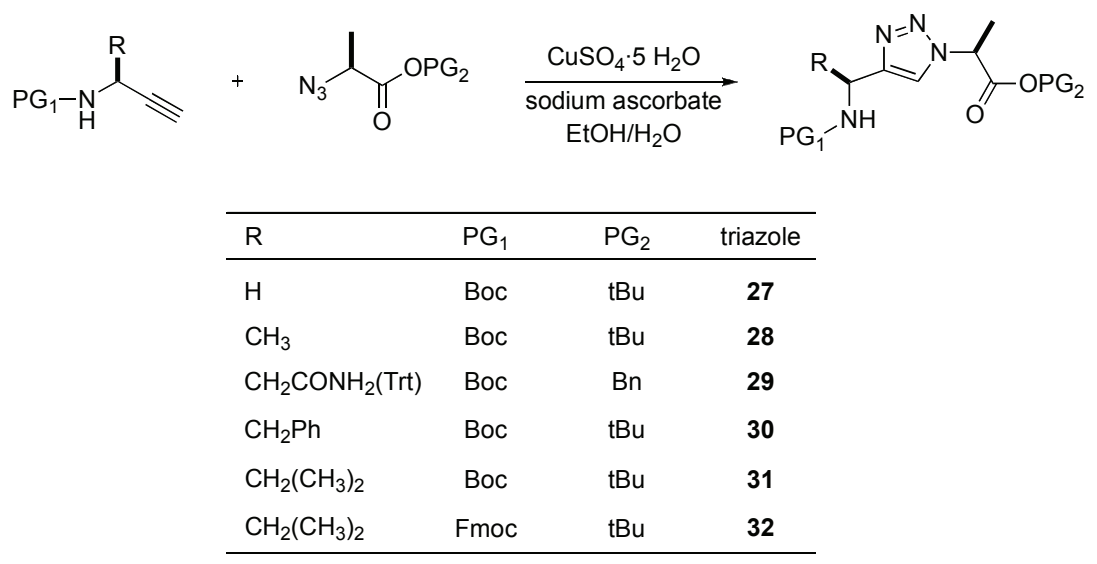

Triazole 27. Azide 1 (538 mg, $3.14 \mathrm{mmol})$ and alkyne 3 (488 $\mathrm{mg}, 3.14 \mathrm{mmol}$ ) were dissolved in degassed toluene $(15 \mathrm{~mL})$ under $\operatorname{Ar}(\mathrm{g})$. 1,8-Diazabicyclo[5.4.0]undec-7-ene (DBU) $(939 \mu \mathrm{L}, 6.28 \mathrm{mmol})$ was added to the mixture, followed by $\mathrm{CuBr}(90 \mathrm{mg}, 0.63 \mathrm{mmol})$ and the resulting solution was heated to $80{ }^{\circ} \mathrm{C}$ with an oil batch and stirred for $12 \mathrm{~h}$. The solution was filtered through Celite ${ }^{\circledR}$ and washed with $\mathrm{MeOH}(10 \mathrm{~mL})$. The filtrate was concentrated under reduced pressure to yield a crude oil, which was then purified by flash chromatography (silica gel, $2 \% \mathrm{v} / \mathrm{v} \mathrm{MeOH}$ in $\mathrm{CH}_{2} \mathrm{Cl}_{2}$ ) to give triazole 27 as a pale yellow solid in $44 \%$ yield. Spectral data. ${ }^{1} \mathrm{H} \mathrm{NMR}\left(\mathrm{CDCl}_{3}, 400 \mathrm{MHz}\right) \delta 7.68(\mathrm{~s}, 1 \mathrm{H}), 5.34(\mathrm{q}, J=7.2 \mathrm{~Hz}, 1 \mathrm{H}), 5.16(\mathrm{bs}, 1 \mathrm{H}), 4.43$ $(\mathrm{d}, J=5.5 \mathrm{~Hz}, 2 \mathrm{H}), 1.78(\mathrm{~d}, J=7.5 \mathrm{~Hz}, 3 \mathrm{H}), 1.45(\mathrm{~s}, 9 \mathrm{H}), 1.45(\mathrm{~s}, 9 \mathrm{H}) \mathrm{ppm} ;{ }^{13} \mathrm{C} \mathrm{NMR}\left(\mathrm{CDCl}_{3}\right.$, $100.6 \mathrm{MHz}) \delta 168.51,156.01,145.68,121.29,83.61,79.85,59.12,36.35,28.56,28.04,18.43$ ppm; MS (ESI) $m / z$ 349.1852 $\left(\mathrm{MNa}^{+}\left[\mathrm{C}_{15} \mathrm{H}_{26} \mathrm{~N}_{4} \mathrm{O}_{4} \mathrm{Na}^{+}\right]=349.1845\right)$.

Triazole 28. Azide 1 (50 mg, $0.30 \mathrm{mmol})$ and alkyne $5(50 \mathrm{mg}, 0.30 \mathrm{mmol})$ were dissolved in ethanol $(600 \mu \mathrm{L})$ and $\mathrm{H}_{2} \mathrm{O}(600 \mu \mathrm{L})$. Catalytic copper sulfate pentahydrate $(0.8 \mathrm{mg}, 3.0 \mu \mathrm{mol})$ was added to solution followed by $15 \mu \mathrm{L}$ of a freshly prepared $2 \mathrm{M}$ aqueous solution of sodium ascorbate. The resulting mixture was stirred for $16 \mathrm{~h}$, then diluted with $\mathrm{CH}_{2} \mathrm{Cl}_{2}(5 \mathrm{~mL})$ and layers were separated. The organic extracts were dried over anhydrous $\mathrm{MgSO}_{4}(\mathrm{~s})$, and concentrated. The crude residue was purified by flash chromatography (silica gel, $2 \% \mathrm{v} / \mathrm{v} \mathrm{MeOH}$ in $\mathrm{CH}_{2} \mathrm{Cl}_{2}$ ) to give triazole 28 as a pale yellow oil in 91\% yield. Spectral data. ${ }^{1} \mathrm{H}$ NMR $\left(\mathrm{CDCl}_{3}, 400 \mathrm{MHz}\right) \delta$ $7.61(\mathrm{~s}, 1 \mathrm{H}), 5.34$ (q, $J=7.6 \mathrm{~Hz}, 1 \mathrm{H}), 5.14(\mathrm{bs}, 1 \mathrm{H}), 4.96(\mathrm{q}, J=6.7 \mathrm{~Hz}, 1 \mathrm{H}), 1.78$ (d, $J=7.3 \mathrm{~Hz}$, $3 \mathrm{H}), 1.57(\mathrm{~d}, J=6.7 \mathrm{~Hz}, 3 \mathrm{H}), 1.46(\mathrm{~s}, 9 \mathrm{H}), 1.46(\mathrm{~s}, 9 \mathrm{H}) \mathrm{ppm} ;{ }^{13} \mathrm{C} \mathrm{NMR}\left(\mathrm{CDCl}_{3}, 100.6 \mathrm{MHz}\right) \delta$ $168.61,155.28,150.02,119.88,83.48,79.62,60.58,43.11,28.55,28.34,18.48,14.37$ ppm; MS (ESI) $m / z 341.2175\left(\mathrm{MH}^{+}\left[\mathrm{C}_{16} \mathrm{H}_{28} \mathrm{~N}_{4} \mathrm{O}_{4} \mathrm{H}^{+}\right]=341.2189\right)$.

Triazole 29. Azide 2 (45 mg, $0.22 \mathrm{mmol}$ ) and alkyne 4 (100 mg, $0.22 \mathrm{mmol}$ ) were dissolved in ethanol $(650 \mu \mathrm{L})$ and $\mathrm{H}_{2} \mathrm{O}(650 \mu \mathrm{L})$. Catalytic copper sulfate pentahydrate $(0.5 \mathrm{mg}, 2.2 \mu \mathrm{mol})$ was added to solution followed by $12 \mu \mathrm{L}$ of a freshly prepared $2 \mathrm{M}$ aqueous solution of sodium ascorbate. The resulting mixture was stirred for $16 \mathrm{~h}$, then diluted with $\mathrm{CH}_{2} \mathrm{Cl}_{2}(5 \mathrm{~mL})$ and layers were separated. The organic extracts were dried over anhydrous $\mathrm{MgSO}_{4}(\mathrm{~s})$, and concentrated. The crude residue was purified by flash chromatography (silica gel, $2 \% \mathrm{v} / \mathrm{v} \mathrm{MeOH}$ in $\mathrm{CH}_{2} \mathrm{Cl}_{2}$ ) to give triazole 29 as a pale yellow oil in $90 \%$ yield. Spectral data. ${ }^{1} \mathrm{H} \mathrm{NMR}\left(\mathrm{CDCl}_{3}, 400 \mathrm{MHz}\right) \delta$ $7.56(\mathrm{~s}, 1 \mathrm{H}), 7.36-7.18(\mathrm{~m}, 14 \mathrm{H}), 7.08(\mathrm{~d}, J=6.8 \mathrm{~Hz}, 6 \mathrm{H}), 6.97$ (bs, 1H), 6.21 (bs, 1H), 5.42 (q, $J=7.1 \mathrm{~Hz}, 1 \mathrm{H}), 5.23-5.17(\mathrm{~m}, 1 \mathrm{H}), 5.17(\mathrm{~s}, 2 \mathrm{H}), 3.30-3.25(\mathrm{~m}, 1 \mathrm{H}), 2.87-2.81(\mathrm{~m}, 1 \mathrm{H}), 1.79$ $(\mathrm{d}, J=7.6 \mathrm{~Hz}, 3 \mathrm{H}), 1.41(\mathrm{~s}, 9 \mathrm{H}) \mathrm{ppm} ;{ }^{13} \mathrm{C} \mathrm{NMR}\left(\mathrm{CDCl}_{3}, 100.6 \mathrm{MHz}\right) \delta 169.93,168.96,155.51$, 
$148.94,144.49,134.82,128.92,128.88,128.79,128.72,128.35,127.93,126.99,79.62,70.65$, 67.88, 58.27, 45.08, 40.38, 28.44, 18.00 ppm; MS (ESI) $m / z 682.3002\left(\mathrm{MNa}^{+}\left[\mathrm{C}_{16} \mathrm{H}_{28} \mathrm{~N}_{4} \mathrm{O}_{4} \mathrm{Na}^{+}\right]\right.$ $=682.3005)$.

Triazole 30. Azide 1 (68 mg, $0.40 \mathrm{mmol})$ and alkyne 6 (97 mg, $0.40 \mathrm{mmol}$ ) were dissolved in a mixture of ethanol $(800 \mu \mathrm{L})$ and $\mathrm{H}_{2} \mathrm{O}(800 \mu \mathrm{L})$. Catalytic copper sulfate pentahydrate (1.0 mg, $4.0 \mu \mathrm{mol}$ ) was added followed by $20 \mu \mathrm{L}$ of a freshly prepared aqueous solution of sodium ascorbate $(2.0 \mathrm{M})$. The resulting mixture was stirred for $16 \mathrm{~h}$, and then diluted with $\mathrm{CH}_{2} \mathrm{Cl}_{2}(5 \mathrm{~mL})$. The organic extract was dried over anhydrous $\mathrm{MgSO}_{4}(\mathrm{~s})$, and concentrated under reduced pressure. The crude residue was purified by flash chromatography (silica gel, $2 \%$ $\mathrm{v} / \mathrm{v} \mathrm{MeOH}$ in $\mathrm{CH}_{2} \mathrm{Cl}_{2}$ ) to give triazole 30 as a colorless oil in $91 \%$ yield. Spectral data. ${ }^{1} \mathrm{H}$ NMR $\left(\mathrm{CDCl}_{3}, 400 \mathrm{MHz}\right) \delta 7.30-7.10(\mathrm{~m}, 6 \mathrm{H}), 5.32-5.28(\mathrm{~m}, 2 \mathrm{H}), 5.11-5.09(\mathrm{~m}, 1 \mathrm{H}), 3.37-3.14(\mathrm{~m}$, $2 \mathrm{H}), 1.73(\mathrm{~d}, J=7.4 \mathrm{~Hz}, 3 \mathrm{H}), 1.44(\mathrm{~s}, 9 \mathrm{H}), 1.41(\mathrm{~s}, 9 \mathrm{H}) \mathrm{ppm} ;{ }^{13} \mathrm{C} \mathrm{NMR}\left(\mathrm{CDCl}_{3}, 100.6 \mathrm{MHz}\right) \delta$ $168.35,155.34,148.02,137.58,129.81,128.49,126.68,120.55,83.47,79.76,59.05,48.83$, 42.00, 28.54, 28.02, $18.42 \mathrm{ppm}$; MS (ESI) $m / z 439.2318\left(\mathrm{MNa}^{+}\left[\mathrm{C}_{22} \mathrm{H}_{32} \mathrm{~N}_{4} \mathrm{O}_{4} \mathrm{Na}^{+}\right]=439.2321\right)$.

Triazole 31. Azide 1 (87 mg, $0.51 \mathrm{mmol})$ and alkyne $7(100 \mathrm{mg}, 0.51 \mathrm{mmol})$ were dissolved in a mixture of tert-butanol $(1.2 \mathrm{~mL})$ and $\mathrm{H}_{2} \mathrm{O}(1.2 \mathrm{~mL})$. Catalytic copper sulfate pentahydrate $(1.3 \mathrm{mg}, 5.1 \mu \mathrm{mol})$ was added followed by $25 \mu \mathrm{L}$ of a freshly prepared aqueous solution of sodium ascorbate $(2.0 \mathrm{M})$. The resulting mixture was stirred for $16 \mathrm{~h}$, then diluted with $\mathrm{CH}_{2} \mathrm{Cl}_{2}$ $(7 \mathrm{~mL})$ and layers were separated. The organic extract was dried over anhydrous $\mathrm{MgSO}_{4}(\mathrm{~s})$, and concentrated under reduced pressure. The crude residue was purified by flash chromatography ( silica gel, $2 \% \mathrm{v} / \mathrm{v} \mathrm{MeOH}$ in $\mathrm{CH}_{2} \mathrm{Cl}_{2}$ ) to give triazole 31 as a pale yellow oil in 33\% yield. Spectral data. ${ }^{1} \mathrm{H}$ NMR $\left(\mathrm{CDCl}_{3}, 500 \mathrm{MHz}\right) \delta 7.55(\mathrm{~s}, 1 \mathrm{H}), 5.41-5.31(\mathrm{~m}, 2 \mathrm{H}), 4.68-4.66(\mathrm{~m}$, $1 \mathrm{H}), 2.20(\mathrm{sep}, J=6.5 \mathrm{~Hz}, 1 \mathrm{H}), 1.78(\mathrm{~d}, J=7.5 \mathrm{~Hz}, 3 \mathrm{H}), 1.44(\mathrm{~s}, 9 \mathrm{H}), 1.43(\mathrm{~s}, 9 \mathrm{H}), 0.95(\mathrm{~d}, J=$ $6.8 \mathrm{~Hz}, 3 \mathrm{H}), 0.87(\mathrm{~d}, J=6.4 \mathrm{~Hz}, 3 \mathrm{H}) \mathrm{ppm} ;{ }^{13} \mathrm{C} \mathrm{NMR}\left(\mathrm{CDCl}_{3}, 125 \mathrm{MHz}\right) \delta 168.49,155.77$, $147.57,120.41,83.38,79.45,58.96,52.77,33.22,28.53,27.99,19.01 .18 .71,18.40$ ppm; MS (ESI) $m / z 369.2488\left(\mathrm{MH}^{+}\left[\mathrm{C}_{18} \mathrm{H}_{32} \mathrm{~N}_{4} \mathrm{O}_{4} \mathrm{H}^{+}\right]=369.2502\right)$.

Triazole 32. Azide 1 (23 mg, $0.13 \mathrm{mmol}$ ) and alkyne 8 (42 mg, $0.13 \mathrm{mmol})$ were dissolved in a mixture of tert-butanol $(265 \mu \mathrm{L})$ and $\mathrm{H}_{2} \mathrm{O}(265 \mu \mathrm{L})$. Catalytic copper sulfate pentahydrate $(0.4 \mathrm{mg}, 1.3 \mu \mathrm{mol})$ was added followed by $7 \mu \mathrm{L}$ of a freshly prepared aqueous solution of sodium ascorbate $(2.0 \mathrm{M})$. The resulting mixture was stirred for $16 \mathrm{~h}$, and then diluted with $\mathrm{CH}_{2} \mathrm{Cl}_{2}(5 \mathrm{~mL})$. The organic extract was dried over anhydrous $\mathrm{MgSO}_{4}(\mathrm{~s})$, and concentrated under reduced pressure. The crude residue was purified by flash chromatography (silica gel, $2 \%$ $\mathrm{v} / \mathrm{v} \mathrm{MeOH}$ in $\mathrm{CH}_{2} \mathrm{Cl}_{2}$ ) to give triazole 32 as a pale yellow oil in $33 \%$ yield. Spectral data. ${ }^{1} \mathrm{H}$ $\operatorname{NMR}\left(\mathrm{CDCl}_{3}, 400 \mathrm{MHz}\right) \delta 7.76(\mathrm{~d}, J=7.3 \mathrm{~Hz}, 2 \mathrm{H}), 7.60(\mathrm{~d}, J=7.3 \mathrm{~Hz}, 2 \mathrm{H}), 7.55(\mathrm{~s}, 1 \mathrm{H}), 7.40$ $(\mathrm{t}, J=7.2 \mathrm{~Hz}, 2 \mathrm{H}), 7.33-7.28(\mathrm{~m}, 2 \mathrm{H}), 5.66(\mathrm{~d}, J=7.8 \mathrm{~Hz}, 1 \mathrm{H}), 5.33(\mathrm{~d}, J=6.8 \mathrm{~Hz}, 1 \mathrm{H})$, 4.73-4.69 (m, 1H), 4.44-4.33 (m, 2H), $4.22(\mathrm{t}, J=6.3 \mathrm{~Hz}, 1 \mathrm{H}), 2.26(\mathrm{sep}, J=7.1 \mathrm{~Hz}, 1 \mathrm{H}), 1.78$ $(\mathrm{d}, J=7.4 \mathrm{~Hz}, 3 \mathrm{H}), 1.44(\mathrm{~s}, 9 \mathrm{H}), 0.99(J=6.2 \mathrm{~Hz}, 3 \mathrm{H}), 0.88(J=5.6 \mathrm{~Hz}, 3 \mathrm{H}) \mathrm{ppm} ;{ }^{13} \mathrm{C} \mathrm{NMR}$ $\left(\mathrm{CDCl}_{3}, 100.6 \mathrm{MHz}\right) \delta 168.48,156.29,144.18,141.51,127.86,127.26,125.37,120.62,120.16$, $105.21,83.53,67.04,59.05,53.45,47.45,33.18,29.91,28.04,19.05,18.48 \mathrm{ppm}$; MS (ESI) $\mathrm{m} / z$ $513.2457\left(\mathrm{MNa}^{+}\left[\mathrm{C}_{28} \mathrm{H}_{34} \mathrm{~N}_{4} \mathrm{O}_{4} \mathrm{Na}^{+}\right]=513.2478\right)$. 
Scheme S3. Derivatization of triazoles 28 and 29 for solid-phase peptide synthesis.

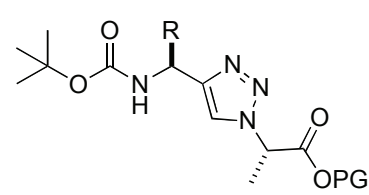

$28 \mathrm{R}=\mathrm{CH}_{3}, \mathrm{PG}=t \mathrm{Bu}$ $29 \mathrm{R}=\mathrm{CH}_{2} \mathrm{CONH}_{2}(\mathrm{Trt}), \mathrm{PG}=\mathrm{Bn}$

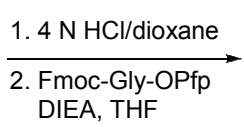

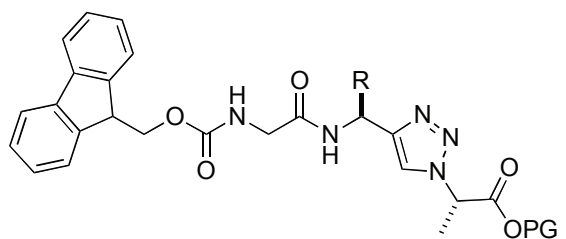

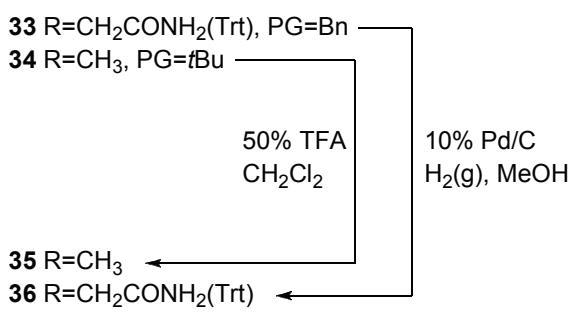

$\mathrm{CH}_{2} \mathrm{CONH}_{2}(\mathrm{Trt})$

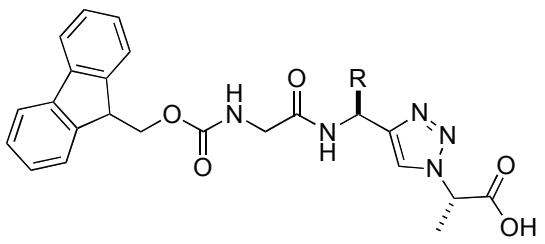

Triazole 33. Compound $29(275 \mathrm{mg}, 0.42 \mathrm{mmol})$ was dissolved in $4 \mathrm{~N} \mathrm{HCl}$ in dioxane $(5.0 \mathrm{~mL})$ and cooled to $0{ }^{\circ} \mathrm{C}$ with an ice/water bath. The reaction mixture was stirred until all the starting material was consumed $(1 \mathrm{~h})$, as judged by TLC. The solvent was removed under reduced pressure, and excess TFA was removed as an azeotrope with toluene. In a separate round-bottom flask, FmocGlyOPfP $(212 \mathrm{mg}, 0.46 \mathrm{mmol})$ was dissolved in THF $(5.0 \mathrm{~mL})$. The crude residue from above was added to this solution, followed by DIEA (145 $\mu \mathrm{L}, 0.83 \mathrm{mmol}$ ). The resulting mixture was stirred for $12 \mathrm{~h}$. The solvent was removed under reduced pressure, and the crude residue was purified by flash chromatography (silica gel, $2 \% \mathrm{v} / \mathrm{v} \mathrm{MeOH}$ in $\mathrm{CH}_{2} \mathrm{Cl}_{2}$ ) to give compound 33 as a white solid in $95 \%$ yield. Spectral data. ${ }^{1} \mathrm{H}$ NMR $\left(\mathrm{CDCl}_{3}, 400 \mathrm{MHz}\right) \delta$ $7.78(\mathrm{~d}, J=8.1 \mathrm{~Hz}, 1 \mathrm{H}), 7.73(\mathrm{~d}, J=7.5 \mathrm{~Hz}, 2 \mathrm{H}), 7.67(\mathrm{~s}, 1 \mathrm{H}), 7.52(\mathrm{t}, J=6.5 \mathrm{~Hz}, 2 \mathrm{H}), 7.36(\mathrm{t}, J$ $=7.4 \mathrm{~Hz}, 2 \mathrm{H}), 7.33-7.16(\mathrm{~m}, 14 \mathrm{H}), 7.07(\mathrm{~d}, J=6.2 \mathrm{~Hz}, 6 \mathrm{H}), 5.54-5.50(\mathrm{~m}, 2 \mathrm{H}), 5.40-5.34(\mathrm{~m}$, $1 \mathrm{H}), 5.15-5.06(\mathrm{~m}, 2 \mathrm{H}), 4.30(\mathrm{~d}, J=7.1 \mathrm{~Hz}, 2 \mathrm{H}), 4.14(\mathrm{t}, J=7.3 \mathrm{~Hz}, 1 \mathrm{H}), 3.78-3.73(\mathrm{~m}, 2 \mathrm{H})$, $3.30-3.25(\mathrm{~m}, 1 \mathrm{H}), 2.82-2.76(\mathrm{~m}, 1 \mathrm{H}), 1.76(\mathrm{~d}, J=6.9 \mathrm{~Hz}, 3 \mathrm{H}) \mathrm{ppm} ;{ }^{13} \mathrm{C} \mathrm{NMR}\left(\mathrm{CDCl}_{3}, 100.6\right.$ $\mathrm{MHz}) \delta 170.18,168.97,168.88,156.75,147.82,144.53,144.41,143.98,141.43,134.88,128.88$, $128.79,128.45,128.07,127.88,127.28,127.17,125.32,121.99,120.13,70.89,68.03,67.37$, 58.49, 47.21, 44.54, 43.84, 39.66, 17.97 ppm; MS (ESI) $m / z 861.3412\left(\mathrm{MNa}^{+}\left[\mathrm{C}_{51} \mathrm{H}_{46} \mathrm{~N}_{6} \mathrm{O}_{6} \mathrm{Na}^{+}\right]\right.$ $=861.3377)$.

Triazole 34. Compound 28 (91 mg, $0.27 \mathrm{mmol}$ ) was dissolved in 30\% v/v TFA in $\mathrm{CH}_{2} \mathrm{Cl}_{2}$ $(2.5 \mathrm{~mL})$, and the resulting solution was cooled to $0{ }^{\circ} \mathrm{C}$ with an ice/water bath. The reaction mixture was stirred until all the starting material was consumed $(1 \mathrm{~h})$, as judged by TLC. The solvent was removed under reduced pressure, and excess TFA was removed as an azeotrope with toluene. In a separate round-bottom flask, FmocGlyOPfP (136 mg, $0.29 \mathrm{mmol})$ was dissolved in THF $(2.5 \mathrm{~mL})$. The crude residue from above was added, followed by DIEA (93 $\mu \mathrm{L}$, $0.53 \mathrm{mmol}$ ). The resulting reaction mixture was stirred for $12 \mathrm{~h}$. The solvent was removed under reduced pressure, and the crude residue was purified by flash chromatography (silica gel, $2 \% \mathrm{v} / \mathrm{v}$ $\mathrm{MeOH}$ in $\mathrm{CH}_{2} \mathrm{Cl}_{2}$ ) to give compound 34 as a white solid in $91 \%$ yield. Spectral data. ${ }^{1} \mathrm{H}$ NMR $\left(\mathrm{CDCl}_{3}, 400 \mathrm{MHz}\right) \delta 7.73(\mathrm{~d}, J=7.3 \mathrm{~Hz}, 2 \mathrm{H}), 7.65(\mathrm{~s}, 1 \mathrm{H}), 7.57(\mathrm{~d}, J=7.5 \mathrm{~Hz}, 2 \mathrm{H}), 7.37(\mathrm{t}, J=$ $7.5 \mathrm{~Hz}, 2 \mathrm{H}), 7.27(\mathrm{t}, J=7.7 \mathrm{~Hz}, 2 \mathrm{H}), 7.10(\mathrm{~d}, J=8.2 \mathrm{~Hz}, 1 \mathrm{H}), 5.91-5.83(\mathrm{~m}, 1 \mathrm{H}), 5.31(\mathrm{~m}, 2 \mathrm{H})$, $4.36(\mathrm{~d}, J=6.5 \mathrm{~Hz}, 2 \mathrm{H}), 4.19(\mathrm{t}, J=6.8 \mathrm{~Hz}, 1 \mathrm{H}), 3.89$ (d, $J=5.3 \mathrm{~Hz}, 2 \mathrm{H}), 1.74(\mathrm{~d}, J=6.9 \mathrm{~Hz}$, $3 \mathrm{H}), 1.57(\mathrm{~d}, J=6.9 \mathrm{~Hz}, 3 \mathrm{H}), 1.43(\mathrm{~s}, 9 \mathrm{H}) \mathrm{ppm} ;{ }^{13} \mathrm{C} \mathrm{NMR}\left(\mathrm{CDCl}_{3}, 100.6 \mathrm{MHz}\right) \delta 168.54$, 
$168.45,156.74,149.04,143.93,141.37,127.83,127.21,125.24,120.41,120.08,83.53,67.29$, $58.96,47.17,44.51,41.78,27.94,21.01,18.32 \mathrm{ppm}$; MS (ESI) $\mathrm{m} / z$ 542.2353 $\left(\mathrm{MNa}^{+}\right.$ $\left.\left[\mathrm{C}_{28} \mathrm{H}_{33} \mathrm{~N}_{5} \mathrm{O}_{5} \mathrm{Na}^{+}\right]=542.2379\right)$.

Triazole 35. Compound 34 (126 mg, $0.24 \mathrm{mmol})$ was dissolved in 50\% v/v TFA in $\mathrm{CH}_{2} \mathrm{Cl}_{2}$ $(2 \mathrm{~mL})$. The resulting solution was stirred until all the starting material was consumed $(2-3 \mathrm{~h})$, as judged by TLC. The solvent was removed under reduced pressure, and excess TFA was removed as an azeotrope with toluene. The residue was purified by flash chromatography (silica gel, $5 \%$ $\mathrm{v} / \mathrm{v} \mathrm{MeOH}$ in $\mathrm{CH}_{2} \mathrm{Cl}_{2}$ ) to give compound 35 as a white solid in $53 \%$ yield. Spectral data. ${ }^{1} \mathrm{H}$ $\operatorname{NMR}\left(1: 1 \mathrm{CD}_{3} \mathrm{OD} / \mathrm{CDCl}_{3}, 400 \mathrm{MHz}\right) \delta 7.82(\mathrm{~s}, 1 \mathrm{H}), 7.77(\mathrm{~d}, J=7.1 \mathrm{~Hz}, 2 \mathrm{H}), 7.63(\mathrm{~d}, J=7.6$ $\mathrm{Hz}, 2 \mathrm{H}), 7.40(\mathrm{t}, J=7.3 \mathrm{~Hz}, 2 \mathrm{H}), 7.31(\mathrm{t}, J=6.9 \mathrm{~Hz}, 2 \mathrm{H}), 5.39(\mathrm{q}, J=7.6 \mathrm{~Hz}, 1 \mathrm{H}), 5.28-5.24$ $(\mathrm{m}, 1 \mathrm{H}), 4.42(\mathrm{~m}, 2 \mathrm{H}), 4.23(\mathrm{t}, J=6.6 \mathrm{~Hz}, 1 \mathrm{H}), 3.84(\mathrm{~d}, J=6.0 \mathrm{~Hz}, 2 \mathrm{H}), 1.84(\mathrm{~d}, J=7.0 \mathrm{~Hz}$, $3 \mathrm{H}), 1.57(\mathrm{~d}, J=6.5 \mathrm{~Hz}, 3 \mathrm{H}) \mathrm{ppm} ;{ }^{13} \mathrm{C} \mathrm{NMR}\left(1: 1 \mathrm{CD}_{3} \mathrm{OD} / \mathrm{CDCl}_{3}, 100.6 \mathrm{MHz}\right) \delta 171.00,169.30$, $157.18,149.00,143.66,141.16,127.63,126.98,124.90,121.00,119.82,67.01,58.39,46.95$, 43.88, 41.39, 19.86, 17.57 ppm; MS (ESI) $m / z$ 486.2 $\left(\mathrm{MNa}^{+}\left[\mathrm{C}_{28} \mathrm{H}_{33} \mathrm{~N}_{5} \mathrm{O}_{5} \mathrm{Na}^{+}\right]=486.5\right)$.

Triazole 36. A round-bottom flask containing compound $33(154 \mathrm{mg}, 0.18 \mathrm{mmol})$ was flushed with $\operatorname{Ar}(\mathrm{g})$. To the flask was added $10 \% \mathrm{w} / \mathrm{w} \mathrm{Pd} / \mathrm{C}(8 \mathrm{mg})$ and $\mathrm{MeOH}(2 \mathrm{~mL})$. The reaction suspension was stirred until all the starting material was consumed $(4 \mathrm{~h})$, as judged by TLC. The reaction suspension was diluted with $\mathrm{MeOH}(5 \mathrm{~mL})$ and filtered through a pad of Celite $^{\circledR}$ and washed with $\mathrm{MeOH}(10 \mathrm{~mL})$. The filtrate was concentrated under reduced pressure to yield a crude oil, which was then purified by flash chromatography (silica gel, $15 \% \mathrm{v} / \mathrm{v} \mathrm{MeOH}$ in $\mathrm{CH}_{2} \mathrm{Cl}_{2}$ ) to give compound $\mathbf{3 6}$ as an off-white solid in $71 \%$ yield. Spectral data. ${ }^{1} \mathrm{H}$ NMR $\left(\mathrm{CD}_{3} \mathrm{OD}, 400 \mathrm{MHz}\right) \delta 8.60(\mathrm{bs}, 1 \mathrm{H}), 7.86(\mathrm{~s}, 1 \mathrm{H}), 7.78(\mathrm{~d}, J=7.7 \mathrm{~Hz}, 2 \mathrm{H}), 7.60(\mathrm{t}, J=7.6 \mathrm{~Hz}$, $2 \mathrm{H}), 7.38(\mathrm{t}, J=7.6 \mathrm{~Hz}, 2 \mathrm{H}), 7.28-7.13(\mathrm{~m}, 17 \mathrm{H}), 5.52-5.48(\mathrm{~m}, 1 \mathrm{H}), 5.25-5.18(\mathrm{~m}, 1 \mathrm{H})$, $4.30-4.29(\mathrm{~m}, 2 \mathrm{H}), 4.16-4.12(\mathrm{~m}, 1 \mathrm{H}), 3.01-2.97(\mathrm{~m}, 2 \mathrm{H}), 1.73(\mathrm{~d}, J=7.5 \mathrm{~Hz}, 3 \mathrm{H}) \mathrm{ppm} ;{ }^{13} \mathrm{C}$ NMR $\left(\mathrm{CD}_{3} \mathrm{OD}, 100.6 \mathrm{MHz}\right) \delta 170.06,169.69,157.20,146.57,144.07,143.55,141.05,128.46$, $127.45,127.44,126.86,126.85,126.55,124.81,121.85,119.64,70.35,66.92,60.41,46.80$, 43.53, 39.81, 27.81, $17.81 \mathrm{ppm}$; MS (ESI) $m / z 747.30\left(\mathrm{MH}^{-}\left[\mathrm{C}_{48} \mathrm{H}_{40} \mathrm{~N}_{6} \mathrm{O}_{6} \mathrm{H}^{-}\right]=747.83\right)$.

Stability of a Triazole to Solid-phase Peptide Synthesis Conditions. Triazole $12(25 \mathrm{mg})$ was dissolved in $20 \% \mathrm{v} / \mathrm{v}$ piperidine in DMF and stirred at ambient temperature for $45 \mathrm{~min}$, which is $9 \times$ longer than a typical deprotection step during solid-phase peptide synthesis. The solvent was removed under reduced pressure, and the residue was dissolved in $\mathrm{CH}_{2} \mathrm{Cl}_{2}(10 \mathrm{ml})$ and washed with water $(3 \mathrm{~mL})$ and brine $(3 \mathrm{~mL})$. The organic extracts were dried over anhydrous $\mathrm{MgSO}_{4}(\mathrm{~s})$, filtered, and concentrated under reduced pressure. The crude residue was determined by NMR to be identical to that of the starting triazole. The limit of NMR detection is $\sim 5 \%$, indicating that the compound retained $>95 \%$ of its stereochemical integrity.

Peptide Synthesis. Peptides were synthesized on a $25-\mu \mathrm{mol}$ scale with a Synergy automated peptide synthesizer (Applied Biosystems) at the University of Wisconsin Biotechnology Center. A methylbenzhydrylamine (MBHA) polystyrene resin that had been functionalized with a 4-hydroxymethylphenoxy (HMP) acid-labile linker and loaded with valine (which is the C-terminal residue of RNase A) was used for peptide synthesis. Appropriate Fmoc-protected monomers and the triazoles were coupled by using standard HATU-activation, followed by piperidine-deprotection of the Fmoc group. The sequence of the synthetic peptide was CAYKTTQANKHIIVACEGX-triazole-YVPVHFDASV, which corresponds to residues 95-124, where "X" denotes either Asn or Ala and "triazole" refers to the triazole-Ala isostere. The mass of each peptide variant was determined by MALDI-TOF mass spectrometry (Table S-1). 
Plasmid Construction for N113A RNase A. cDNA encoding the N113A variant of RNase A was produced by site-directed mutagenesis starting from the gene encoding RNase A as fusion protein to the mxe-intein in plasmid pTXB1 by use of the primers 5'-GGCTTGTGAGGGAGCACCGTACGTGCCAGTCC-3' and 5'-GGACTGGCACGTACGGTGCTCCCTCACAAGCC- $3^{\prime}$. The correct sequence was verified by DNA sequencing (University of Wisconsin-Biotechnology Center).

Production of Intein Fusion Protein. Plasmid pTXB1, E. coli cells strain ER2566, and chitin beads were from New England Biolabs (Beverly, MA). E. coli ER2566 cells that had been transformed with plasmids encoding RNase A 1-94 or N113A RNase A fused to the mxe-intein were grown as reported previously, ${ }^{6}$ and cells were stored at $-20{ }^{\circ} \mathrm{C}$ until used. The proteins produced by this method possess an additional methionine residue at their $\mathrm{N}$-terminus, $\operatorname{Met}(-1)$, which does not affect the stability or activity of the enzyme. ${ }^{7}$

Production of RNase A(1-94) Thioester. RNase A(1-94) thioeseter was produced essentially as described previously. ${ }^{7}$ The lysis and column buffer was $20 \mathrm{mM}$ 3 -( $N$-morpholino)propanesulfonic acid (MOPS)- $\mathrm{NaOH}$ buffer ( $\mathrm{pH} 6.8)$ containing $\mathrm{NaCl}(0.5 \mathrm{M})$, ethylenediaminetetraacetic acid (EDTA, $1 \mathrm{mM})$, and Triton X-100 $(0.1 \% \mathrm{v} / \mathrm{v})$; the cleavage buffer was $20 \mathrm{mM}$ MOPS- $\mathrm{NaOH}$ buffer (pH 6.8) containing $\mathrm{NaCl} \quad(0.5 \mathrm{M})$, 2-mercaptoethanesulfonic acid (MESNA, $0.10 \mathrm{M})$, and EDTA $(0.10 \mathrm{mM})$. The cleavage product, RNase $\mathrm{A}(1-94)$ thioester, was eluted from the resin after $16 \mathrm{~h}$ at $25^{\circ} \mathrm{C}$ with $2.0 \mathrm{M} \mathrm{NaCl}$ and subsequently precipitated by the addition of sodium deoxycholate (to $0.24 \mathrm{mM}$ ) and trichloroacetic acid (to $30 \mathrm{mM}$ ). This precipitate was washed with acetone, dissolved in $2 \mathrm{M}$ guanidine $-\mathrm{HCl}(\mathrm{GdnHCl})$ in $0.10 \mathrm{M}$ sodium phosphate buffer, $\mathrm{pH} 7.5$, to a concentration of $\sim 1 \mathrm{mM}$ and used in ligation reactions.

Production of N113A RNase A. N113A RNase A was produced like thioester-tagged RNase $\mathrm{A}(1-94)$ but with the cleavage buffer at $\mathrm{pH} 7.5$ and the cleavage reaction allowed to proceed. N113A RNase A was eluted, precipitated, and redissolved like the RNase A(1-94) fragment.

Ligation of RNase A(1-94) Thioester and Peptide. Expressed protein ligation reactions were performed in $0.10 \mathrm{M}$ sodium phosphate buffer $(\mathrm{pH} 7.5)$ containing EDTA $(10 \mathrm{mM})$, $\mathrm{Gdn}-\mathrm{HCl} \quad(2.0 \mathrm{M}), \quad$ tris(2-carboxyethyl)phosphine-HCl) (TCEP, $20 \mathrm{mM}$ ), 4-(carboxymethyl)thiophenol (MPAA, $0.10 \mathrm{M})$, protein thioester $(1 \mathrm{mM})$, and peptide $(10 \mathrm{mM})$. Ligation reactions were allowed to proceed at RT for $44 \mathrm{~h}$.

Protein Folding and Purification. The ligation reaction was diluted with $0.10 \mathrm{M}$ sodium phosphate buffer $(\mathrm{pH} 7.5)$ containing DTT $(10 \mathrm{mM})$ to reduce any disulfide bonds. Similarly, DTT $(10 \mathrm{mM})$ was added to redissolved N113A RNase A,. After incubation at RT under $\mathrm{N}_{2}(\mathrm{~g})$ for $2 \mathrm{~h}$, insoluble material was removed by centrifugation $(20,000 \mathrm{~g}$ at RT for $15 \mathrm{~min})$. The supernatant was diluted with $0.10 \mathrm{M}$ Tris $-\mathrm{HCl}$ buffer $(\mathrm{pH} 8.3)$ containing $\mathrm{NaCl}(0.10 \mathrm{M})$ and EDTA $(1 \mathrm{mM})$ to give $\sim 20 \mu \mathrm{g}$ of protein $/ \mathrm{mL}$ and $\sim 10 \mathrm{mM} \mathrm{Gdn}-\mathrm{HCl}$. Reduced glutathione (GSH) and oxidized glutathione (GSSG) were added with stirring at $4{ }^{\circ} \mathrm{C}$ to final concentrations of 1.0 and $0.2 \mathrm{mM}$, respectively. After adjusting the $\mathrm{pH}$ to $\sim 8$ with $1.0 \mathrm{M} \mathrm{NaOH}$, the solution was warmed to RT and protein folding was allowed to proceed with no stirring for $48 \mathrm{~h}$.

Proteins were purified by hydrophobic interaction chromatography (Phenyl Sepharose ${ }^{\mathrm{TM}}$ Fast Flow, Amersham Biosciences) using a linear gradient of $(\mathrm{NH})_{4} \mathrm{SO}_{4}(1.7-0.0 \mathrm{M})$ in $0.10 \mathrm{M}$ sodium phosphate buffer ( $\mathrm{pH} 7.0){ }^{6}$ Only the first few, most pure fractions of protein were collected, as located by absorbance at $278 \mathrm{~nm}$, ribonucleolytic activity, and SDS-PAGE using a $17.5 \% \mathrm{w} / \mathrm{v}$ acrylamide gel. These fractions were combined and dialyzed against $50 \mathrm{mM}$ sodium 
phosphate buffer ( $\mathrm{pH} 8.0)$ containing $\mathrm{NaCl}(25 \mathrm{mM})$. After dialysis, the semisynthetic protein was concentrated to $0.5-1.0 \mathrm{mg} / \mathrm{mL}$.

After purification, $5 \mathrm{mg}$ of peptide typically yielded $600 \mu \mathrm{g}$ of semisynthetic RNase A. The mass of each semisynthetic protein was determined by MALDI-TOF mass spectrometry (Table S-2). Wild-type RNase A was from Sigma Chemical (St. Louis, MO), and was purified as described previously. ${ }^{\text {? }}$

Ribonucleolytic Activity. Values of $k_{\text {cat }} / K_{\mathrm{M}}$ for the enzymatic cleavage of a fluorogenic substrate, 6-carboxyfluorescein- $\mathrm{dArU}(\mathrm{dA})_{2}-6$-carboxytetramethylrhodamine, were determined as described previously. ${ }^{8}$ Activity was measured in $0.10 \mathrm{M} 2-(\mathrm{N}$-morpholino)ethanesulfonic acid- (MES-) $\mathrm{NaOH}$ buffer (pH 6.0) containing $\mathrm{NaCl}(0.10 \mathrm{M})$.

CD Spectroscopy. Circular dichroism (CD) spectra were recorded on a J-810 spectropolarimeter (JASCO) at $20^{\circ} \mathrm{C}$ using a protein concentration of $0.5-1.0 \mathrm{mg} / \mathrm{mL}$ in $50 \mathrm{mM}$ sodium phosphate buffer $(\mathrm{pH} 8.0)$ containing $\mathrm{NaCl}(25 \mathrm{mM})$. Cuvettes of $1-\mathrm{cm}$ and $0.01-\mathrm{cm}$ path-length were used for CD spectroscopy in the near-UV region $(250-330 \mathrm{~nm})$ and in the farUV region (190-260 nm), respectively.

Thermal Denaturation. The thermal stability of wild-type RNase A and each of its variants was determined by CD spectroscopy. Protein samples $(0.5-1.0 \mathrm{mg} / \mathrm{mL})$ were in $50 \mathrm{mM}$ sodium phosphate buffer $(\mathrm{pH} 8.0)$ containing $\mathrm{NaCl}(25 \mathrm{mM})$. The transition in molar ellipticity at 276 $\mathrm{nm}$ upon heating at $1{ }^{\circ} \mathrm{C} / \mathrm{min}$ was monitored with a J-810 spectropolarimeter (JASCO, GroßUmstadt, Germany;). The value of $T_{\mathrm{m}}$, which is the temperature at the midpoint of the thermal transition, was determined as described previously. ${ }^{9}$

X-ray Crystallography Data Collection. Colorless crystals of triazole $\mathbf{1 2}$ were grown in $\mathrm{CH}_{2} \mathrm{Cl}_{2} /$ hexanes. A crystal with approximate dimensions $0.49 \times 0.42 \times 0.38 \mathrm{~mm}^{3}$ was selected under oil under ambient conditions and attached to the tip of a nylon loop. The crystal was mounted in a stream of cold $\mathrm{N}_{2}(\mathrm{~g})$ at $(100 \pm 2) \mathrm{K}$ and centered in the X-ray beam by using a video camera. The crystal evaluation and data collection were performed on a Bruker CCD-1000 diffractometer with Mo $_{\alpha}(\lambda=0.71073 \AA)$ radiation and a diffractometer-to-crystal distance of $4.9 \mathrm{~cm}$.

The initial cell constants were obtained from three series of $\omega$ scans at different starting angles. Each series consisted of 20 frames collected at intervals of $0.3^{\circ}$ in a $6^{\circ}$-range about $\omega$ with an exposure time of $10 \mathrm{~s}$ per frame. A total of 84 reflections were obtained. The reflections were successfully indexed by an automated indexing routine built in the program SMART. The final cell constants were calculated from a set of 2786 strong reflections from the actual data collection.

The data were collected by using the full-sphere data collection routine to survey the reciprocal space to the extent of a full sphere to a resolution of $0.80 \AA$. A total of 14009 data were harvested by collecting four sets of frames with $0.36^{\circ}$ scans in $\omega$ with an exposure time of $30 \mathrm{~s}$ per frame. These highly redundant datasets were corrected for Lorentz and polarization effects. The absorption correction was based on fitting a function to the empirical transmission surface as sampled by multiple equivalent measurements. ${ }^{10}$

Structure Solution and Refinement. The systematic absences in the diffraction data were uniquely consistent for the space group $P 22_{1} 2_{1} 2_{1}$ that yielded chemically reasonable and computationally stable results of refinement. ${ }^{10}$ A successful solution by the direct methods provided most non-hydrogen atoms from the $E$-map. The remaining non-hydrogen atoms were located in an alternating series of least-squares cycles and difference Fourier maps. All nonhydrogen atoms were refined with anisotropic displacement coefficients. All hydrogen atoms 
were included in the structure factor calculation at idealized positions and were allowed to ride on the neighboring atoms with relative isotropic displacement coefficients. The absolute configuration was assigned according to the configuration of the L-alanine component.

The final least-squares refinement of 225 parameters against 1940 data resulted in residuals $R$ (based on $F^{2}$ for $I \geq 2 \sigma$ ) and $w R$ (based on $F^{2}$ for all data) of 0.0476 and 0.1195 , respectively. The final difference Fourier map was featureless.

\section{References}

(1) Dickson, H. D.; Smith, S. C.; Hinkle, K. W. Tetrahedron Lett. 2004, 45, 5597-5599.

(2) Pietruszka, J.; Witt, A. Synthesis 2006, 4266-4268.

(3) Lundquist, J. T.; Pelletier, J. C. Org. Lett. 2001, 3, 781-783.

(4) Denton, T. T.; Zhang, X. D.; Cashman, J. R. J. Med. Chem. 2005, 48, 224-239.

(5) Reginato, G.; Mordini, A.; Messina, F.; DeglInnocenti, A.; Poli, G. Tetrahedron 1996, 52, 10985-10996.

(6) Arnold, U.; Hinderaker, M. P.; Köditz, J.; Golbik, R.; Ulbrich-Hofmann, R.; Raines, R. T. J. Am. Chem. Soc. 2003, 125, 7500-7501.

(7) Arnold, U.; Hinderaker, M. P.; Nilsson, B. L.; Huck, B. R.; Gellman, S. H.; Raines, R. T. J. Am. Chem. Soc. 2002, 124, 8522-8523.

(8) Kelemen, B. R.; Klink, T. A.; Behlke, M. A.; Eubanks, S. R.; Leland, P. A.; Raines, R. T. Nucleic Acids Res. 1999, 27, 3696-3701.

(9) Pace, C. N.; Hebert, E. J.; Shaw, K. L.; Schell, D.; Both, V.; Krajcikova, D.; Sevcik, J.; Wilson, K. S.; Dauter, Z.; Hartley, R. W.; Grimsley, G. R. J. Mol. Biol. 1998, 279, 271286.

(10) Bruker-AXS. (2000-2003) SADABS v.2.05, SAINT v.6.22, SHELXTL v.6.10 \& SMART 5.622 Software Reference Manuals. Bruker-AXS, Madison, Wisconsin, USA. 
Table S-1. Molecular Masses $(\mathrm{m} / \mathrm{z}$ ) of Peptides Corresponding to (95-124)RNase A

Residues 113-114 observed expected

Asn-1,5-triazole-Ala 3275.2 3275.7

Asn-1,4-triazole-Ala

3275.0

3275.7

Ala-1,5-triazole-Ala

3232.3

3232.6

Ala-1,4-triazole-Ala

3232.7

3232.6

Table S-2. Molecular Masses $(\mathrm{m} / \mathrm{z})$ of RNase A Variants

\begin{tabular}{llll}
\hline Residues 113-114 & origin & observed & expected \\
\hline Asn-1,5-triazole-Ala & semisynthesis & 13815 & 13811 \\
Asn-1,4-triazole-Ala & semisynthesis & 13820 & 13811 \\
Ala-Pro & Escherichia coli & 13779 & 13770 \\
Ala-1,5-triazole-Ala & semisynthesis & 13781 & 13768 \\
Ala-1,4-triazole-Ala & semisynthesis & 13781 & 13768 \\
\hline
\end{tabular}


Table S-3. Crystal Data and Structure Refinement for Triazole 12

\begin{tabular}{|c|c|c|}
\hline Identification code & \multicolumn{2}{|l|}{ raines06 } \\
\hline Empirical formula & \multicolumn{2}{|l|}{$\mathrm{C}_{16} \mathrm{H}_{28} \mathrm{~N}_{4} \mathrm{O}_{4}$} \\
\hline Formula weight & \multicolumn{2}{|l|}{340.42} \\
\hline Temperature & \multicolumn{2}{|l|}{$100(2) \mathrm{K}$} \\
\hline Wavelength & \multicolumn{2}{|l|}{$0.71073 \AA$} \\
\hline Crystal system & \multicolumn{2}{|l|}{ Orthorhombic } \\
\hline Space group & \multicolumn{2}{|l|}{$\mathrm{P} 2{ }_{1}{ }_{1} 2_{1}$} \\
\hline \multirow[t]{3}{*}{ Unit cell dimensions } & $a=9.582(3) \AA$ & $\alpha=90^{\circ}$ \\
\hline & $b=10.598(3) \AA$ & $\beta=90^{\circ}$ \\
\hline & $c=18.800(5) \AA$ & $\gamma=90^{\circ}$ \\
\hline Volume & \multicolumn{2}{|l|}{$1909.0(9) \AA^{3}$} \\
\hline$Z$ & \multicolumn{2}{|l|}{4} \\
\hline Density (calculated) & \multicolumn{2}{|l|}{$1.184 \mathrm{Mg} / \mathrm{m}^{3}$} \\
\hline Absorption coefficient & \multicolumn{2}{|l|}{$0.086 \mathrm{~mm}^{-1}$} \\
\hline$F(000)$ & \multicolumn{2}{|l|}{736} \\
\hline Crystal size & \multicolumn{2}{|c|}{$0.49 \times 0.42 \times 0.38 \mathrm{~mm}^{3}$} \\
\hline Theta range for data collection & \multicolumn{2}{|c|}{2.17 to $25.02^{\circ}$} \\
\hline Index ranges & \multicolumn{2}{|c|}{$-11 \leq h \leq 11,-12 \leq k \leq 12,-22 \leq l \leq 22$} \\
\hline Reflections collected & \multicolumn{2}{|c|}{14009} \\
\hline Independent reflections & \multicolumn{2}{|c|}{$1940\left[R_{\mathrm{int}}=0.0797\right]$} \\
\hline Completeness to theta $=25.02^{\circ}$ & \multicolumn{2}{|c|}{$99.9 \%$} \\
\hline Absorption correction & \multicolumn{2}{|c|}{ Multi-scan with SADABS } \\
\hline Max. and min. transmission & \multicolumn{2}{|c|}{0.9681 and 0.9591} \\
\hline Refinement method & \multicolumn{2}{|c|}{ Full-matrix least-squares on $F^{2}$} \\
\hline Data / restraints / parameters & \multicolumn{2}{|l|}{$1940 / 0 / 225$} \\
\hline Goodness-of-fit on $F^{2}$ & \multicolumn{2}{|l|}{1.069} \\
\hline Final $R$ indices $[I>2 \sigma(I)]$ & \multicolumn{2}{|c|}{$R_{1}=0.0476, w R_{2}=0.1122$} \\
\hline$R$ indices (all data) & \multicolumn{2}{|c|}{$R_{1}=0.0644, w R_{2}=0.1195$} \\
\hline Absolute structure parameter & \multicolumn{2}{|l|}{$\mathrm{N} / \mathrm{A}$} \\
\hline Largest diff. peak and hole & \multicolumn{2}{|c|}{0.192 and -0.232 e. $\AA^{-3}$} \\
\hline
\end{tabular}


Table S-4. Atomic Coordinates $\left(\times 10^{4}\right)$ and Equivalent Isotropic Displacement Parameters $\left(\AA^{2} \times 10^{3}\right)$ for Triazole 12

\begin{tabular}{lcrrr}
\hline & $x$ & $y$ & \multicolumn{1}{c}{$z$} & $U_{\mathrm{eq}}{ }^{a}$ \\
\hline $\mathrm{O}(1)$ & $4810(2)$ & $7031(2)$ & $-909(1)$ & $25(1)$ \\
$\mathrm{O}(2)$ & $6980(2)$ & $7423(2)$ & $-478(1)$ & $27(1)$ \\
$\mathrm{O}(3)$ & $6224(3)$ & $4087(3)$ & $25(1)$ & $34(1)$ \\
$\mathrm{O}(4)$ & $4620(3)$ & $4517(2)$ & $864(1)$ & $24(1)$ \\
$\mathrm{N}(1)$ & $5071(3)$ & $7468(3)$ & $227(1)$ & $20(1)$ \\
$\mathrm{N}(2)$ & $5276(4)$ & $6464(3)$ & $2563(2)$ & $34(1)$ \\
$\mathrm{N}(3)$ & $5982(4)$ & $5614(3)$ & $2199(2)$ & $30(1)$ \\
$\mathrm{N}(4)$ & $6209(3)$ & $6112(3)$ & $1546(1)$ & $21(1)$ \\
$\mathrm{C}(1)$ & $6133(4)$ & $5466(4)$ & $-1579(2)$ & $34(1)$ \\
$\mathrm{C}(2)$ & $3938(4)$ & $6430(5)$ & $-2016(2)$ & $42(1)$ \\
$\mathrm{C}(3)$ & $6098(5)$ & $7737(4)$ & $-1966(2)$ & $37(1)$ \\
$\mathrm{C}(4)$ & $5293(4)$ & $6664(4)$ & $-1629(2)$ & $28(1)$ \\
$\mathrm{C}(5)$ & $5720(4)$ & $7327(3)$ & $-395(2)$ & $21(1)$ \\
$\mathrm{C}(6)$ & $5750(4)$ & $8074(3)$ & $835(2)$ & $18(1)$ \\
$\mathrm{C}(7)$ & $5181(4)$ & $9382(3)$ & $962(2)$ & $27(1)$ \\
$\mathrm{C}(8)$ & $5642(4)$ & $7271(3)$ & $1487(2)$ & $17(1)$ \\
$\mathrm{C}(9)$ & $5064(4)$ & $7484(3)$ & $2144(2)$ & $26(1)$ \\
$\mathrm{C}(10)$ & $6881(4)$ & $5361(3)$ & $991(2)$ & $21(1)$ \\
$\mathrm{C}(11)$ & $8011(4)$ & $4509(4)$ & $1294(2)$ & $35(1)$ \\
$\mathrm{C}(12)$ & $5855(4)$ & $4587(3)$ & $567(2)$ & $21(1)$ \\
$\mathrm{C}(13)$ & $3527(4)$ & $3667(3)$ & $572(2)$ & $23(1)$ \\
$\mathrm{C}(14)$ & $3162(4)$ & $4045(4)$ & $-173(2)$ & $35(1)$ \\
$\mathrm{C}(15)$ & $4058(4)$ & $2326(3)$ & $613(2)$ & $35(1)$ \\
$\mathrm{C}(16)$ & $2342(5)$ & $3877(5)$ & $1080(3)$ & $59(2)$ \\
\hline
\end{tabular}

${ }^{a} U_{\text {eq }}$ is defined as $1 / 3$ of the trace of the orthogonalized $U^{i j}$ tensor. 
Table S-5. Bond Lengths $[\AA]$ and Angles $\left[{ }^{\circ}\right]$ for Triazole 12

\begin{tabular}{|c|c|c|c|}
\hline $\mathrm{O}(1)-\mathrm{C}(5)$ & $1.339(4)$ & $C(6)-C(8)$ & $1.496(4)$ \\
\hline $\mathrm{O}(1)-\mathrm{C}(4)$ & $1.483(4)$ & $C(6)-C(7)$ & $1.508(5)$ \\
\hline $\mathrm{O}(2)-\mathrm{C}(5)$ & $1.221(4)$ & $\mathrm{C}(6)-\mathrm{H}(6)$ & 1.0000 \\
\hline $\mathrm{O}(3)-\mathrm{C}(12)$ & $1.202(4)$ & $\mathrm{C}(7)-\mathrm{H}(7 \mathrm{~A})$ & 0.9800 \\
\hline $\mathrm{O}(4)-\mathrm{C}(12)$ & $1.310(4)$ & $\mathrm{C}(7)-\mathrm{H}(7 \mathrm{~B})$ & 0.9800 \\
\hline $\mathrm{O}(4)-\mathrm{C}(13)$ & $1.486(4)$ & $\mathrm{C}(7)-\mathrm{H}(7 \mathrm{C})$ & 0.9800 \\
\hline $\mathrm{N}(1)-\mathrm{C}(5)$ & $1.333(4)$ & $\mathrm{C}(8)-\mathrm{C}(9)$ & $1.372(5)$ \\
\hline $\mathrm{N}(1)-\mathrm{C}(6)$ & $1.464(4)$ & $\mathrm{C}(9)-\mathrm{H}(9)$ & 0.9500 \\
\hline $\mathrm{N}(1)-\mathrm{H}(1)$ & 0.8800 & $\mathrm{C}(10)-\mathrm{C}(12)$ & $1.508(5)$ \\
\hline $\mathrm{N}(2)-\mathrm{N}(3)$ & $1.318(5)$ & $\mathrm{C}(10)-\mathrm{C}(11)$ & $1.520(5)$ \\
\hline $\mathrm{N}(2)-\mathrm{C}(9)$ & $1.352(5)$ & $\mathrm{C}(10)-\mathrm{H}(10)$ & 1.0000 \\
\hline $\mathrm{N}(3)-\mathrm{N}(4)$ & $1.353(4)$ & $\mathrm{C}(11)-\mathrm{H}(11 \mathrm{~A})$ & 0.9800 \\
\hline $\mathrm{N}(4)-\mathrm{C}(8)$ & $1.348(4)$ & $\mathrm{C}(11)-\mathrm{H}(11 \mathrm{~B})$ & 0.9800 \\
\hline $\mathrm{N}(4)-\mathrm{C}(10)$ & $1.462(4)$ & $\mathrm{C}(11)-\mathrm{H}(11 \mathrm{C})$ & 0.9800 \\
\hline$C(1)-C(4)$ & $1.507(6)$ & $\mathrm{C}(13)-\mathrm{C}(14)$ & $1.498(5)$ \\
\hline $\mathrm{C}(1)-\mathrm{H}(1 \mathrm{~A})$ & 0.9800 & $\mathrm{C}(13)-\mathrm{C}(16)$ & $1.500(5)$ \\
\hline $\mathrm{C}(1)-\mathrm{H}(1 \mathrm{~B})$ & 0.9800 & $\mathrm{C}(13)-\mathrm{C}(15)$ & $1.512(5)$ \\
\hline $\mathrm{C}(1)-\mathrm{H}(1 \mathrm{C})$ & 0.9800 & $\mathrm{C}(14)-\mathrm{H}(14 \mathrm{~A})$ & 0.9800 \\
\hline$C(2)-C(4)$ & $1.508(5)$ & $\mathrm{C}(14)-\mathrm{H}(14 \mathrm{~B})$ & 0.9800 \\
\hline $\mathrm{C}(2)-\mathrm{H}(2 \mathrm{~A})$ & 0.9800 & $\mathrm{C}(14)-\mathrm{H}(14 \mathrm{C})$ & 0.9800 \\
\hline $\mathrm{C}(2)-\mathrm{H}(2 \mathrm{~B})$ & 0.9800 & $\mathrm{C}(15)-\mathrm{H}(15 \mathrm{~A})$ & 0.9800 \\
\hline $\mathrm{C}(2)-\mathrm{H}(2 \mathrm{C})$ & 0.9800 & $\mathrm{C}(15)-\mathrm{H}(15 \mathrm{~B})$ & 0.9800 \\
\hline$C(3)-C(4)$ & $1.513(6)$ & $\mathrm{C}(15)-\mathrm{H}(15 \mathrm{C})$ & 0.9800 \\
\hline $\mathrm{C}(3)-\mathrm{H}(3 \mathrm{~A})$ & 0.9800 & $\mathrm{C}(16)-\mathrm{H}(16 \mathrm{~A})$ & 0.9800 \\
\hline $\mathrm{C}(3)-\mathrm{H}(3 \mathrm{~B})$ & 0.9800 & $\mathrm{C}(16)-\mathrm{H}(16 \mathrm{~B})$ & 0.9800 \\
\hline $\mathrm{C}(3)-\mathrm{H}(3 \mathrm{C})$ & 0.9800 & $\mathrm{C}(16)-\mathrm{H}(16 \mathrm{C})$ & 0.9800 \\
\hline $\mathrm{C}(5)-\mathrm{O}(1)-\mathrm{C}(4)$ & $121.2(3)$ & $\mathrm{C}(4)-\mathrm{C}(2)-\mathrm{H}(2 \mathrm{C})$ & 109.5 \\
\hline $\mathrm{C}(12)-\mathrm{O}(4)-\mathrm{C}(13)$ & $120.9(3)$ & $\mathrm{H}(2 \mathrm{~A})-\mathrm{C}(2)-\mathrm{H}(2 \mathrm{C})$ & 109.5 \\
\hline $\mathrm{C}(5)-\mathrm{N}(1)-\mathrm{C}(6)$ & $121.8(3)$ & $\mathrm{H}(2 \mathrm{~B})-\mathrm{C}(2)-\mathrm{H}(2 \mathrm{C})$ & 109.5 \\
\hline $\mathrm{C}(5)-\mathrm{N}(1)-\mathrm{H}(1)$ & 119.1 & $\mathrm{C}(4)-\mathrm{C}(3)-\mathrm{H}(3 \mathrm{~A})$ & 109.5 \\
\hline $\mathrm{C}(6)-\mathrm{N}(1)-\mathrm{H}(1)$ & 119.1 & $\mathrm{C}(4)-\mathrm{C}(3)-\mathrm{H}(3 \mathrm{~B})$ & 109.5 \\
\hline $\mathrm{N}(3)-\mathrm{N}(2)-\mathrm{C}(9)$ & $108.8(3)$ & $\mathrm{H}(3 \mathrm{~A})-\mathrm{C}(3)-\mathrm{H}(3 \mathrm{~B})$ & 109.5 \\
\hline $\mathrm{N}(2)-\mathrm{N}(3)-\mathrm{N}(4)$ & $106.6(3)$ & $\mathrm{C}(4)-\mathrm{C}(3)-\mathrm{H}(3 \mathrm{C})$ & 109.5 \\
\hline $\mathrm{C}(8)-\mathrm{N}(4)-\mathrm{N}(3)$ & $111.5(3)$ & $\mathrm{H}(3 \mathrm{~A})-\mathrm{C}(3)-\mathrm{H}(3 \mathrm{C})$ & 109.5 \\
\hline $\mathrm{C}(8)-\mathrm{N}(4)-\mathrm{C}(10)$ & $127.9(3)$ & $\mathrm{H}(3 \mathrm{~B})-\mathrm{C}(3)-\mathrm{H}(3 \mathrm{C})$ & 109.5 \\
\hline $\mathrm{N}(3)-\mathrm{N}(4)-\mathrm{C}(10)$ & $120.4(3)$ & $\mathrm{O}(1)-\mathrm{C}(4)-\mathrm{C}(1)$ & $109.3(3)$ \\
\hline $\mathrm{C}(4)-\mathrm{C}(1)-\mathrm{H}(1 \mathrm{~A})$ & 109.5 & $\mathrm{O}(1)-\mathrm{C}(4)-\mathrm{C}(2)$ & $102.4(3)$ \\
\hline $\mathrm{C}(4)-\mathrm{C}(1)-\mathrm{H}(1 \mathrm{~B})$ & 109.5 & $\mathrm{C}(1)-\mathrm{C}(4)-\mathrm{C}(2)$ & $110.6(3)$ \\
\hline $\mathrm{H}(1 \mathrm{~A})-\mathrm{C}(1)-\mathrm{H}(1 \mathrm{~B})$ & 109.5 & $\mathrm{O}(1)-\mathrm{C}(4)-\mathrm{C}(3)$ & $110.1(3)$ \\
\hline $\mathrm{C}(4)-\mathrm{C}(1)-\mathrm{H}(1 \mathrm{C})$ & 109.5 & $C(1)-C(4)-C(3)$ & $112.8(3)$ \\
\hline $\mathrm{H}(1 \mathrm{~A})-\mathrm{C}(1)-\mathrm{H}(1 \mathrm{C})$ & 109.5 & $C(2)-C(4)-C(3)$ & $111.1(3)$ \\
\hline $\mathrm{H}(1 \mathrm{~B})-\mathrm{C}(1)-\mathrm{H}(1 \mathrm{C})$ & 109.5 & $\mathrm{O}(2)-\mathrm{C}(5)-\mathrm{N}(1)$ & $124.4(3)$ \\
\hline $\mathrm{C}(4)-\mathrm{C}(2)-\mathrm{H}(2 \mathrm{~A})$ & 109.5 & $\mathrm{O}(2)-\mathrm{C}(5)-\mathrm{O}(1)$ & $124.8(3)$ \\
\hline $\mathrm{C}(4)-\mathrm{C}(2)-\mathrm{H}(2 \mathrm{~B})$ & 109.5 & $\mathrm{~N}(1)-\mathrm{C}(5)-\mathrm{O}(1)$ & $110.8(3)$ \\
\hline $\mathrm{H}(2 \mathrm{~A})-\mathrm{C}(2)-\mathrm{H}(2 \mathrm{~B})$ & 109.5 & $\mathrm{~N}(1)-\mathrm{C}(6)-\mathrm{C}(8)$ & $111.0(3)$ \\
\hline
\end{tabular}




$\begin{array}{ll}\mathrm{N}(1)-\mathrm{C}(6)-\mathrm{C}(7) & 111.5(3) \\ \mathrm{C}(8)-\mathrm{C}(6)-\mathrm{C}(7) & 111.6(3) \\ \mathrm{N}(1)-\mathrm{C}(6)-\mathrm{H}(6) & 107.5 \\ \mathrm{C}(8)-\mathrm{C}(6)-\mathrm{H}(6) & 107.5 \\ \mathrm{C}(7)-\mathrm{C}(6)-\mathrm{H}(6) & 107.5 \\ \mathrm{C}(6)-\mathrm{C}(7)-\mathrm{H}(7 \mathrm{~A}) & 109.5 \\ \mathrm{C}(6)-\mathrm{C}(7)-\mathrm{H}(7 \mathrm{~B}) & 109.5 \\ \mathrm{H}(7 \mathrm{~A})-\mathrm{C}(7)-\mathrm{H}(7 \mathrm{~B}) & 109.5 \\ \mathrm{C}(6)-\mathrm{C}(7)-\mathrm{H}(7 \mathrm{C}) & 109.5 \\ \mathrm{H}(7 \mathrm{~A})-\mathrm{C}(7)-\mathrm{H}(7 \mathrm{C}) & 109.5 \\ \mathrm{H}(7 \mathrm{~B})-\mathrm{C}(7)-\mathrm{H}(7 \mathrm{C}) & 109.5 \\ \mathrm{~N}(4)-\mathrm{C}(8)-\mathrm{C}(9) & 103.7(3) \\ \mathrm{N}(4)-\mathrm{C}(8)-\mathrm{C}(6) & 124.0(3) \\ \mathrm{C}(9)-\mathrm{C}(8)-\mathrm{C}(6) & 132.2(3) \\ \mathrm{N}(2)-\mathrm{C}(9)-\mathrm{C}(8) & 109.4(3) \\ \mathrm{N}(2)-\mathrm{C}(9)-\mathrm{H}(9) & 125.3 \\ \mathrm{C}(8)-\mathrm{C}(9)-\mathrm{H}(9) & 125.3 \\ \mathrm{~N}(4)-\mathrm{C}(10)-\mathrm{C}(12) & 112.8(3) \\ \mathrm{N}(4)-\mathrm{C}(10)-\mathrm{C}(11) & 111.7(3) \\ \mathrm{C}(12)-\mathrm{C}(10)-\mathrm{C}(11) & 109.8(3) \\ \mathrm{N}(4)-\mathrm{C}(10)-\mathrm{H}(10) & 107.4 \\ \mathrm{C}(12)-\mathrm{C}(10)-\mathrm{H}(10) & 107.4 \\ \mathrm{C}(11)-\mathrm{C}(10)-\mathrm{H}(10) & 107.4 \\ \mathrm{C}(10)-\mathrm{C}(11)-\mathrm{H}(11 \mathrm{~A}) & 109.5 \\ \mathrm{C}(10)-\mathrm{C}(11)-\mathrm{H}(11 \mathrm{~B}) & 109.5 \\ \mathrm{H}(11 \mathrm{~A})-\mathrm{C}(11)-\mathrm{H}(11 \mathrm{~B}) & 109.5 \\ \mathrm{C}(10)-\mathrm{C}(11)-\mathrm{H}(11 \mathrm{C}) & 109.5 \\ \mathrm{H}(11 \mathrm{~A})-\mathrm{C}(11)-\mathrm{H}(11 \mathrm{C}) & 109.5 \\ \mathrm{H}(11 \mathrm{~B})-\mathrm{C}(11)-\mathrm{H}(11 \mathrm{C}) & 109.5 \\ \mathrm{O}(3)-\mathrm{C}(12)-\mathrm{O}(4) & 127.0(3) \\ \mathrm{O}(3)-\mathrm{C}(12)-\mathrm{C}(10) & 119.7(3) \\ \mathrm{O}(4)-\mathrm{C}(12)-\mathrm{C}(10) & 113.2(3) \\ \mathrm{O}(4)-\mathrm{C}(13)-\mathrm{C}(14) & 110.3(3) \\ \mathrm{O}(4)-\mathrm{C}(13)-\mathrm{C}(16) & 102.1(3) \\ \mathrm{C}(14)-\mathrm{C}(13)-\mathrm{C}(16) & 112.3(4) \\ \mathrm{O}(4)-\mathrm{C}(13)-\mathrm{C}(15) & 108.3(3) \\ \mathrm{C}(14)-\mathrm{C}(13)-\mathrm{C}(15) & 112.1(3) \\ \mathrm{C}(16)-\mathrm{C}(13)-\mathrm{C}(15) & 111.2(4) \\ \mathrm{C}(13)-\mathrm{C}(14)-\mathrm{H}(14 \mathrm{~A}) & 109.5 \\ \mathrm{C}(13)-\mathrm{C}(14)-\mathrm{H}(14 \mathrm{~B}) & 109.5 \\ \mathrm{H}(14 \mathrm{~A})-\mathrm{C}(14)-\mathrm{H}(14 \mathrm{~B}) & 109.5 \\ \mathrm{C}(13)-\mathrm{C}(14)-\mathrm{H}(14 \mathrm{C}) & 109.5 \\ \mathrm{H}(14 \mathrm{~A})-\mathrm{C}(14)-\mathrm{H}(14 \mathrm{C}) & 109.5 \\ \mathrm{H}(14 \mathrm{~B})-\mathrm{C}(14)-\mathrm{H}(14 \mathrm{C}) & 109.5 \\ \mathrm{C}(13)-\mathrm{C}(15)-\mathrm{H}(15 \mathrm{~A}) & 109.5 \\ \mathrm{C}(13)-\mathrm{C}(15)-\mathrm{H}(15 \mathrm{~B}) & 109.5 \\ & \end{array}$

$\begin{array}{ll}\mathrm{H}(15 \mathrm{~A})-\mathrm{C}(15)-\mathrm{H}(15 \mathrm{~B}) & 109.5 \\ \mathrm{C}(13)-\mathrm{C}(15)-\mathrm{H}(15 \mathrm{C}) & 109.5 \\ \mathrm{H}(15 \mathrm{~A})-\mathrm{C}(15)-\mathrm{H}(15 \mathrm{C}) & 109.5 \\ \mathrm{H}(15 \mathrm{~B})-\mathrm{C}(15)-\mathrm{H}(15 \mathrm{C}) & 109.5 \\ \mathrm{C}(13)-\mathrm{C}(16)-\mathrm{H}(16 \mathrm{~A}) & 109.5 \\ \mathrm{C}(13)-\mathrm{C}(16)-\mathrm{H}(16 \mathrm{~B}) & 109.5 \\ \mathrm{H}(16 \mathrm{~A})-\mathrm{C}(16)-\mathrm{H}(16 \mathrm{~B}) & 109.5 \\ \mathrm{C}(13)-\mathrm{C}(16)-\mathrm{H}(16 \mathrm{C}) & 109.5 \\ \mathrm{H}(16 \mathrm{~A})-\mathrm{C}(16)-\mathrm{H}(16 \mathrm{C}) & 109.5 \\ \mathrm{H}(16 \mathrm{~B})-\mathrm{C}(16)-\mathrm{H}(16 \mathrm{C}) & 109.5\end{array}$


Table S-6. Anisotropic Displacement Parameters $\left(\AA^{2} \times 10^{3}\right)$ for Triazole $12^{a}$

\begin{tabular}{|c|c|c|c|c|c|c|}
\hline & $U^{11}$ & $U^{22}$ & $U^{33}$ & $U^{23}$ & $U^{13}$ & $U^{12}$ \\
\hline$\overline{\mathrm{O}(1)}$ & $16(1)$ & $43(2)$ & $17(1)$ & $-8(1)$ & $-1(1)$ & $1(1)$ \\
\hline $\mathrm{O}(2)$ & $16(1)$ & $39(2)$ & $26(1)$ & $-3(1)$ & $2(1)$ & $0(1)$ \\
\hline $\mathrm{O}(3)$ & $22(1)$ & $49(2)$ & $32(2)$ & $-10(1)$ & 1(1) & $-1(1)$ \\
\hline $\mathrm{O}(4)$ & $23(1)$ & $21(1)$ & $29(1)$ & $-8(1)$ & $1(1)$ & $-6(1)$ \\
\hline $\mathrm{N}(1)$ & $17(2)$ & $24(2)$ & $20(2)$ & $-1(1)$ & $1(1)$ & $-3(2)$ \\
\hline $\mathrm{N}(2)$ & $47(2)$ & $31(2)$ & $23(2)$ & $-1(2)$ & $1(2)$ & $-2(2)$ \\
\hline $\mathrm{N}(3)$ & $41(2)$ & $31(2)$ & $18(2)$ & $5(1)$ & $-3(2)$ & $1(2)$ \\
\hline $\mathrm{N}(4)$ & $28(2)$ & $19(2)$ & $18(1)$ & $1(1)$ & $-3(1)$ & $-2(1)$ \\
\hline $\mathrm{C}(1)$ & $29(2)$ & $46(3)$ & $27(2)$ & $-8(2)$ & $1(2)$ & $5(2)$ \\
\hline$C(2)$ & $26(2)$ & $80(3)$ & $21(2)$ & $-12(2)$ & $-7(2)$ & $8(2)$ \\
\hline $\mathrm{C}(3)$ & $40(3)$ & $48(3)$ & $24(2)$ & $3(2)$ & $6(2)$ & $4(2)$ \\
\hline$C(4)$ & $24(2)$ & $45(2)$ & $15(2)$ & $-5(2)$ & $5(2)$ & $6(2)$ \\
\hline$C(5)$ & $20(2)$ & $19(2)$ & $23(2)$ & $0(2)$ & $-2(2)$ & $0(2)$ \\
\hline$C(6)$ & $16(2)$ & $18(2)$ & $20(2)$ & $1(1)$ & $1(2)$ & $1(2)$ \\
\hline$C(7)$ & $24(2)$ & $19(2)$ & $37(2)$ & $0(2)$ & $5(2)$ & $2(2)$ \\
\hline $\mathrm{C}(8)$ & $18(2)$ & $16(2)$ & $18(2)$ & $0(1)$ & $-1(1)$ & $-2(2)$ \\
\hline$C(9)$ & $32(2)$ & $24(2)$ & $22(2)$ & $1(2)$ & $0(2)$ & $-4(2)$ \\
\hline$C(10)$ & $22(2)$ & $20(2)$ & $22(2)$ & $-2(2)$ & $1(2)$ & $5(2)$ \\
\hline $\mathrm{C}(11)$ & $29(2)$ & $33(2)$ & $43(2)$ & $-9(2)$ & $-14(2)$ & $12(2)$ \\
\hline$C(12)$ & $20(2)$ & $23(2)$ & $21(2)$ & $-1(2)$ & $1(2)$ & $8(2)$ \\
\hline $\mathrm{C}(13)$ & $22(2)$ & $22(2)$ & $26(2)$ & $-3(2)$ & $-3(2)$ & $-6(2)$ \\
\hline $\mathrm{C}(14)$ & $31(2)$ & $30(2)$ & $43(2)$ & $9(2)$ & $-14(2)$ & $-3(2)$ \\
\hline$C(15)$ & $43(3)$ & $18(2)$ & $43(2)$ & $4(2)$ & $-16(2)$ & $-5(2)$ \\
\hline$C(16)$ & $34(3)$ & $66(4)$ & $77(3)$ & $-33(3)$ & $25(3)$ & $-22(3)$ \\
\hline
\end{tabular}

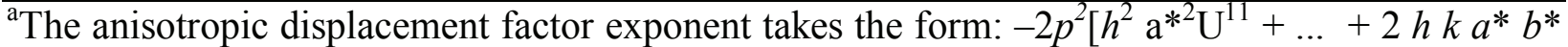
$\left.U^{12}\right]$. 
Table S-7. Hydrogen Coordinates $\left(\times 10^{4}\right)$ and Isotropic Displacement Parameters $\left(\AA^{2} \times 10^{3}\right)$ for Triazole 12.

\begin{tabular}{|c|c|c|c|c|}
\hline & $x$ & $y$ & $z$ & $U_{\mathrm{eq}}$ \\
\hline$\overline{\mathrm{H}(1)}$ & 4210 & 7190 & 274 & 24 \\
\hline $\mathrm{H}(1 \mathrm{~A})$ & 6943 & 5605 & -1270 & 51 \\
\hline $\mathrm{H}(1 \mathrm{~B})$ & 6453 & 5221 & -2054 & 51 \\
\hline $\mathrm{H}(1 \mathrm{C})$ & 5552 & 4793 & -1380 & 51 \\
\hline $\mathrm{H}(2 \mathrm{~A})$ & 3386 & 5806 & -1754 & 64 \\
\hline $\mathrm{H}(2 \mathrm{~B})$ & 4136 & 6112 & -2495 & 64 \\
\hline $\mathrm{H}(2 \mathrm{C})$ & 3413 & 7221 & -2050 & 64 \\
\hline $\mathrm{H}(3 \mathrm{~A})$ & 5569 & 8523 & -1914 & 56 \\
\hline $\mathrm{H}(3 \mathrm{~B})$ & 6242 & 7559 & -2472 & 56 \\
\hline $\mathrm{H}(3 \mathrm{C})$ & 7005 & 7824 & -1730 & 56 \\
\hline $\mathrm{H}(6)$ & 6764 & 8162 & 718 & 21 \\
\hline $\mathrm{H}(7 \mathrm{~A})$ & 5281 & 9886 & 528 & 40 \\
\hline $\mathrm{H}(7 \mathrm{~B})$ & 5700 & 9784 & 1350 & 40 \\
\hline $\mathrm{H}(7 \mathrm{C})$ & 4192 & 9326 & 1091 & 40 \\
\hline $\mathrm{H}(9)$ & 4588 & 8231 & 2283 & 31 \\
\hline $\mathrm{H}(10)$ & 7341 & 5961 & 655 & 25 \\
\hline $\mathrm{H}(11 \mathrm{~A})$ & 8713 & 5024 & 1538 & 53 \\
\hline $\mathrm{H}(11 \mathrm{~B})$ & 8456 & 4040 & 906 & 53 \\
\hline $\mathrm{H}(11 \mathrm{C})$ & 7594 & 3915 & 1632 & 53 \\
\hline $\mathrm{H}(14 \mathrm{~A})$ & 2950 & 4949 & -186 & 52 \\
\hline $\mathrm{H}(14 \mathrm{~B})$ & 2345 & 3566 & -332 & 52 \\
\hline $\mathrm{H}(14 \mathrm{C})$ & 3953 & 3867 & -488 & 52 \\
\hline $\mathrm{H}(15 \mathrm{~A})$ & 4842 & 2220 & 283 & 52 \\
\hline $\mathrm{H}(15 \mathrm{~B})$ & 3307 & 1742 & 483 & 52 \\
\hline $\mathrm{H}(15 \mathrm{C})$ & 4371 & 2145 & 1099 & 52 \\
\hline $\mathrm{H}(16 \mathrm{~A})$ & 2663 & 3729 & 1567 & 88 \\
\hline $\mathrm{H}(16 \mathrm{~B})$ & 1580 & 3292 & 968 & 88 \\
\hline $\mathrm{H}(16 \mathrm{C})$ & 2007 & 4747 & 1035 & 88 \\
\hline
\end{tabular}


Table S-8. Torsion Angles $\left[{ }^{\circ}\right]$ for Triazole 12

\begin{tabular}{|c|c|}
\hline $\mathrm{C}(9)-\mathrm{N}(2)-\mathrm{N}(3)-\mathrm{N}(4)$ & $-0.1(4)$ \\
\hline $\mathrm{N}(2)-\mathrm{N}(3)-\mathrm{N}(4)-\mathrm{C}(8)$ & $-0.6(4)$ \\
\hline $\mathrm{N}(2)-\mathrm{N}(3)-\mathrm{N}(4)-\mathrm{C}(10)$ & $-175.3(3)$ \\
\hline $\mathrm{C}(5)-\mathrm{O}(1)-\mathrm{C}(4)-\mathrm{C}(1)$ & $62.9(4)$ \\
\hline $\mathrm{C}(5)-\mathrm{O}(1)-\mathrm{C}(4)-\mathrm{C}(2)$ & $-179.8(3)$ \\
\hline $\mathrm{C}(5)-\mathrm{O}(1)-\mathrm{C}(4)-\mathrm{C}(3)$ & $-61.5(4)$ \\
\hline $\mathrm{C}(6)-\mathrm{N}(1)-\mathrm{C}(5)-\mathrm{O}(2)$ & $16.3(5)$ \\
\hline $\mathrm{C}(6)-\mathrm{N}(1)-\mathrm{C}(5)-\mathrm{O}(1)$ & $-165.3(3)$ \\
\hline $\mathrm{C}(4)-\mathrm{O}(1)-\mathrm{C}(5)-\mathrm{O}(2)$ & $6.2(5)$ \\
\hline $\mathrm{C}(4)-\mathrm{O}(1)-\mathrm{C}(5)-\mathrm{N}(1)$ & $-172.1(3)$ \\
\hline $\mathrm{C}(5)-\mathrm{N}(1)-\mathrm{C}(6)-\mathrm{C}(8)$ & $-128.9(3)$ \\
\hline $\mathrm{C}(5)-\mathrm{N}(1)-\mathrm{C}(6)-\mathrm{C}(7)$ & $106.1(4)$ \\
\hline $\mathrm{N}(3)-\mathrm{N}(4)-\mathrm{C}(8)-\mathrm{C}(9)$ & $1.0(4)$ \\
\hline $\mathrm{C}(10)-\mathrm{N}(4)-\mathrm{C}(8)-\mathrm{C}(9)$ & $175.2(3)$ \\
\hline $\mathrm{N}(3)-\mathrm{N}(4)-\mathrm{C}(8)-\mathrm{C}(6)$ & $178.4(3)$ \\
\hline $\mathrm{C}(10)-\mathrm{N}(4)-\mathrm{C}(8)-\mathrm{C}(6)$ & $-7.4(5)$ \\
\hline $\mathrm{N}(1)-\mathrm{C}(6)-\mathrm{C}(8)-\mathrm{N}(4)$ & $62.6(4)$ \\
\hline $\mathrm{C}(7)-\mathrm{C}(6)-\mathrm{C}(8)-\mathrm{N}(4)$ & $-172.4(3)$ \\
\hline $\mathrm{N}(1)-\mathrm{C}(6)-\mathrm{C}(8)-\mathrm{C}(9)$ & $-120.8(4)$ \\
\hline$C(7)-C(6)-C(8)-C(9)$ & $4.2(5)$ \\
\hline $\mathrm{N}(3)-\mathrm{N}(2)-\mathrm{C}(9)-\mathrm{C}(8)$ & $0.7(4)$ \\
\hline $\mathrm{N}(4)-\mathrm{C}(8)-\mathrm{C}(9)-\mathrm{N}(2)$ & $-1.0(4)$ \\
\hline $\mathrm{C}(6)-\mathrm{C}(8)-\mathrm{C}(9)-\mathrm{N}(2)$ & $-178.1(3)$ \\
\hline $\mathrm{C}(8)-\mathrm{N}(4)-\mathrm{C}(10)-\mathrm{C}(12)$ & $-86.2(4)$ \\
\hline $\mathrm{N}(3)-\mathrm{N}(4)-\mathrm{C}(10)-\mathrm{C}(12)$ & $87.6(4)$ \\
\hline $\mathrm{C}(8)-\mathrm{N}(4)-\mathrm{C}(10)-\mathrm{C}(11)$ & $149.6(3)$ \\
\hline $\mathrm{N}(3)-\mathrm{N}(4)-\mathrm{C}(10)-\mathrm{C}(11)$ & $-36.6(4)$ \\
\hline $\mathrm{C}(13)-\mathrm{O}(4)-\mathrm{C}(12)-\mathrm{O}(3)$ & $5.8(5)$ \\
\hline $\mathrm{C}(13)-\mathrm{O}(4)-\mathrm{C}(12)-\mathrm{C}(10)$ & $-172.3(3)$ \\
\hline $\mathrm{N}(4)-\mathrm{C}(10)-\mathrm{C}(12)-\mathrm{O}(3)$ & $167.9(3)$ \\
\hline $\mathrm{C}(11)-\mathrm{C}(10)-\mathrm{C}(12)-\mathrm{O}(3)$ & $-66.8(4)$ \\
\hline $\mathrm{N}(4)-\mathrm{C}(10)-\mathrm{C}(12)-\mathrm{O}(4)$ & $-13.7(4)$ \\
\hline $\mathrm{C}(11)-\mathrm{C}(10)-\mathrm{C}(12)-\mathrm{O}(4)$ & $111.6(3)$ \\
\hline $\mathrm{C}(12)-\mathrm{O}(4)-\mathrm{C}(13)-\mathrm{C}(14)$ & $-61.7(4)$ \\
\hline $\mathrm{C}(12)-\mathrm{O}(4)-\mathrm{C}(13)-\mathrm{C}(16)$ & $178.8(4)$ \\
\hline $\mathrm{C}(12)-\mathrm{O}(4)-\mathrm{C}(13)-\mathrm{C}(15)$ & $61.3(4)$ \\
\hline
\end{tabular}


Table S-9. Hydrogen Bonds for Triazole 12 [ $\AA$ and $\left.{ }^{\circ}\right]$

\begin{tabular}{lll}
\hline $\mathrm{D}-\mathrm{H} \cdots \mathrm{A}$ & $r_{\mathrm{D}-\mathrm{H}}$ & $r_{\mathrm{H}} \cdots \mathrm{A}$ \\
\hline $\mathrm{N}(1)-\mathrm{H}(1) \cdots(2) H 1$ & 0.88
\end{tabular}

$\mathrm{N}(1)-\mathrm{H}(1) \cdots \mathrm{O}(2) \# 1 \quad 0.88 \quad 2.21$

$r_{\mathrm{D} \cdots \mathrm{A}}$

$\angle \mathrm{DHA}$

Symmetry transformations used to generate equivalent atoms: $\# 1 x-1 / 2,-y+3 / 2,-z$. 


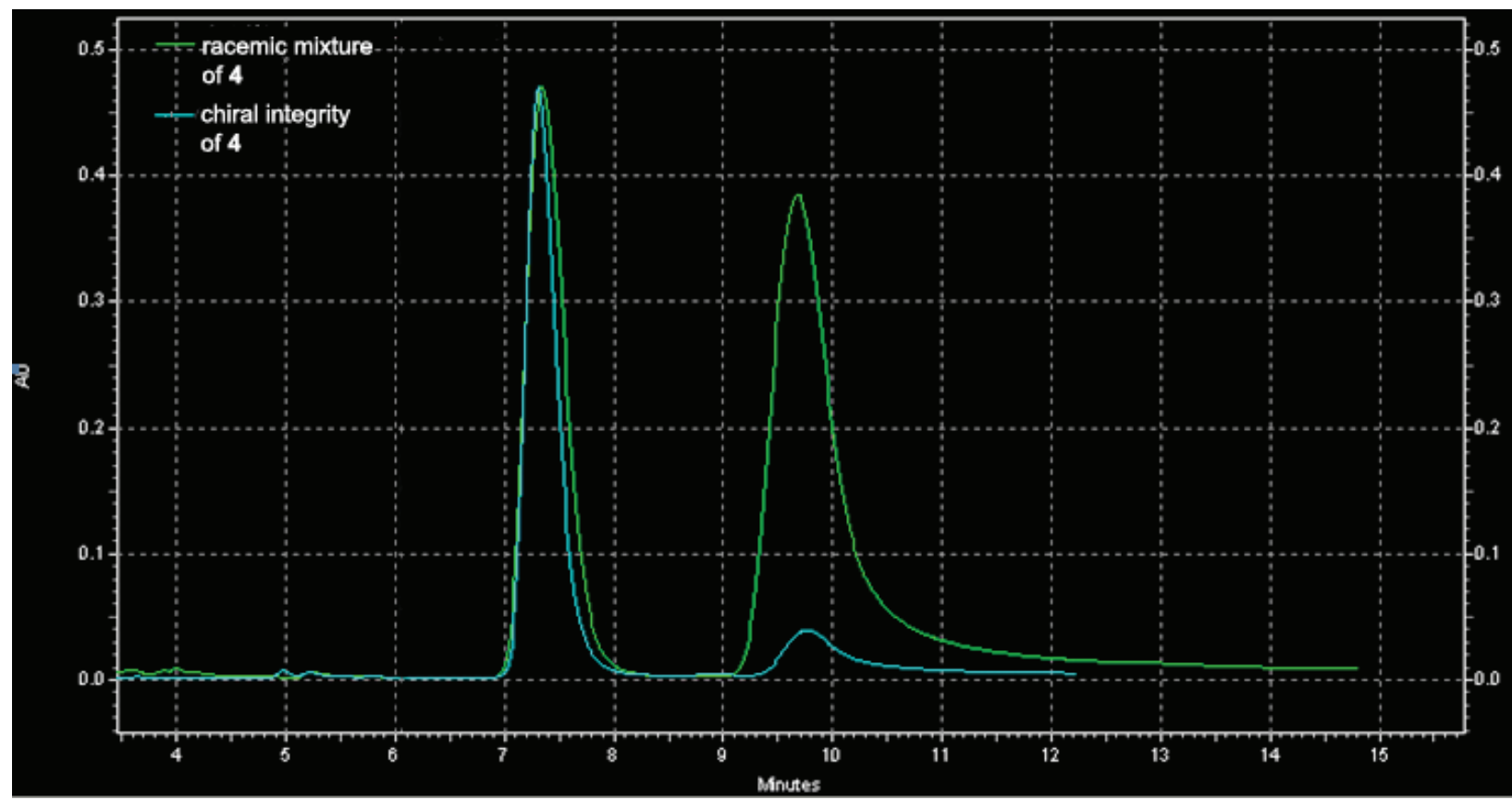

Figure S-1. Chiral HPLC trace overlay of the L-isomer of $\mathbf{4}$ and a racemic mixture of $\mathbf{4}$. Material $(1.0 \mathrm{mg} / \mathrm{mL})$ was injected onto the column and eluted with $10 \% \mathrm{v} / \mathrm{v} 2$-propanol in hexanes (isocratic) for 12-15 min at $0.95 \mathrm{~mL} / \mathrm{min}$, and monitored at $214 \mathrm{~nm}$ (Beckman Coulter, DIACEL Chiral OD column). Integration of the peaks indicated an enantiomeric excess of $88 \%$.

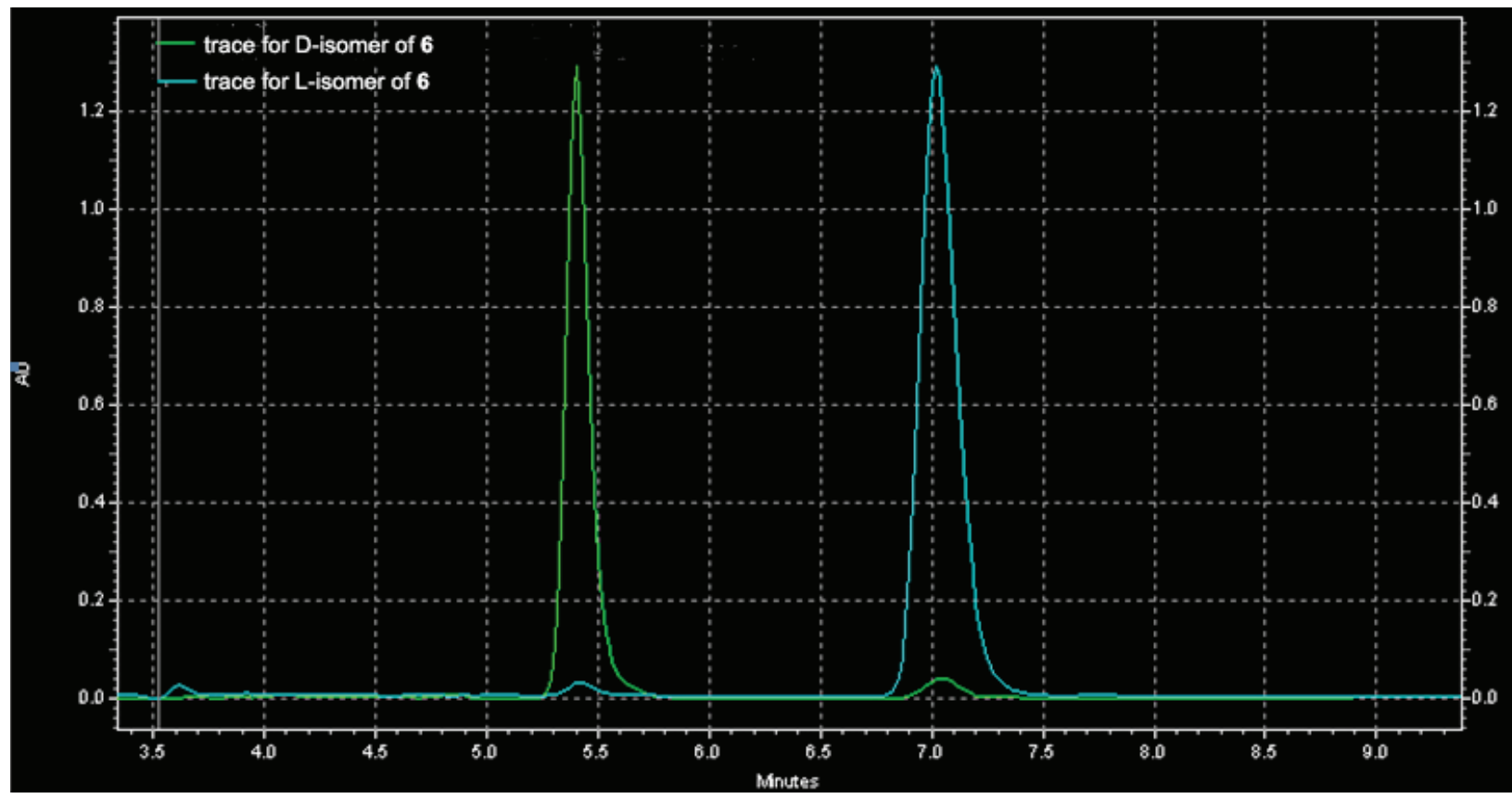

Figure S-2. Chiral HPLC trace overlay of the L- and D-isomers of 6. Material $(1.0 \mathrm{mg} / \mathrm{mL})$ was injected onto the column and eluted with $10 \% \mathrm{v} / \mathrm{v} 2$-propanol in hexanes (isocratic) for $10 \mathrm{~min}$ at $0.92 \mathrm{~mL} / \mathrm{min}$, and monitored at $214 \mathrm{~nm}$ (Beckman Coulter, DIACEL Chiral OD column). Integration of the peaks indicated an enantiomeric excess of $98 \%$ for each isomer. 

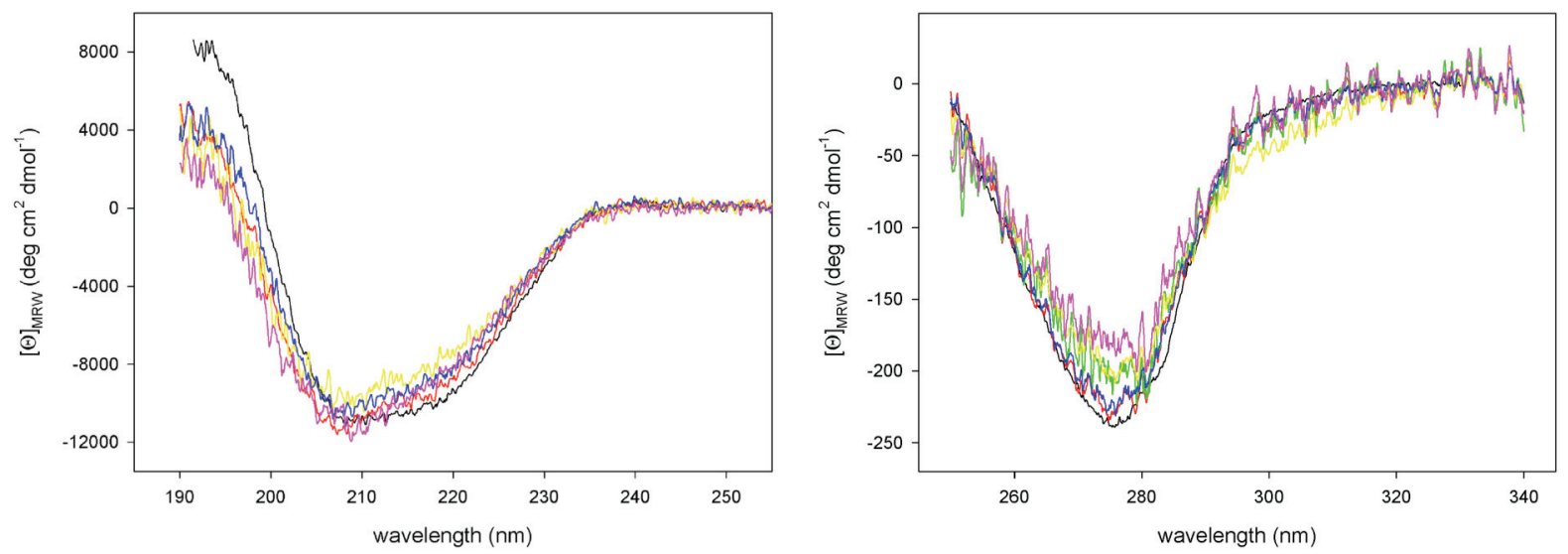

Figure S-3. CD spectra of RNase A and its variants. CD spectra in the far-UV range (left) and near-UV range (right) were recorded at $20^{\circ} \mathrm{C}$ in $50 \mathrm{mM}$ sodium phosphate buffer ( $\left.\mathrm{pH} 8.0\right)$ containing $\mathrm{NaCl}(25 \mathrm{mM})$. Wild-type RNase A $(\mathbf{1 6},-)$ and its variants: Asn-1,5-triazole-Ala $(\mathbf{1 7},-)$, Asn-1,4-triazole-Ala $(\mathbf{1 8},-)$, N113A $(\mathbf{1 9},-)$, Ala-1,5-triazole-Ala $(\mathbf{2 0},-)$, and Asn-1,5-triazole-Ala $(\mathbf{2 1},-)$.

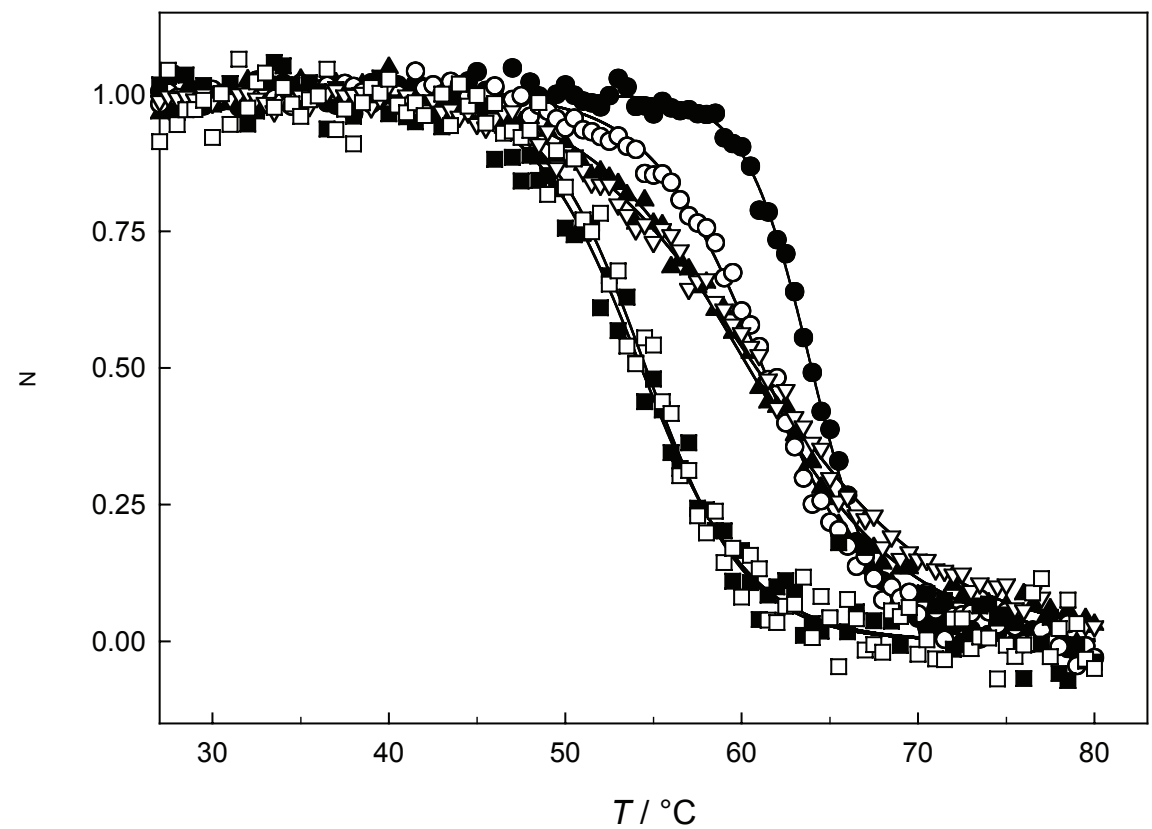

Figure S-4. Thermal denaturation curves of wild-type RNase A and its variants. The thermal denaturation of wild-type RNase A $(\mathbf{1 6}, \bullet)$ and its Asn-1,5-triazole-Ala (17, $\boldsymbol{\Delta})$, Asn-1,4triazole-Ala (18, $\mathbf{- 1})$, N113A (19, o), Ala-1,5-triazole-Ala (20, $\nabla)$, and Ala-1,4-triazole-Ala (21, $\square)$ variants was monitored by $C D$ spectroscopy at $276 \mathrm{~nm}$. 


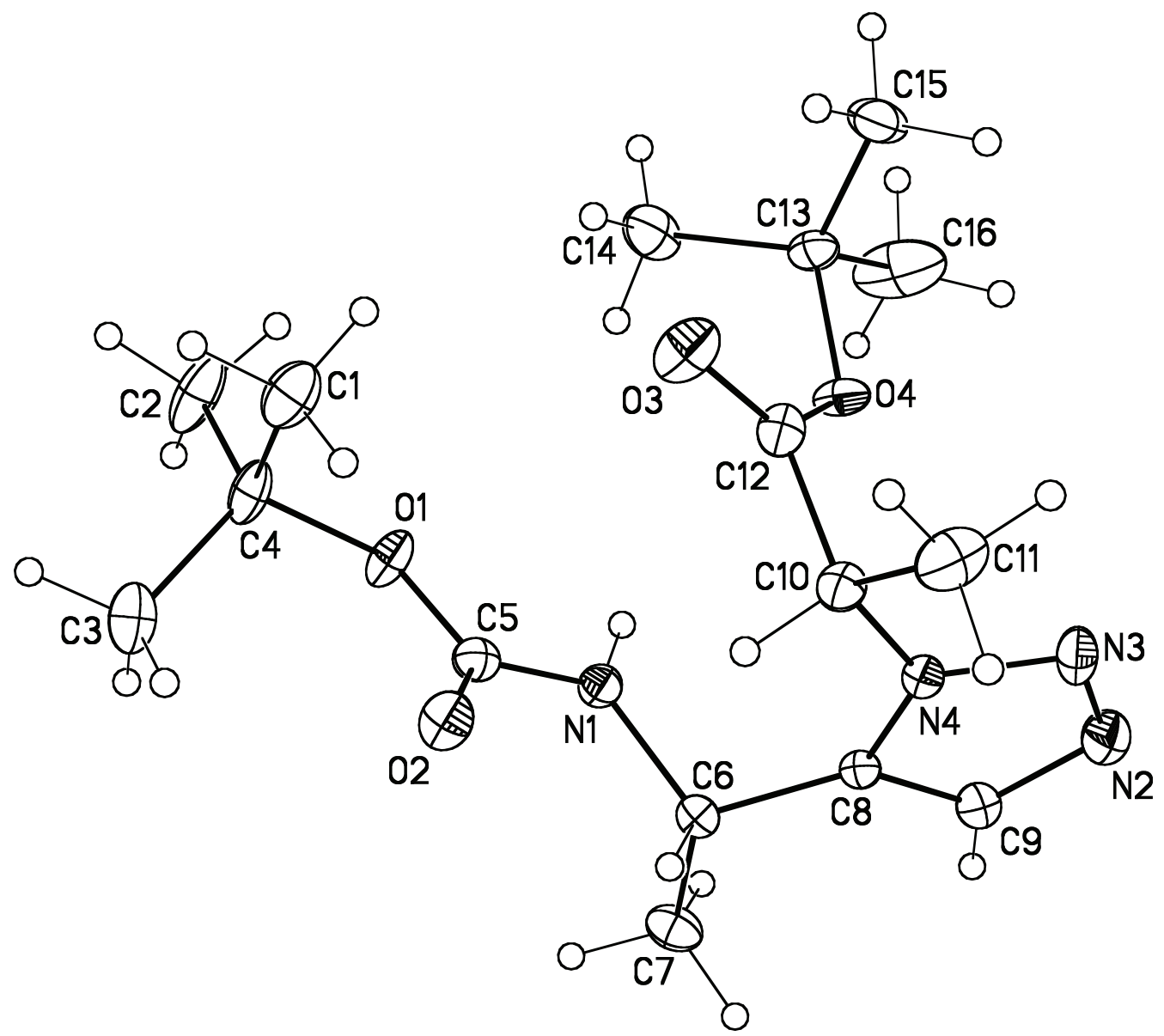

Figure S-5. ORTEP diagram of triazole 12 drawn with $40 \%$ probability ellipsoids and the atom designations used in Tables S-3-S-9. 


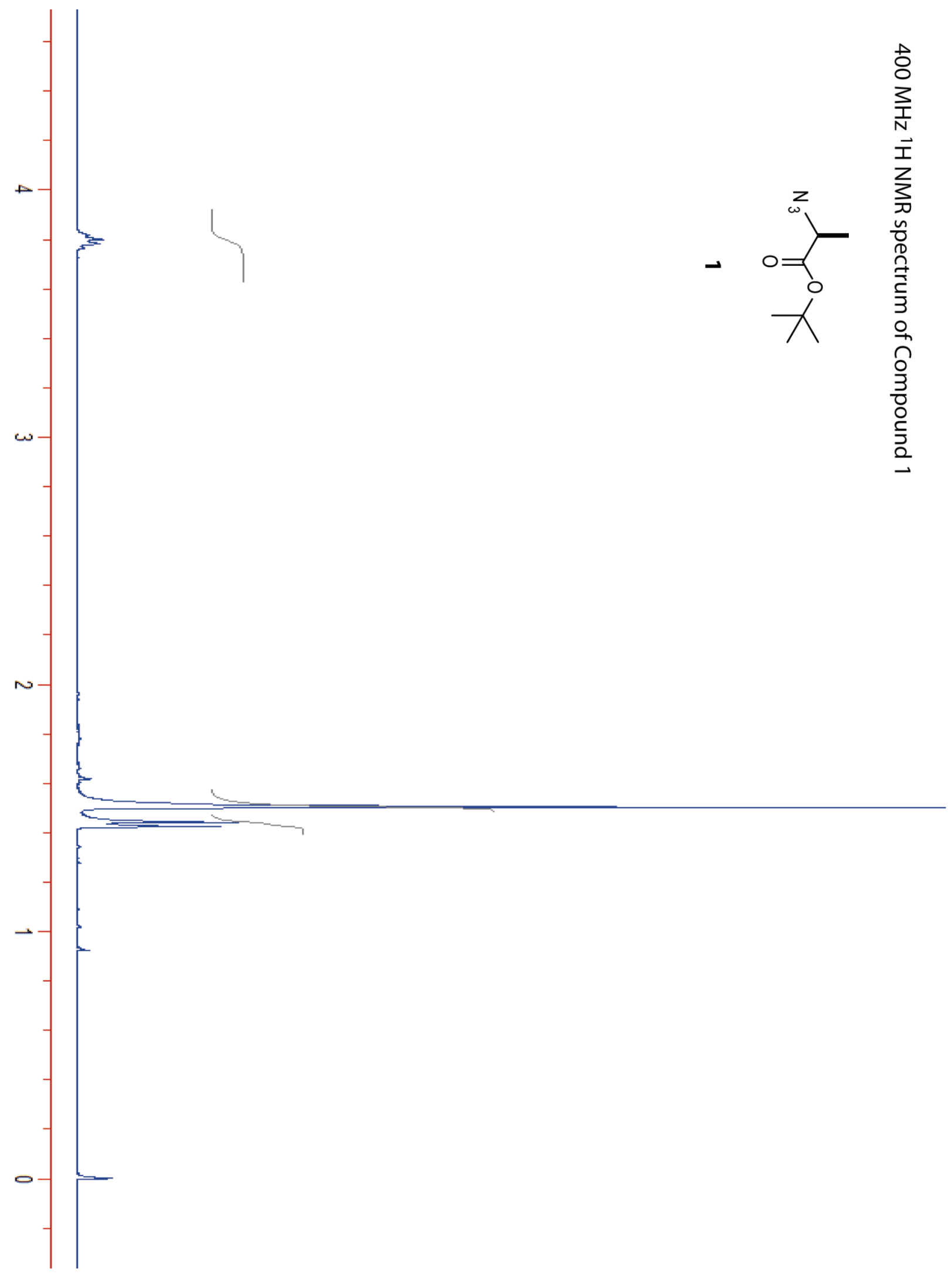



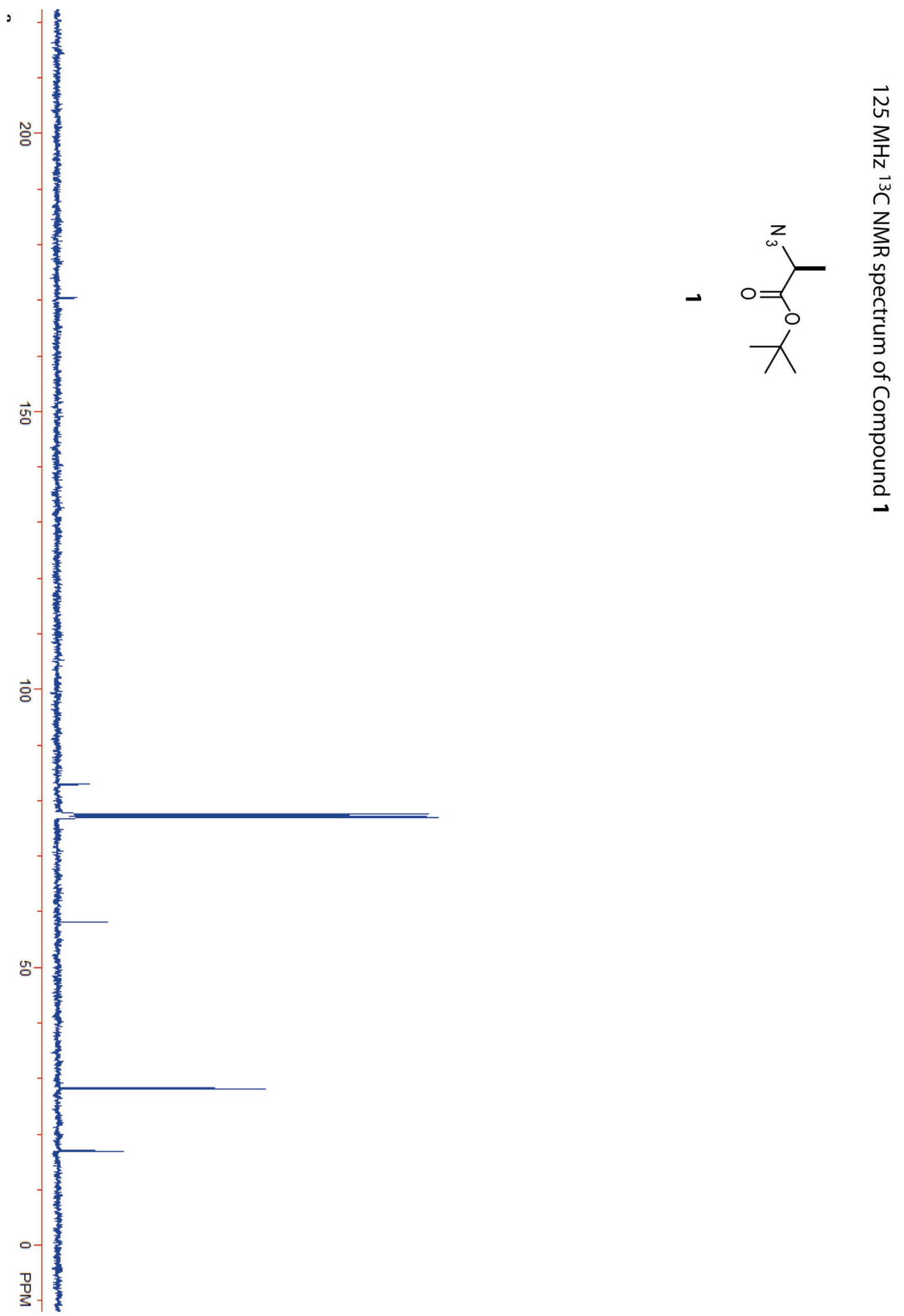


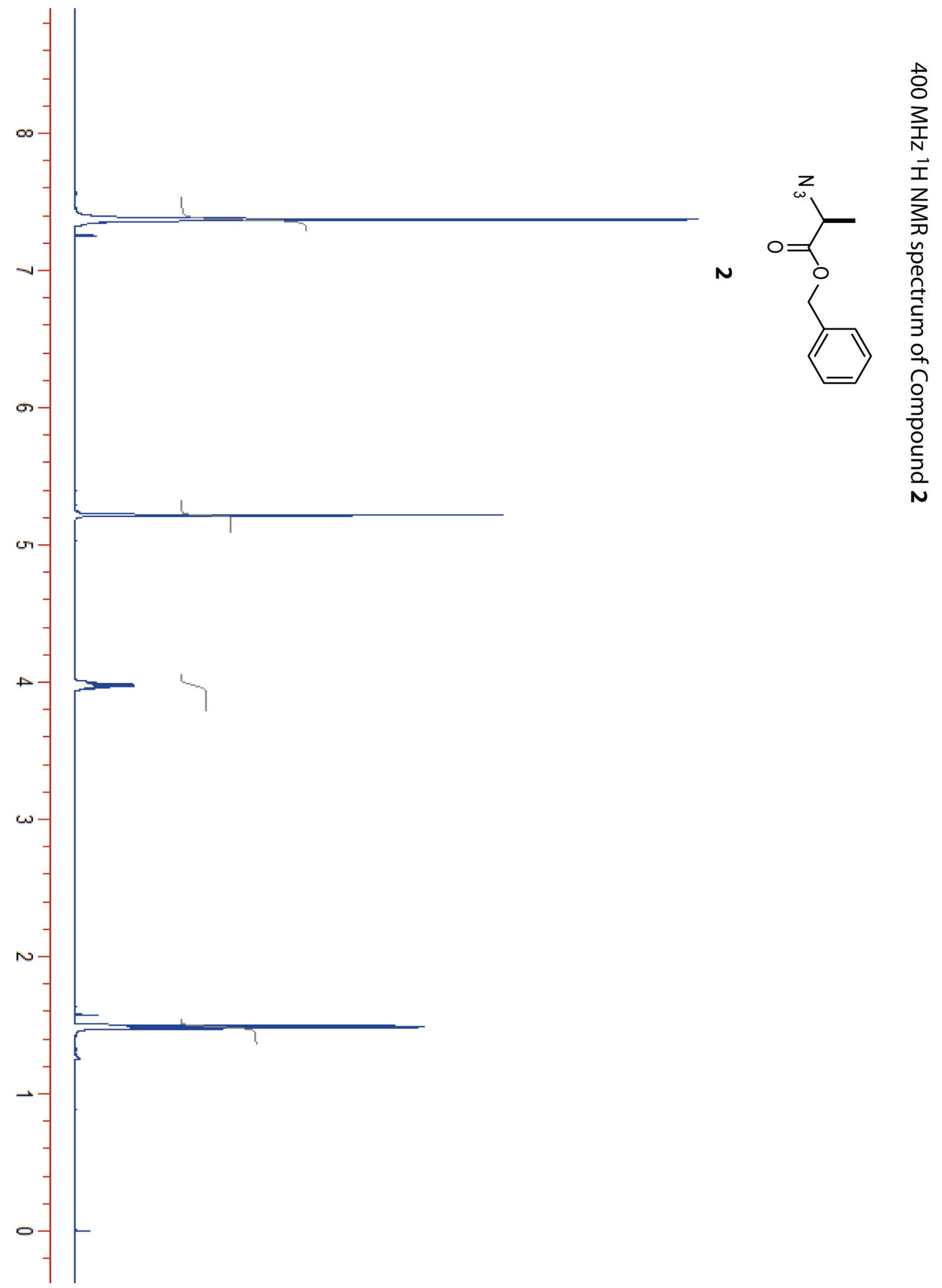



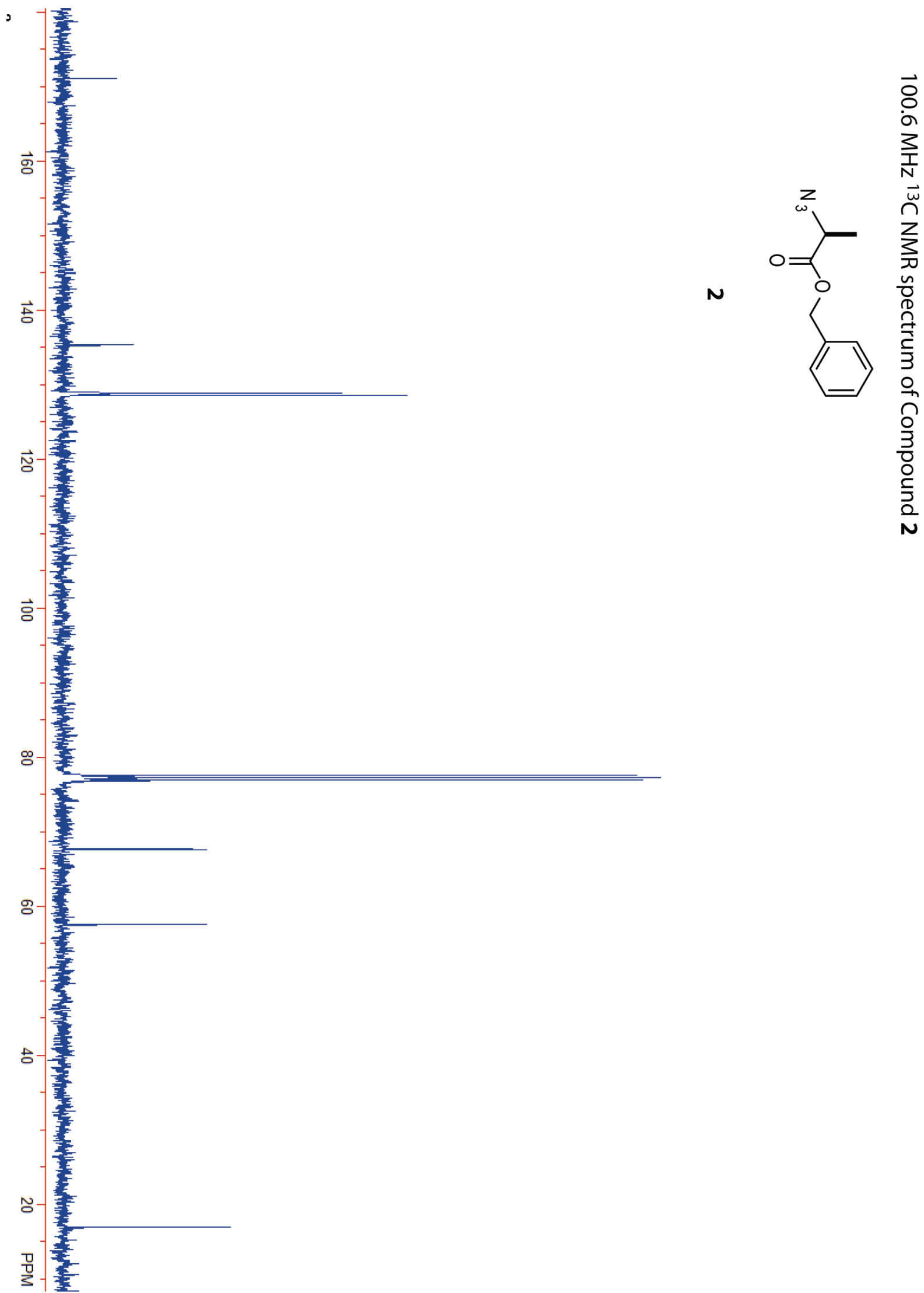


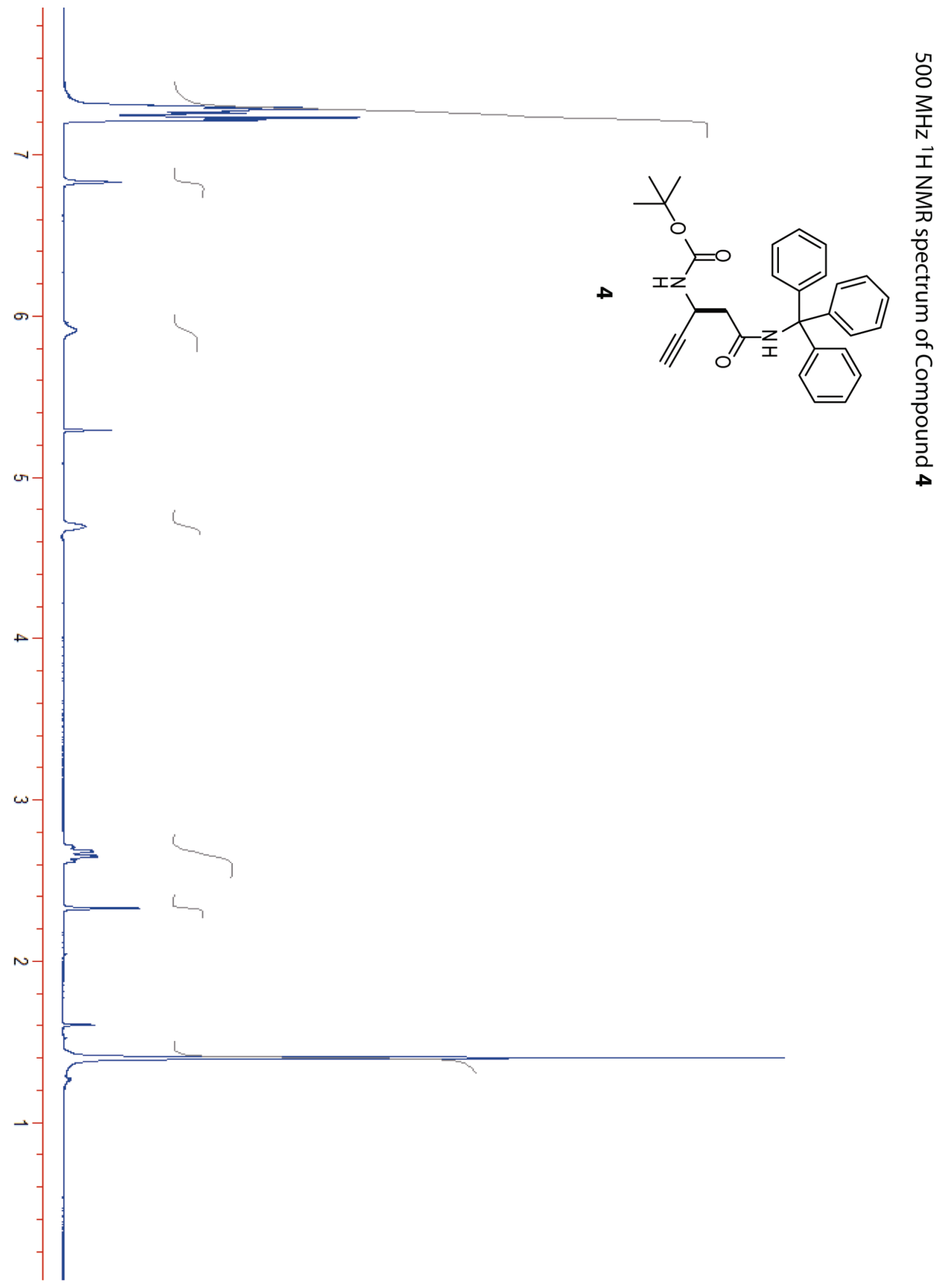




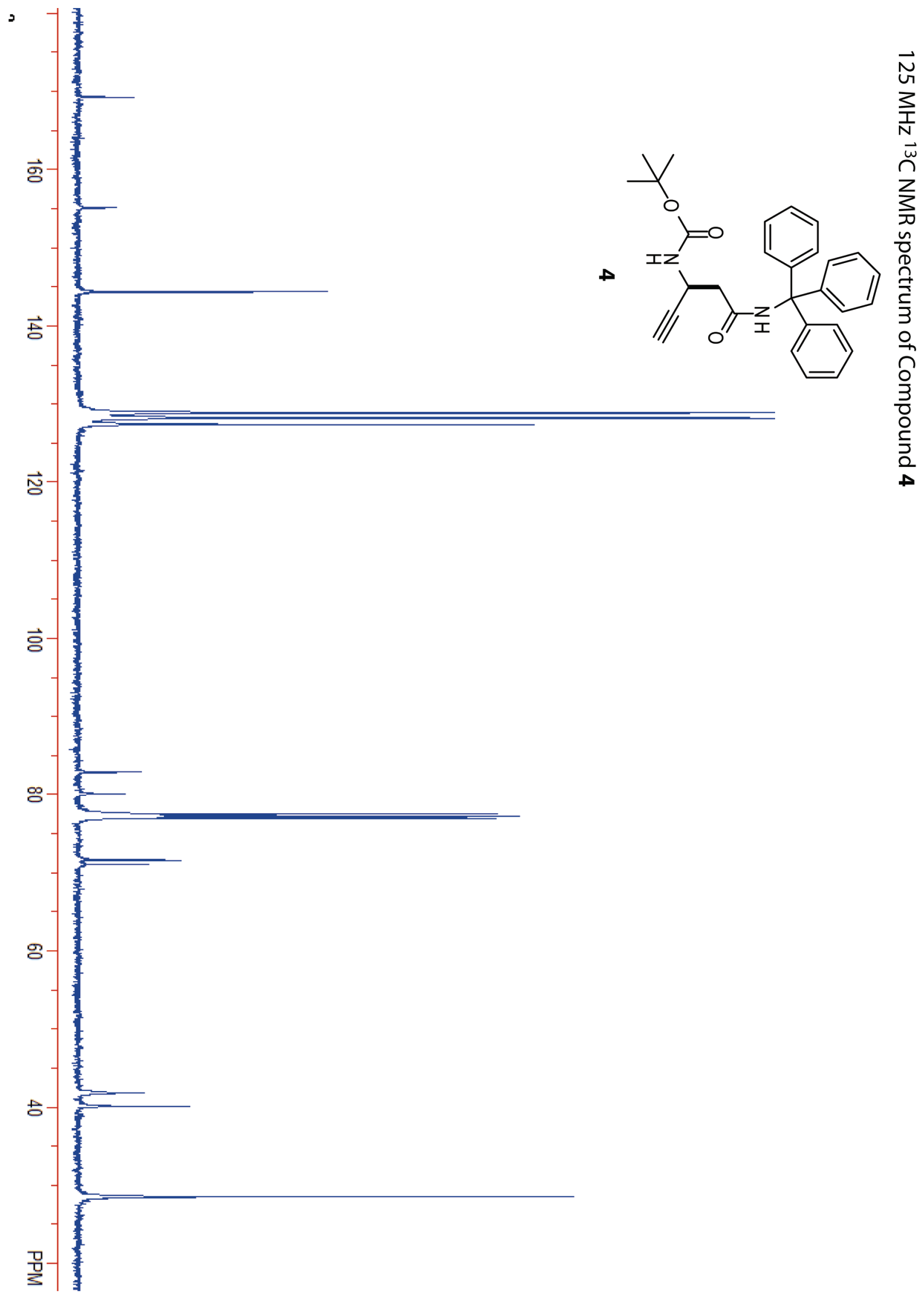




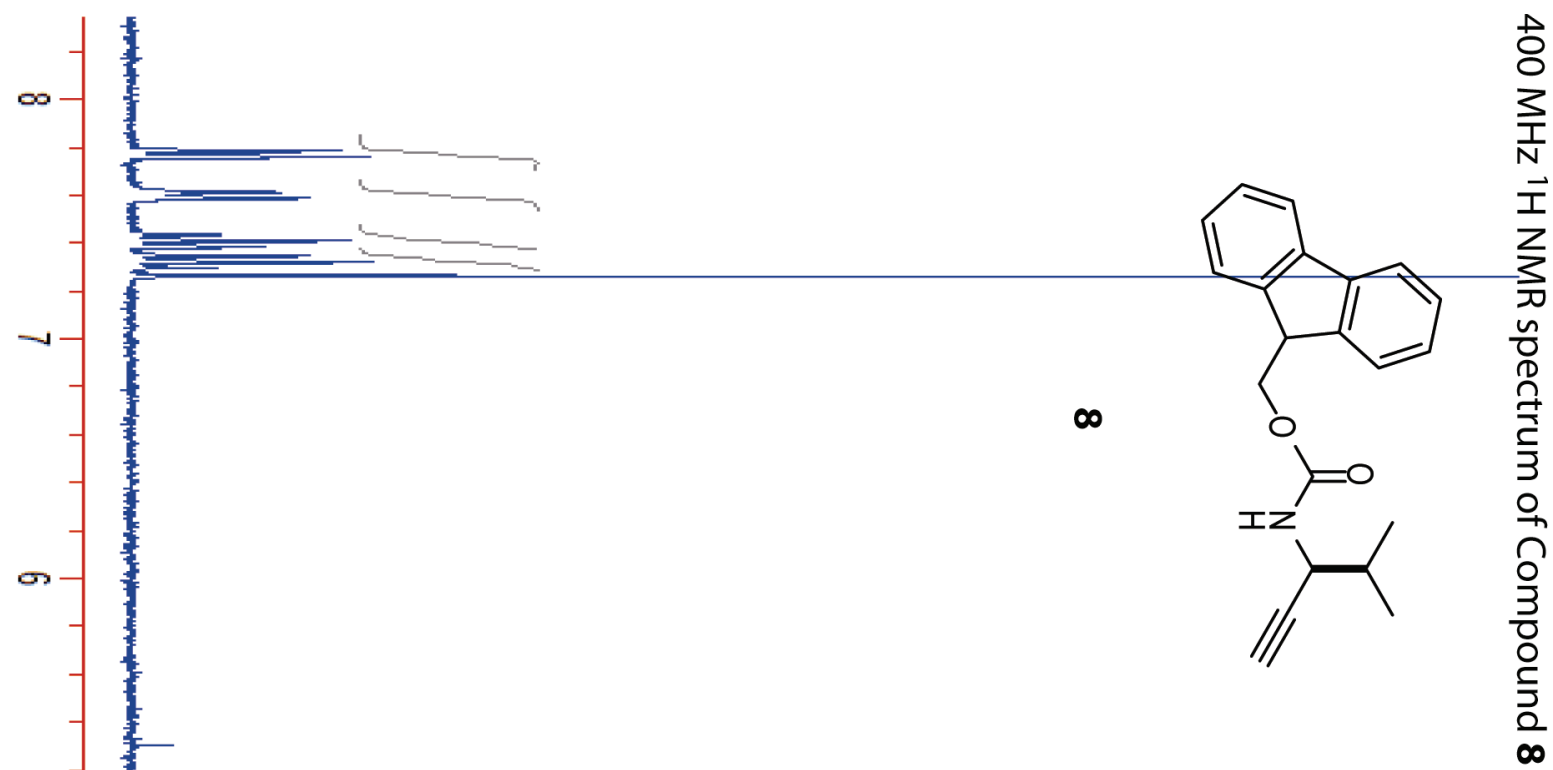

8
0
3
I
I
I
3
0
0
0
$\frac{n}{2}$
3
0
0
0
3
0
0
$\frac{1}{3}$
0
$\infty$

$\omega$

$\pi$

$+$
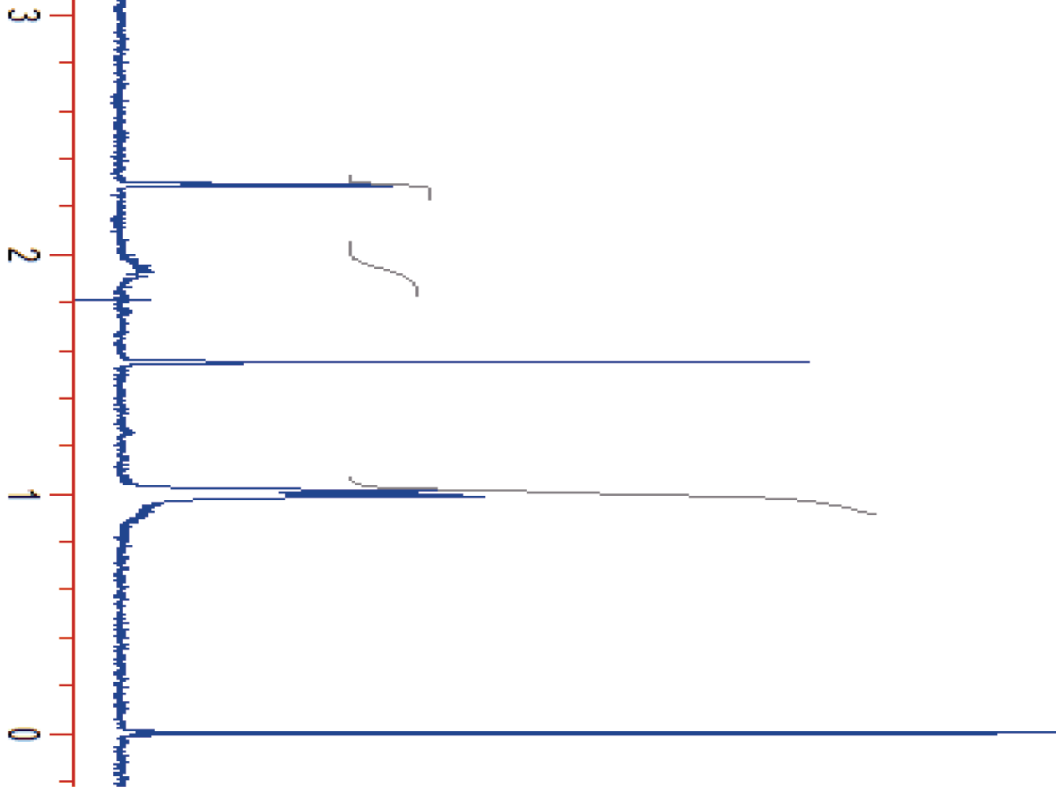


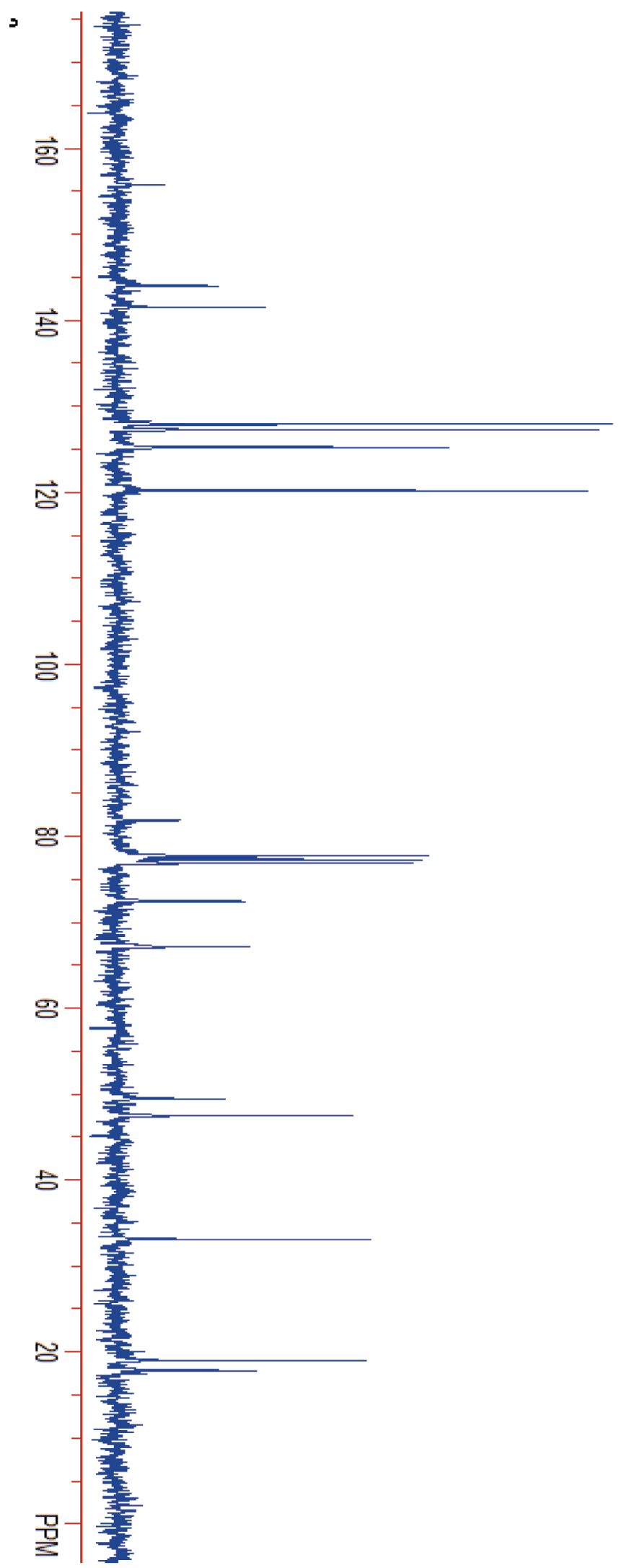

$\infty$<smiles>C#CC(C(=C)C(=O)OCC1c2ccccc2-c2ccccc21)C(C)C</smiles>

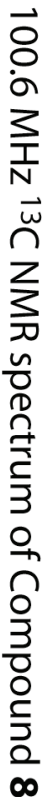




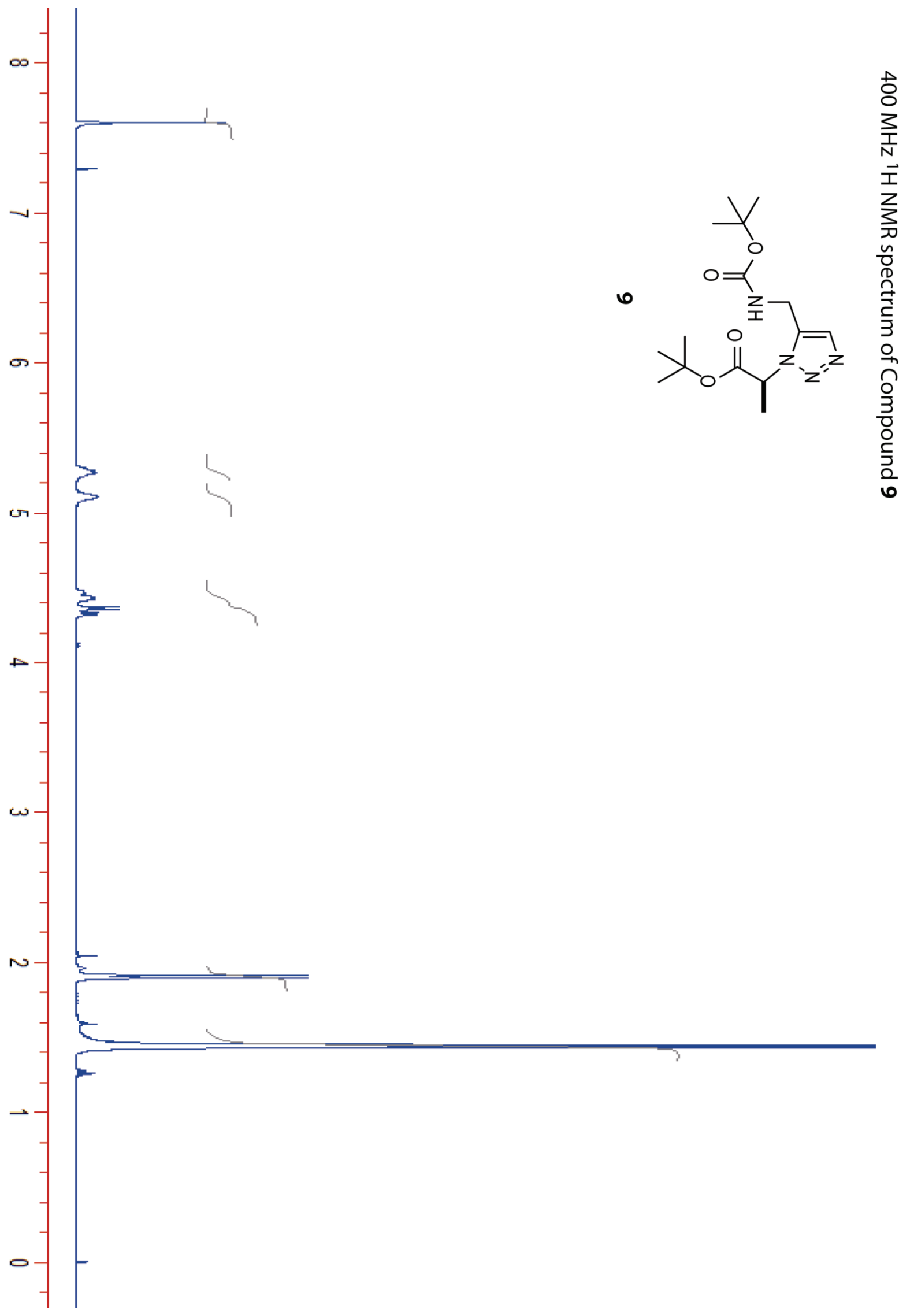




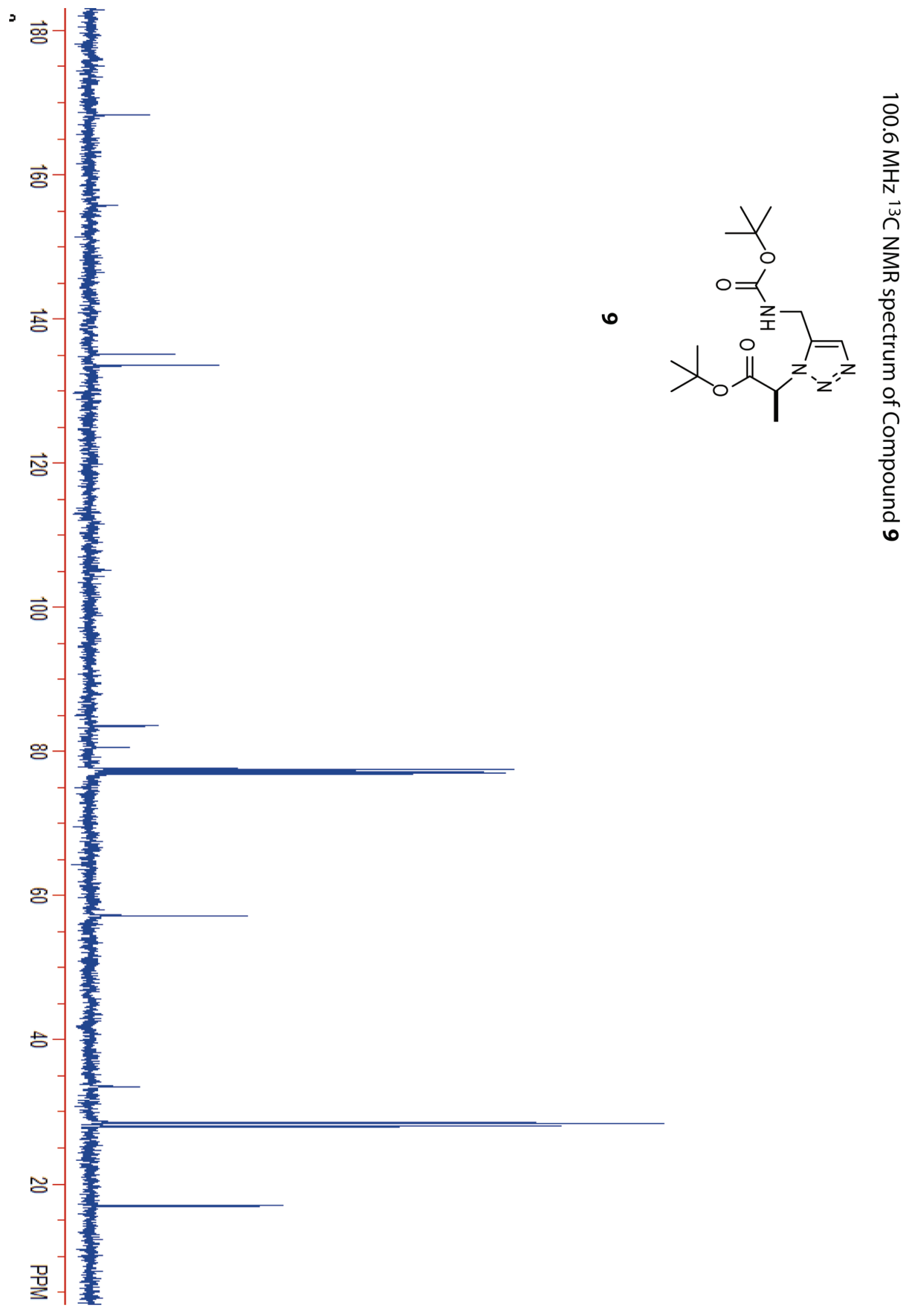




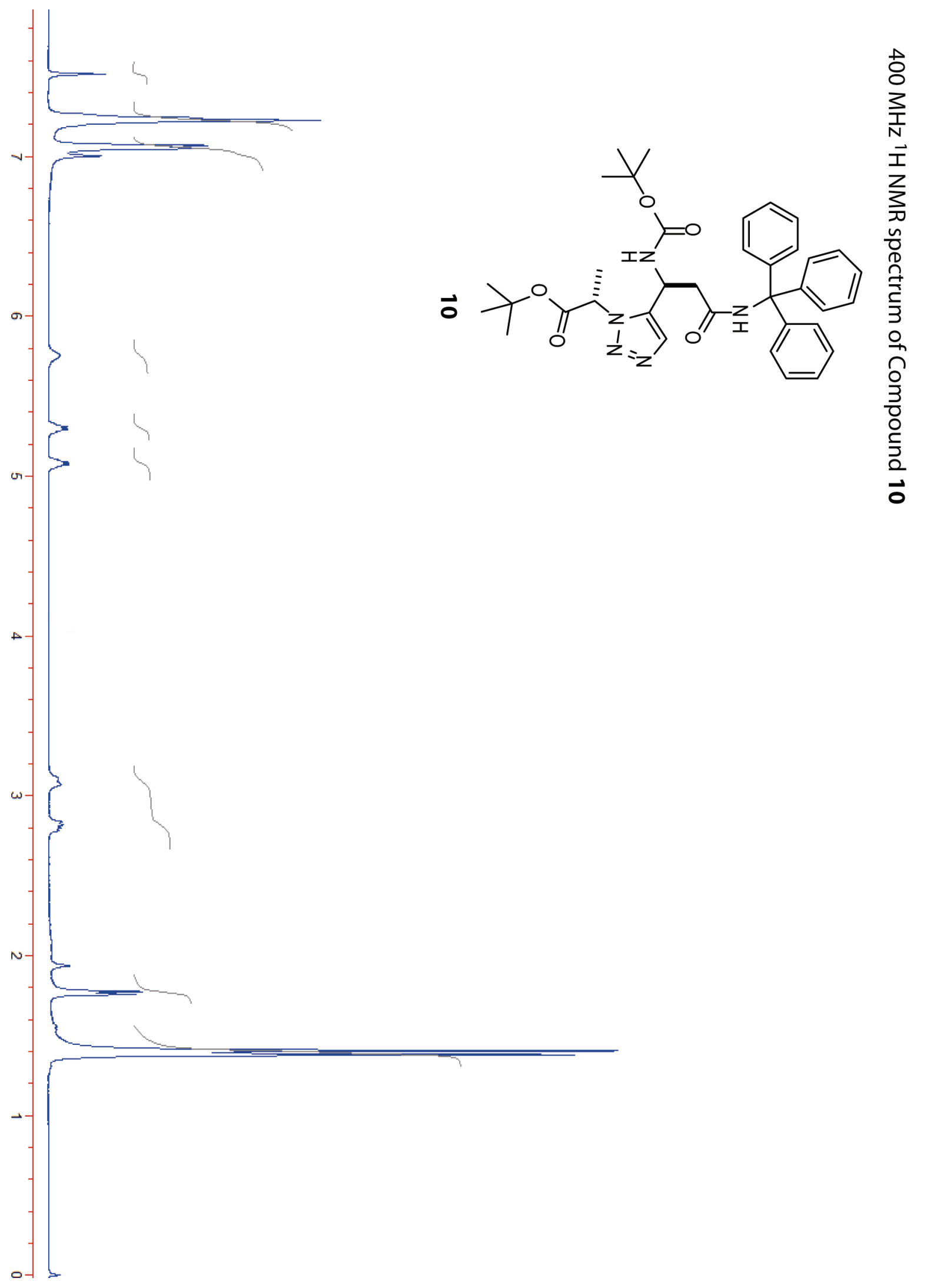


与

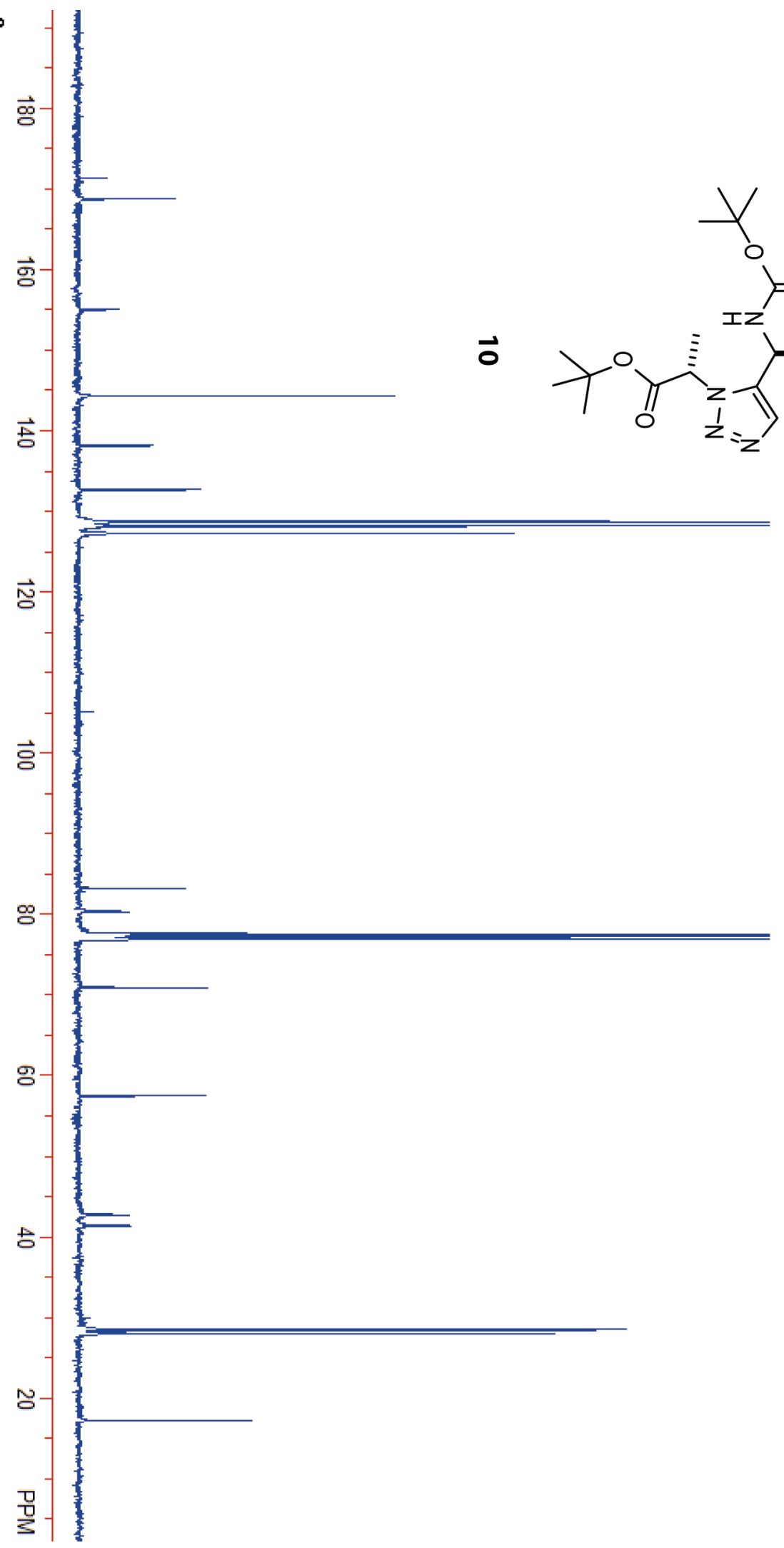

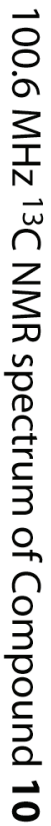




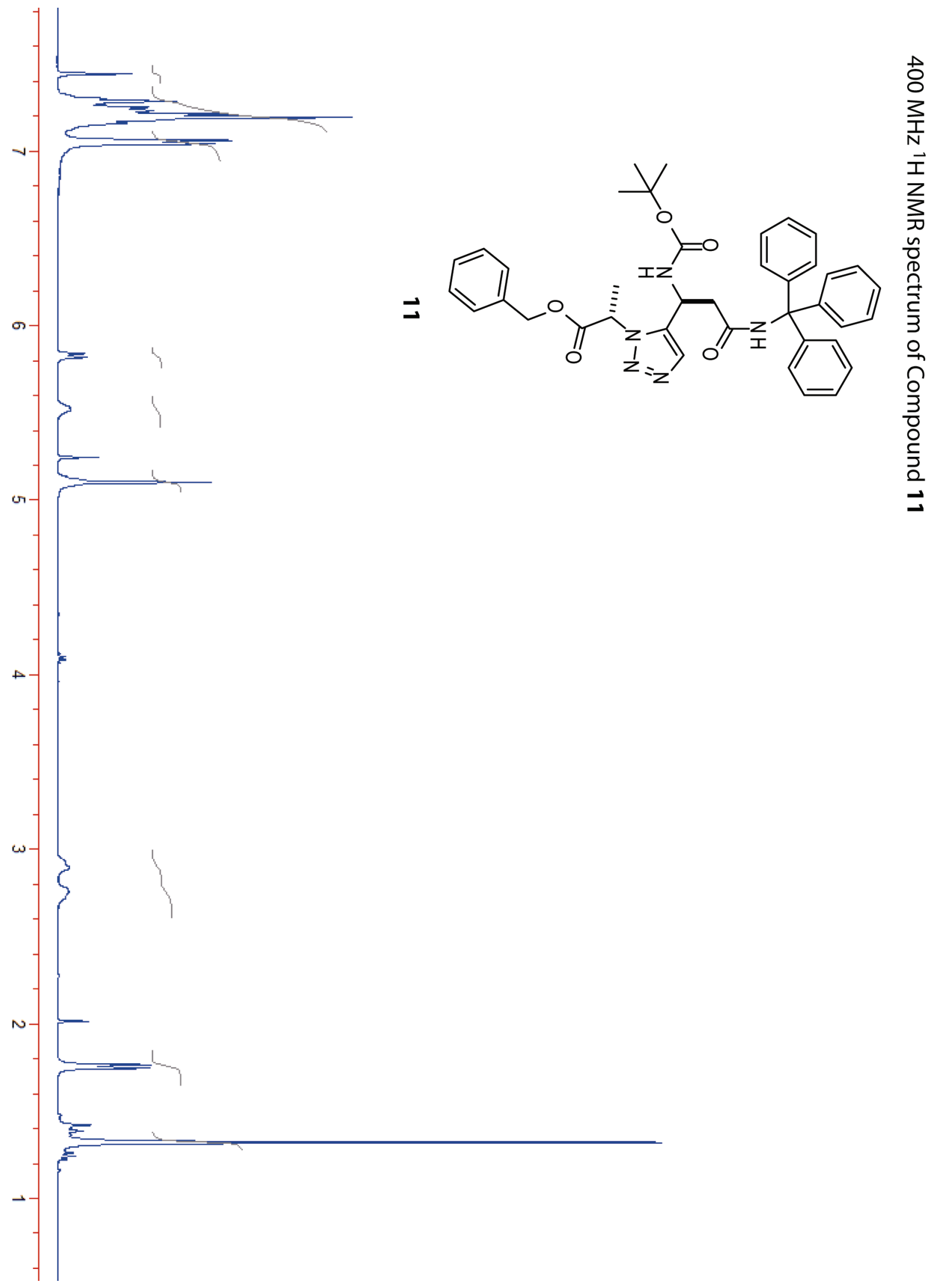




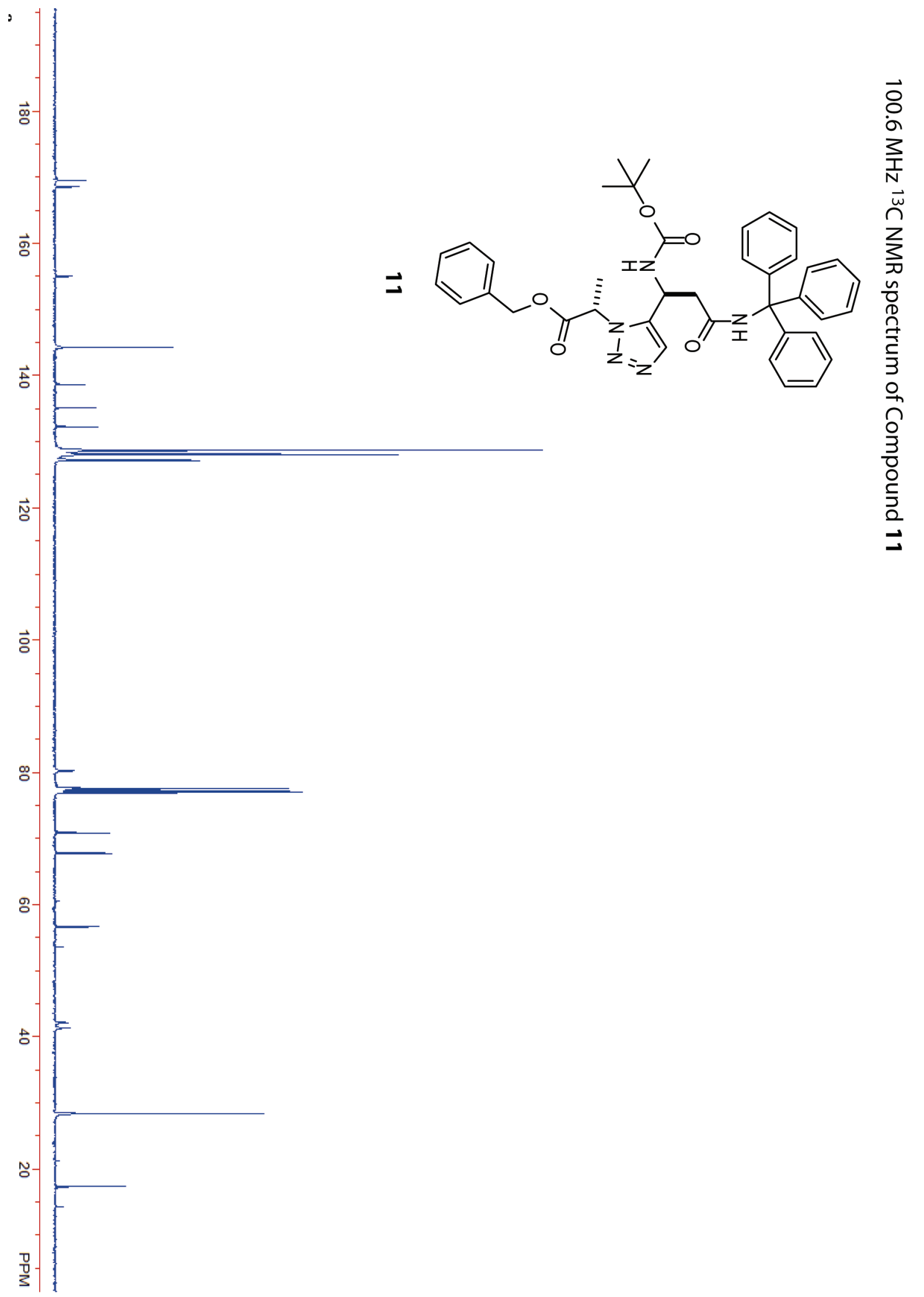




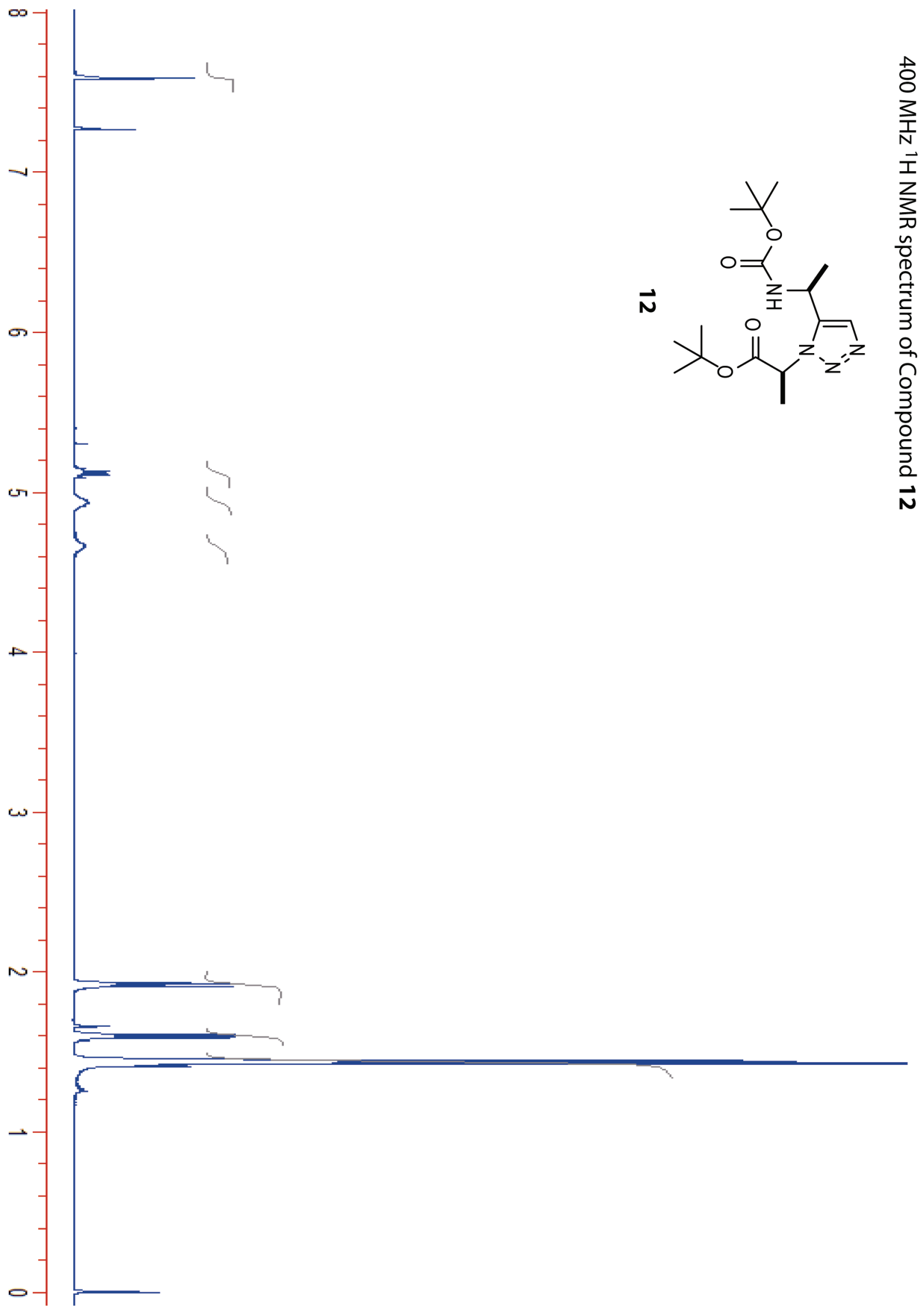




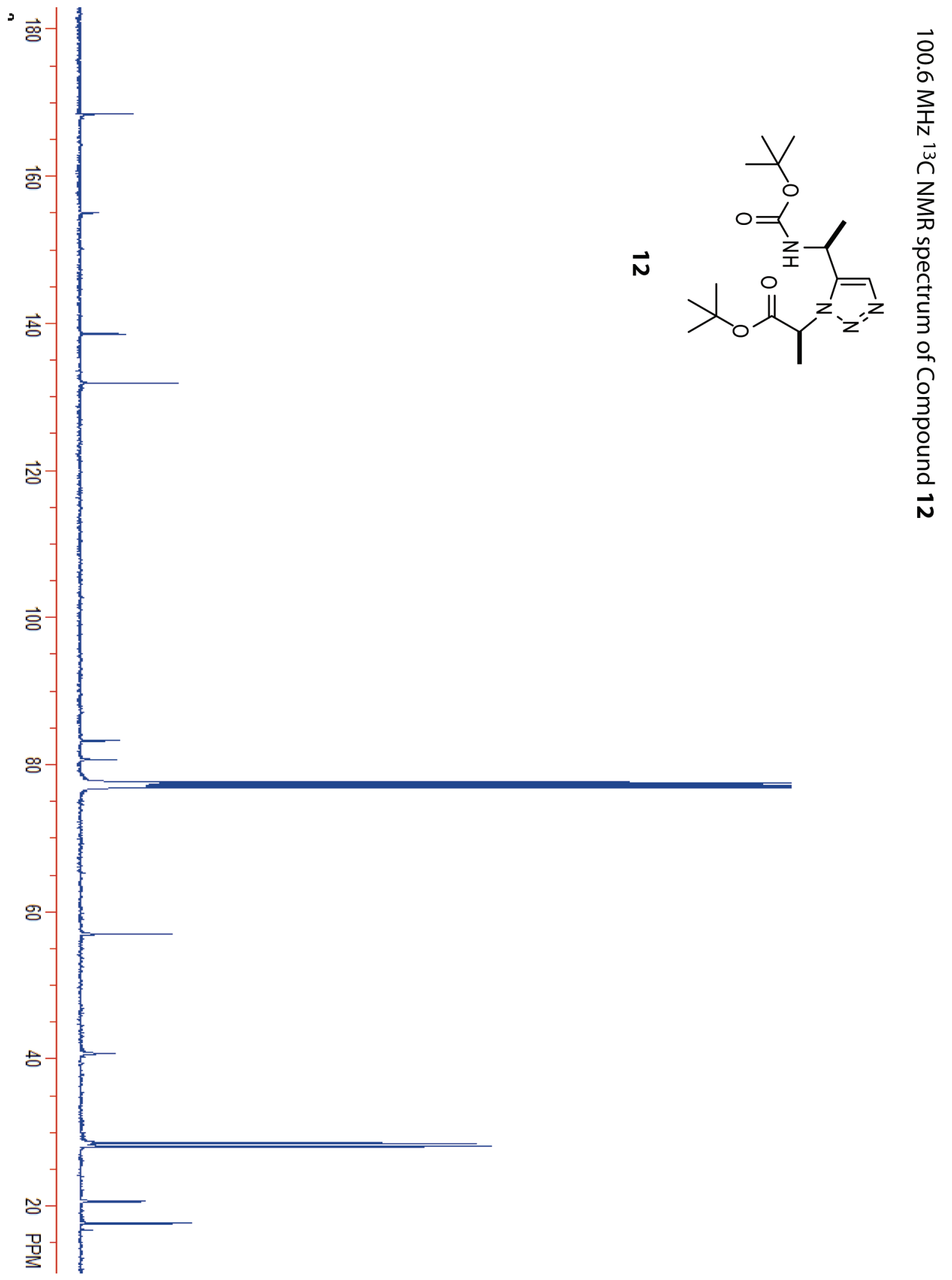




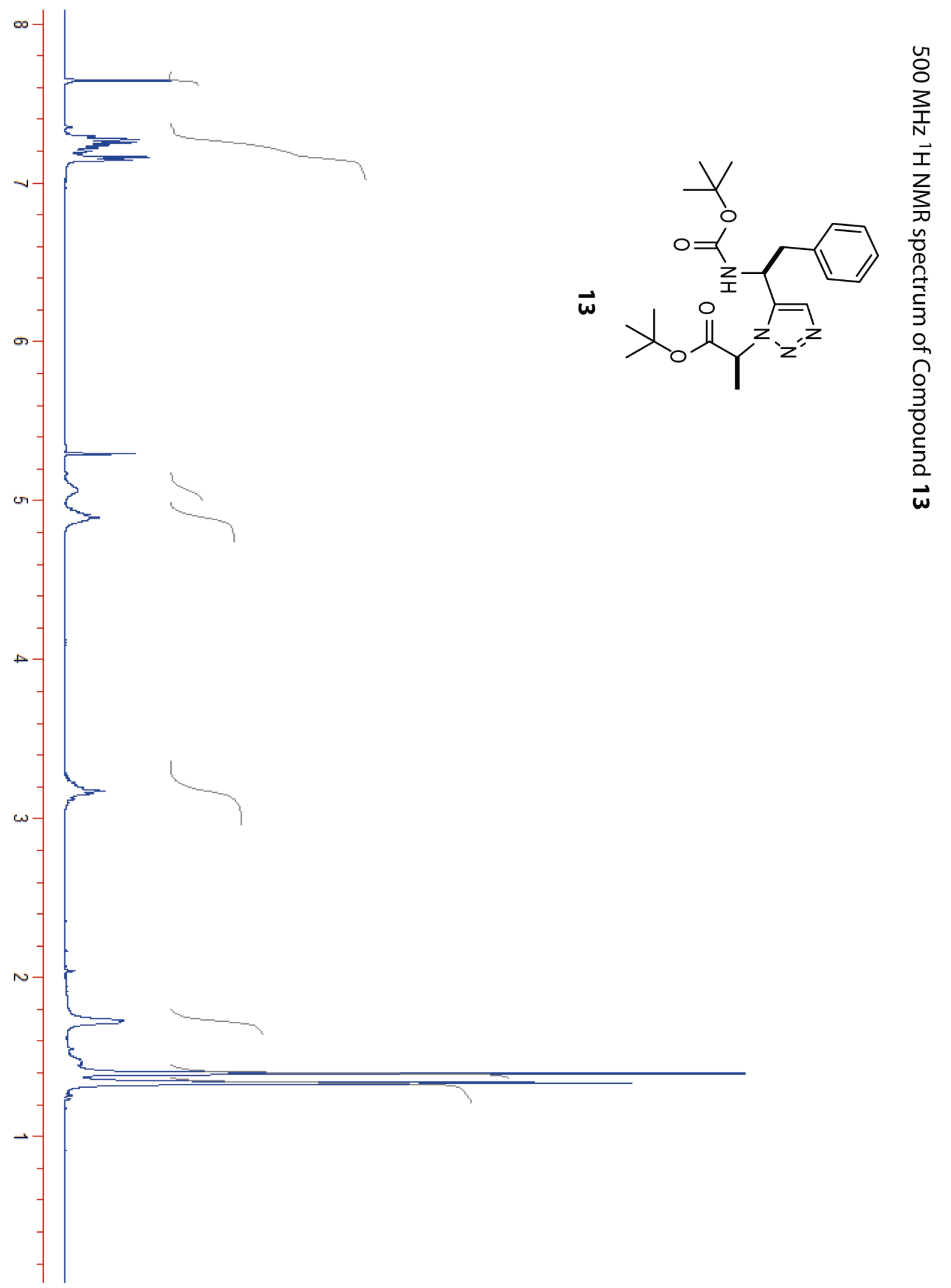



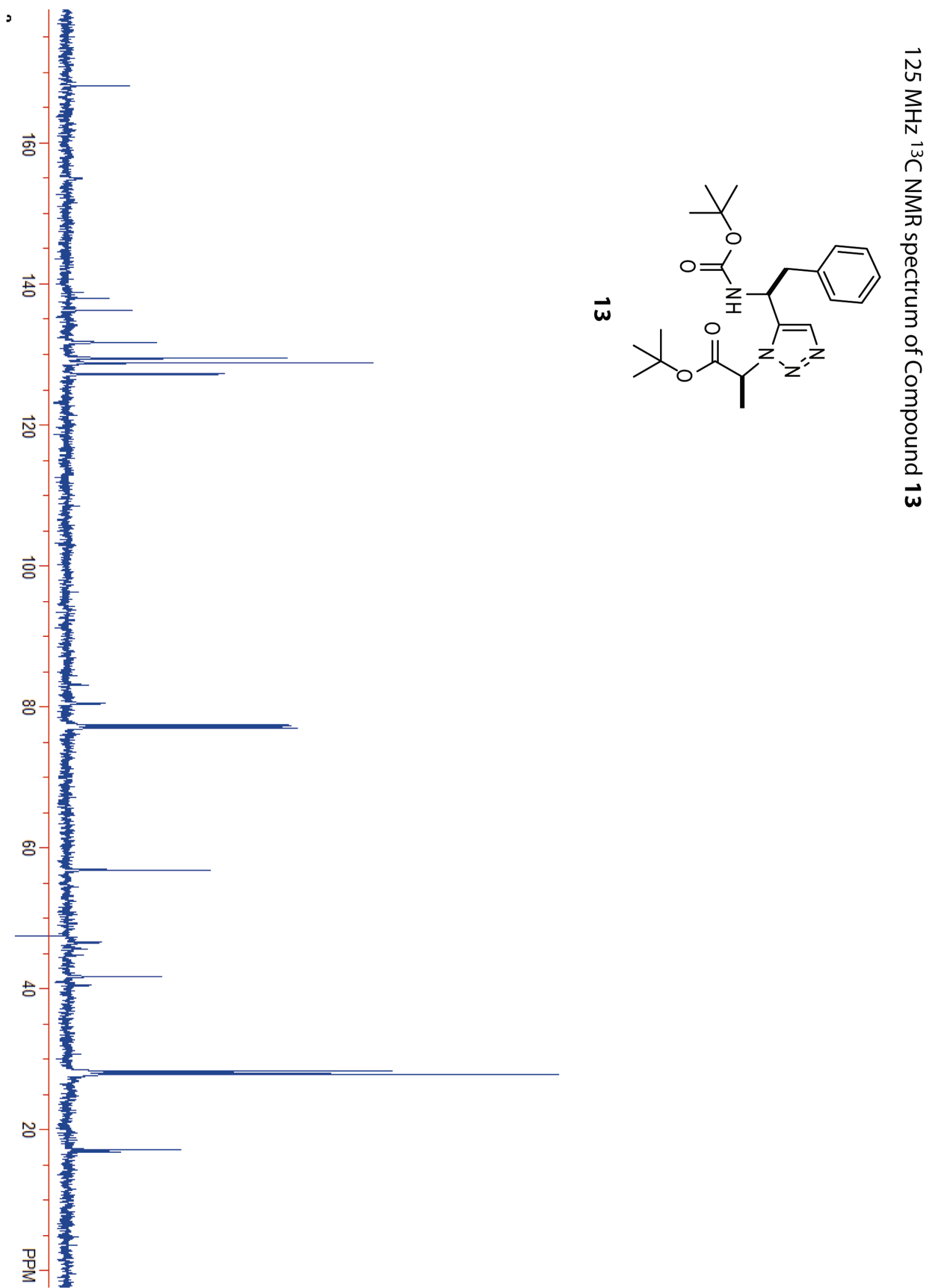


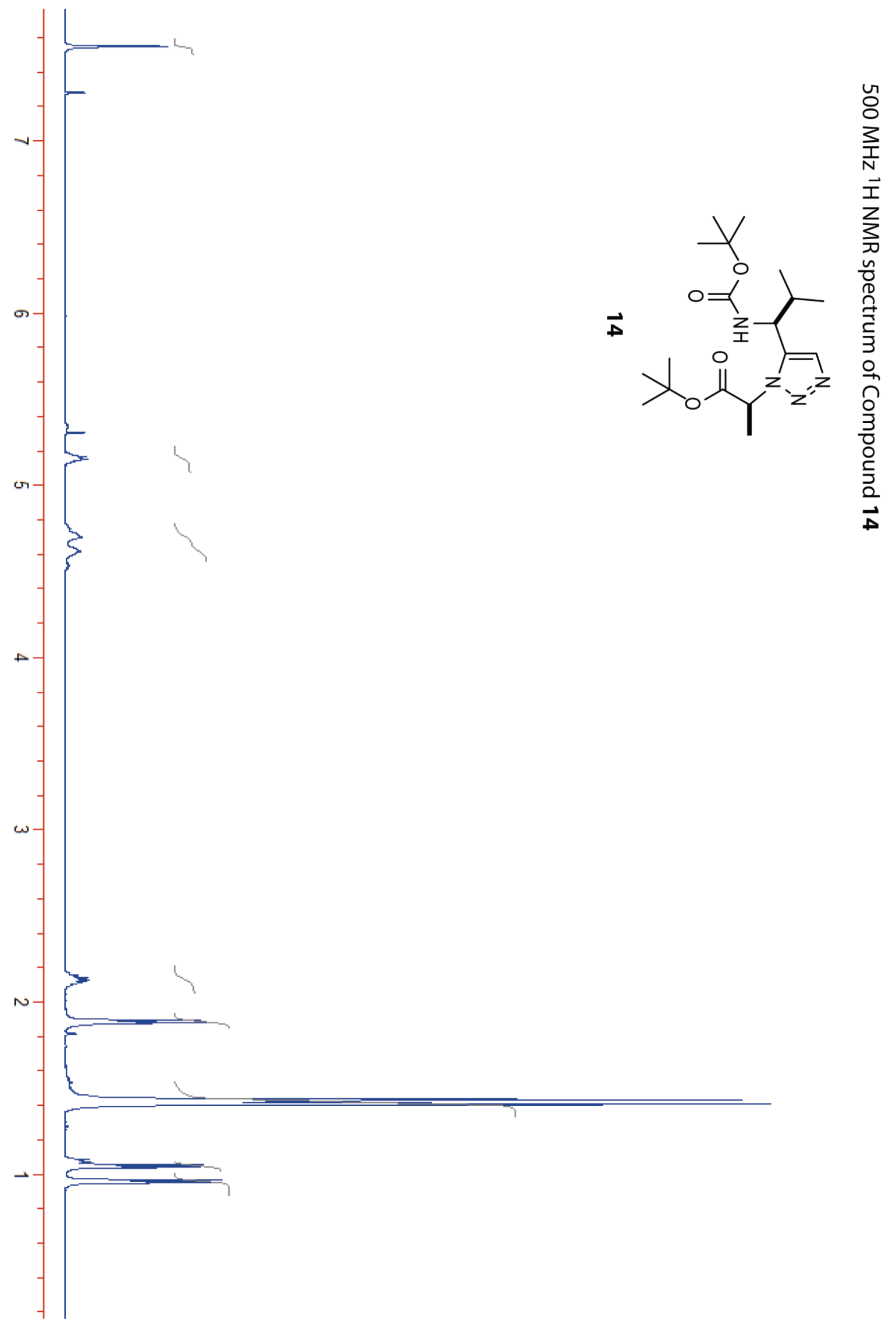




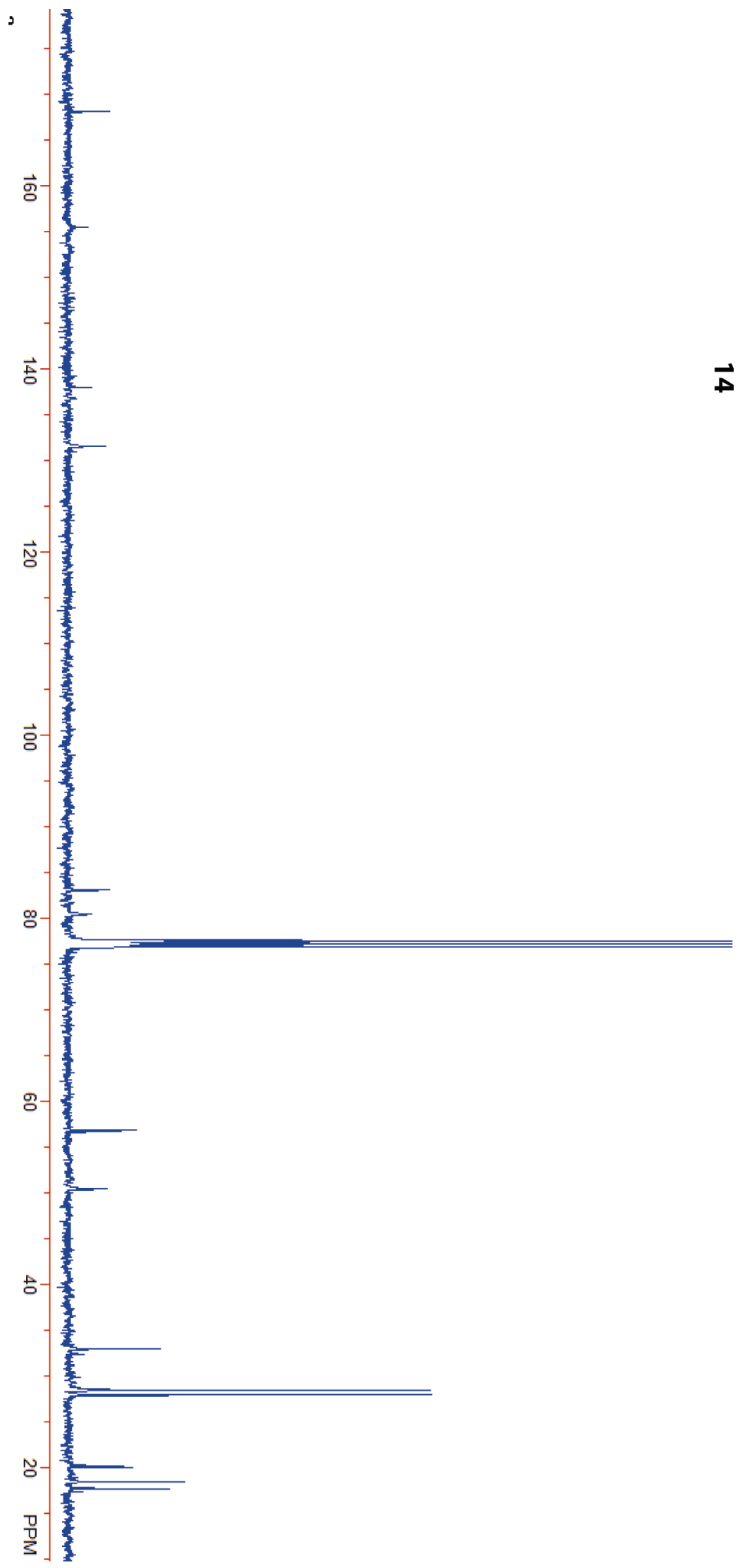

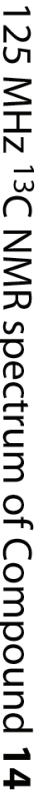




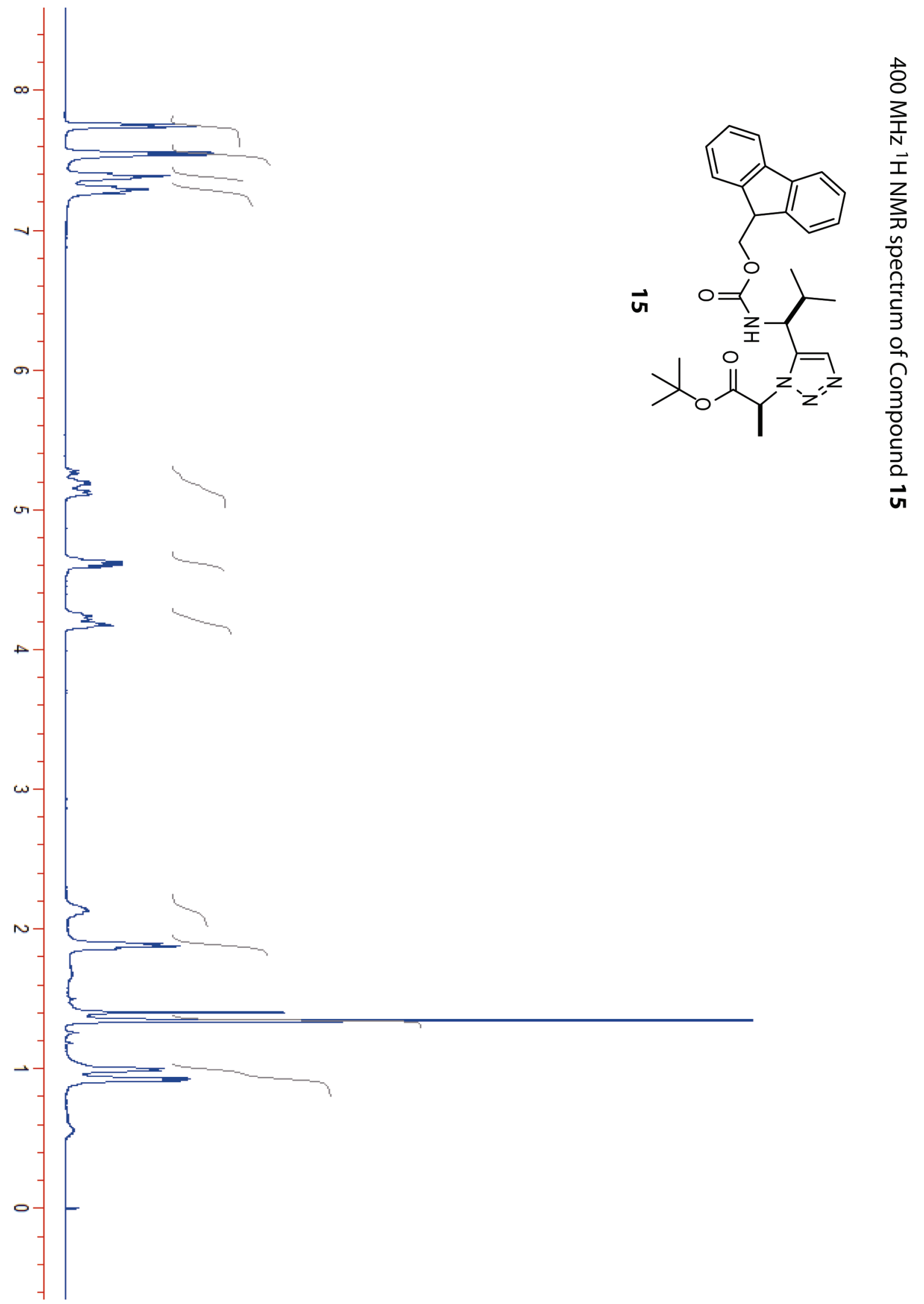




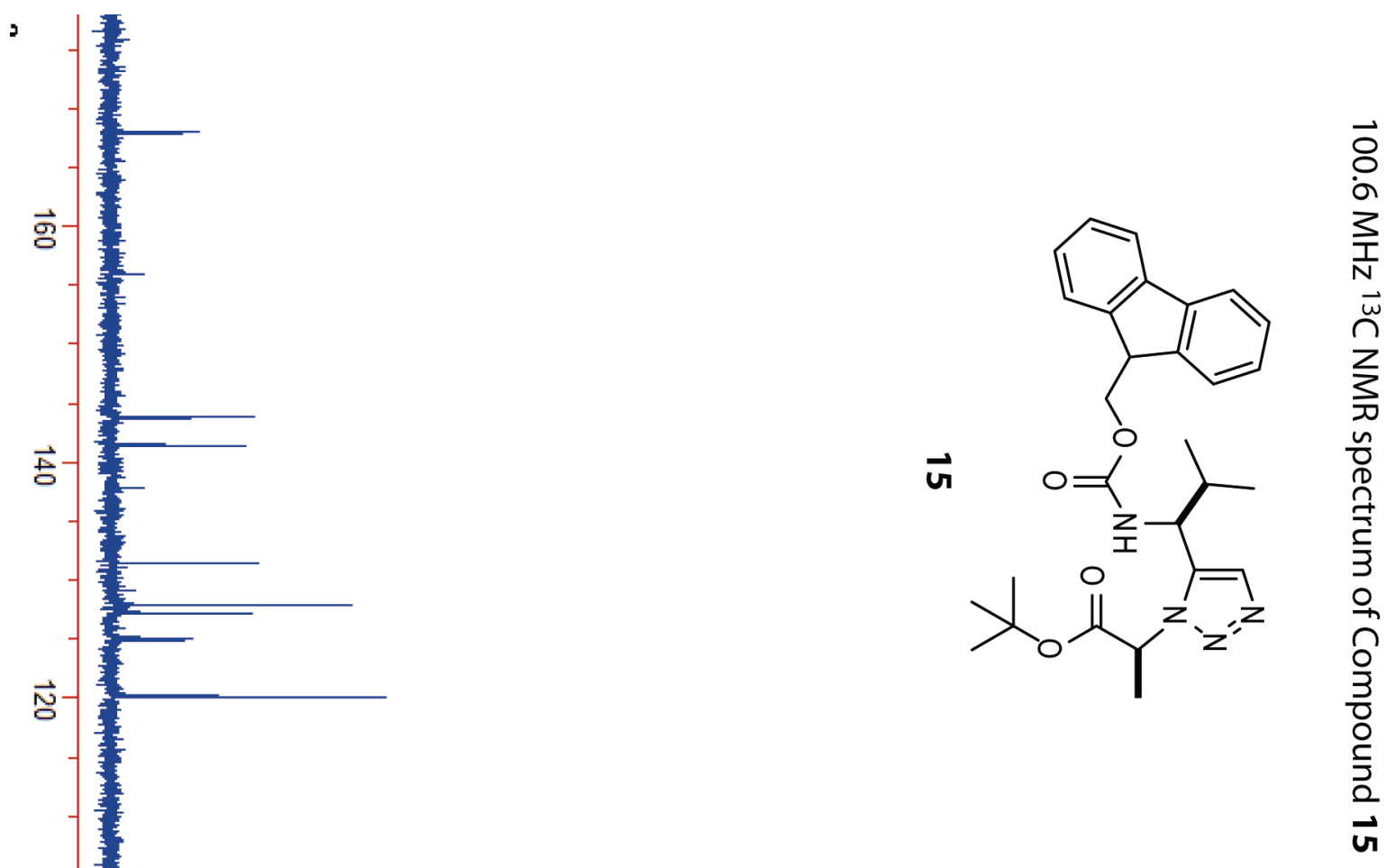

品

홍

.

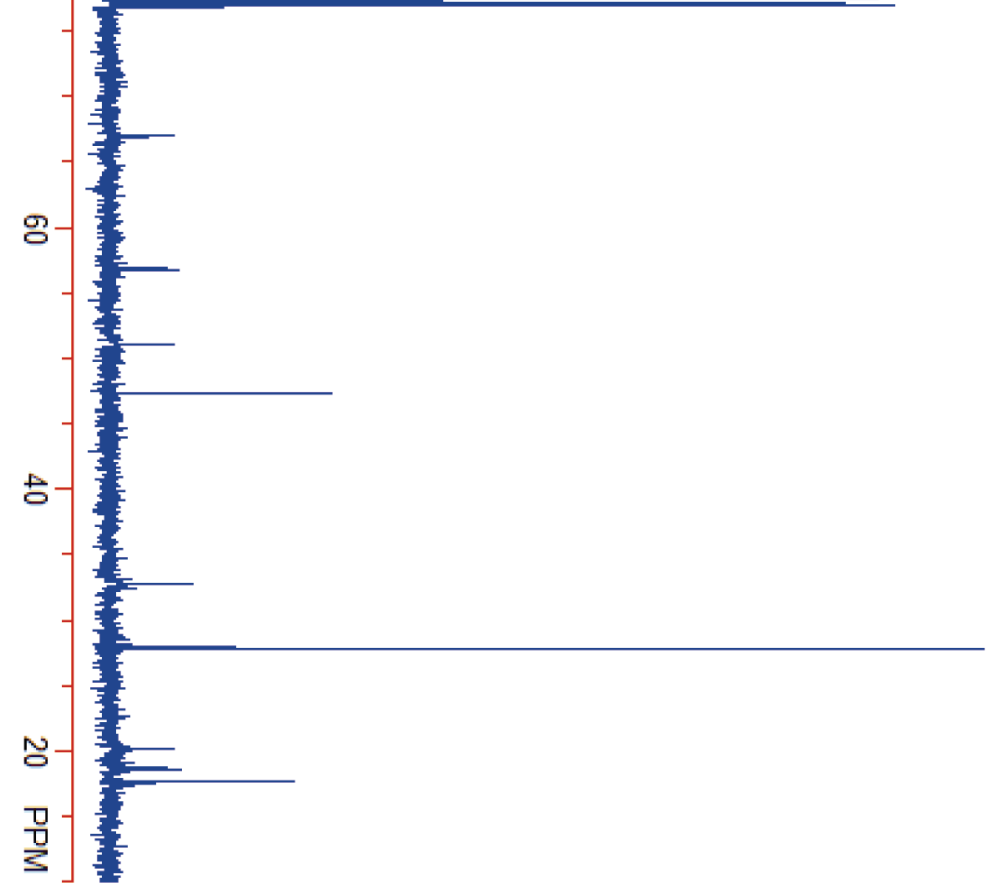



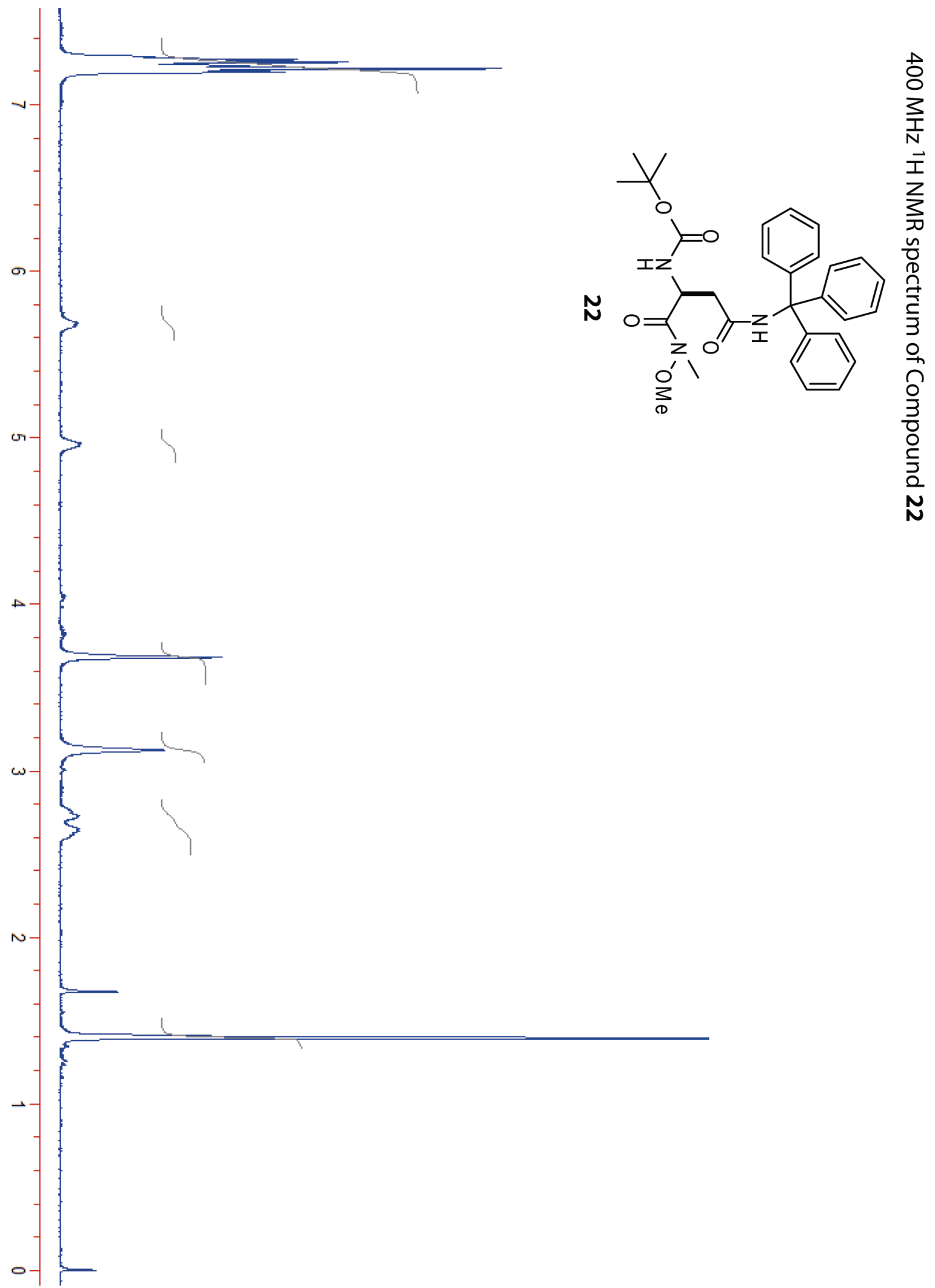


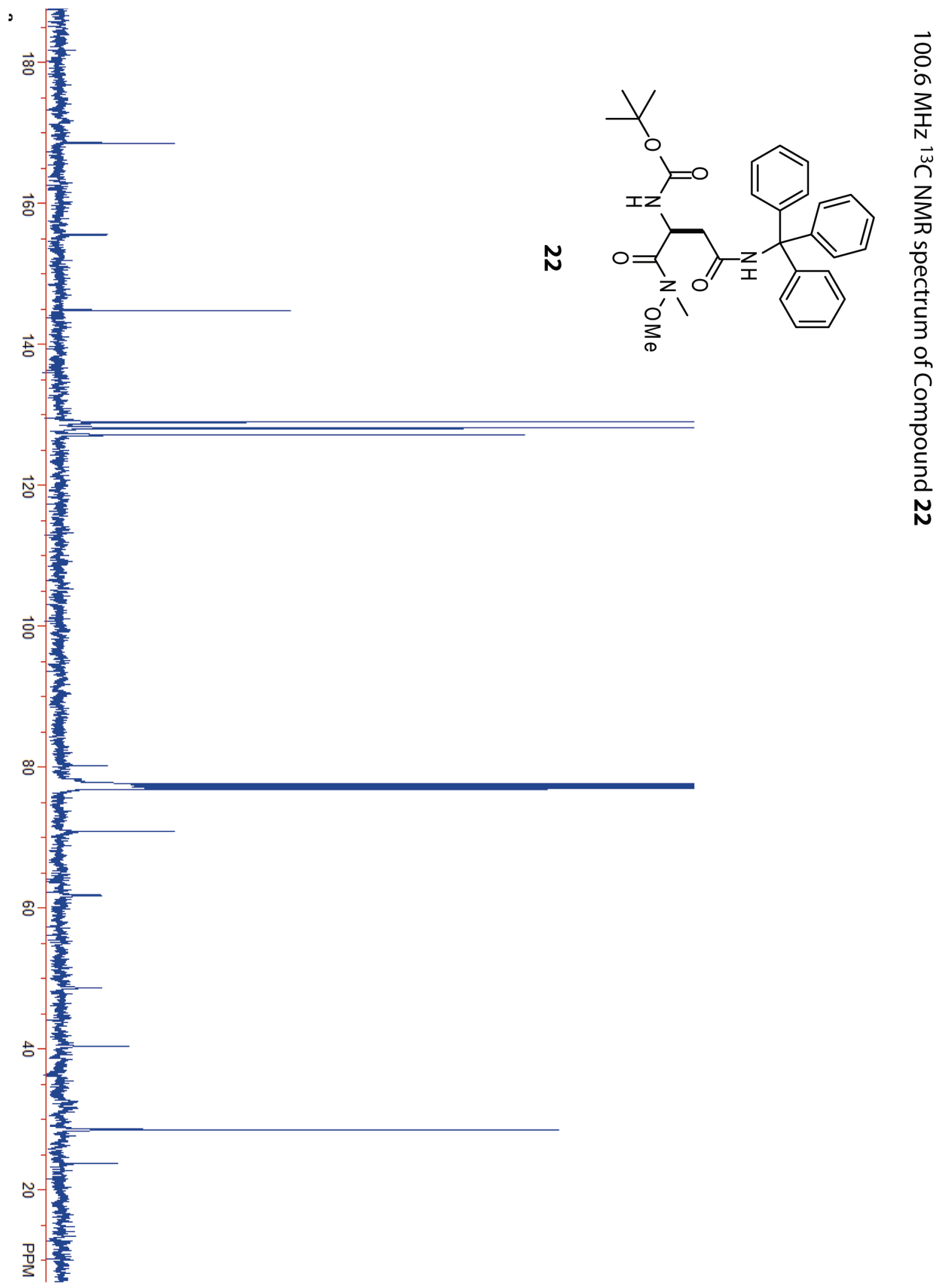




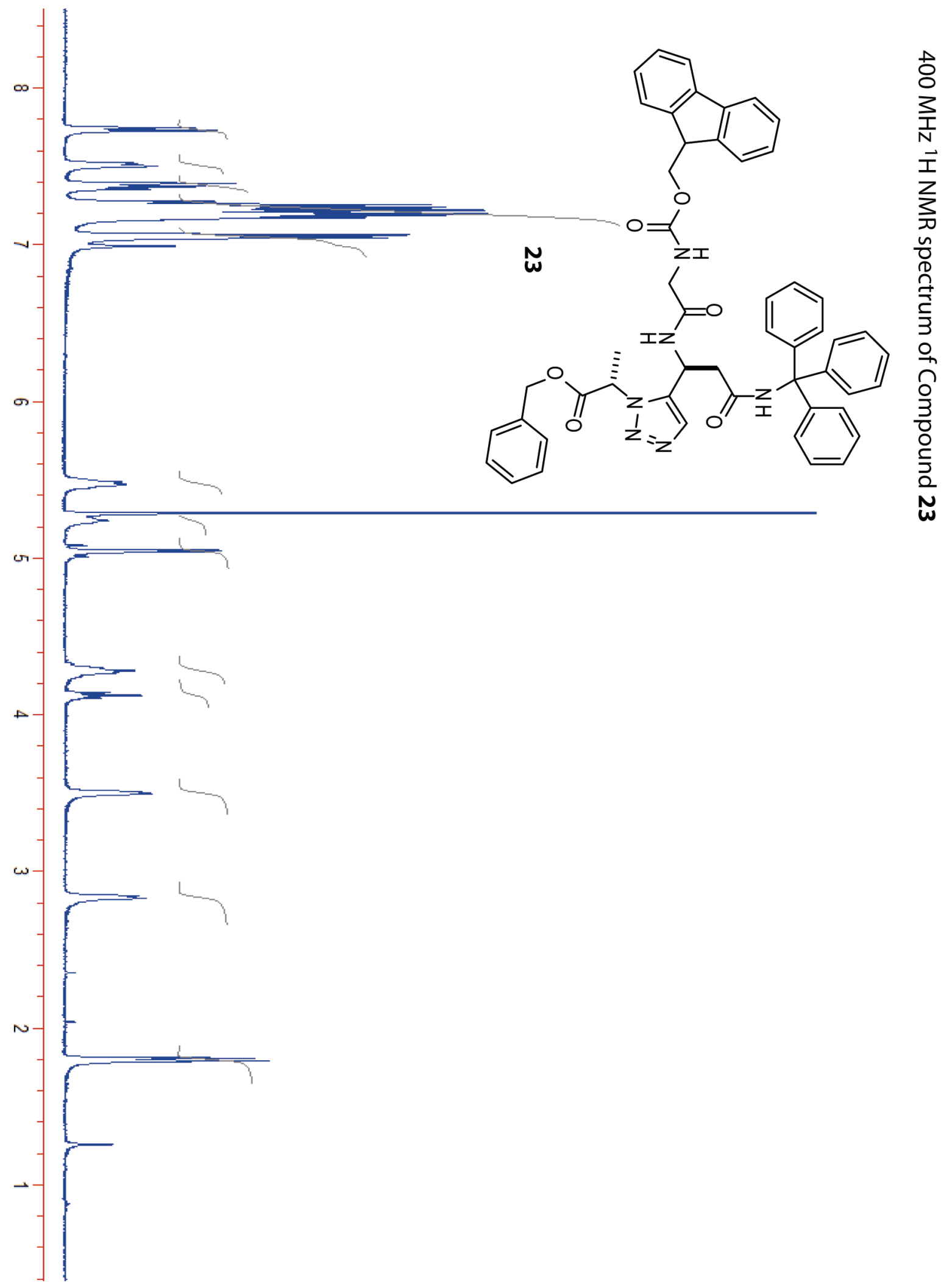




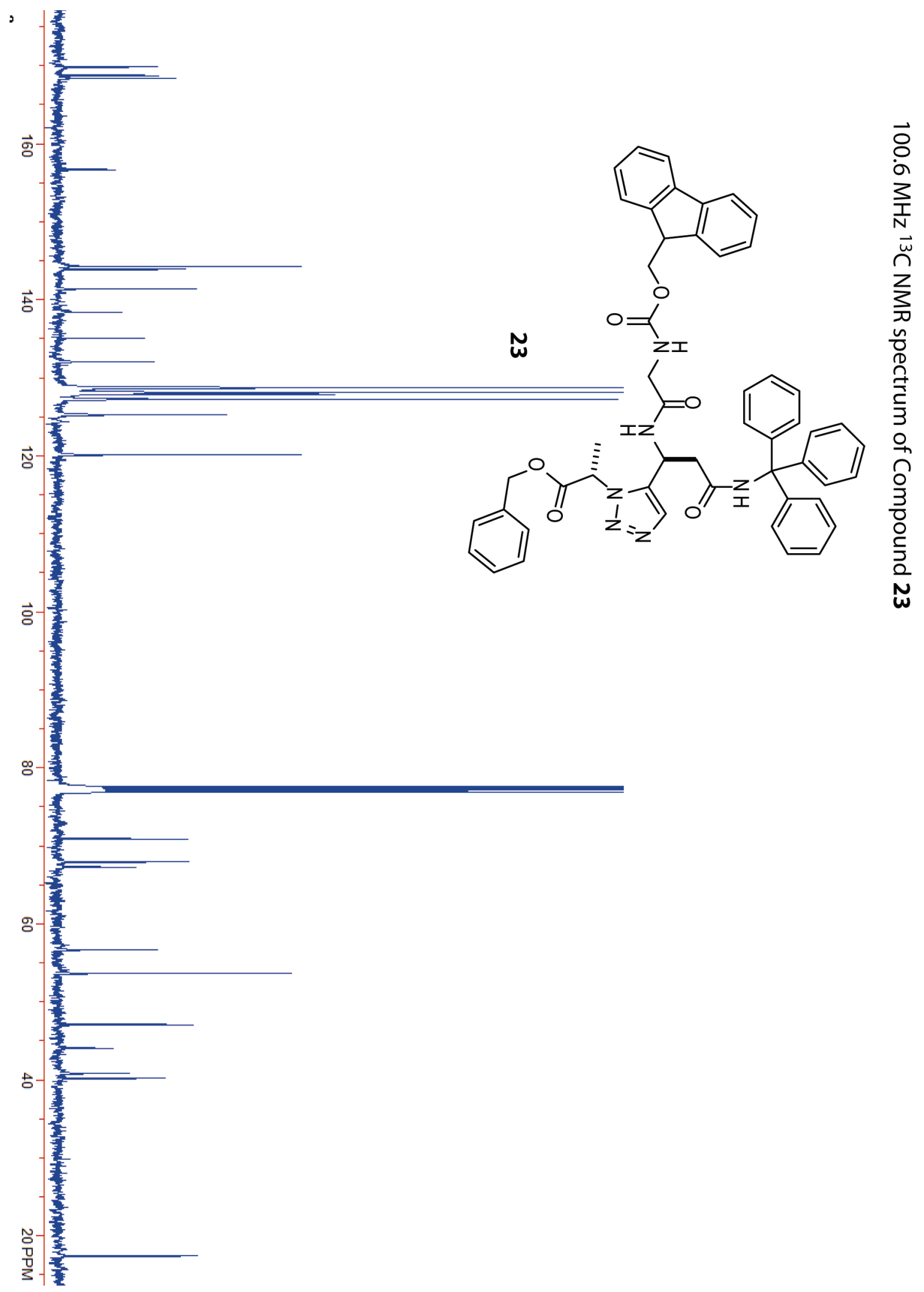




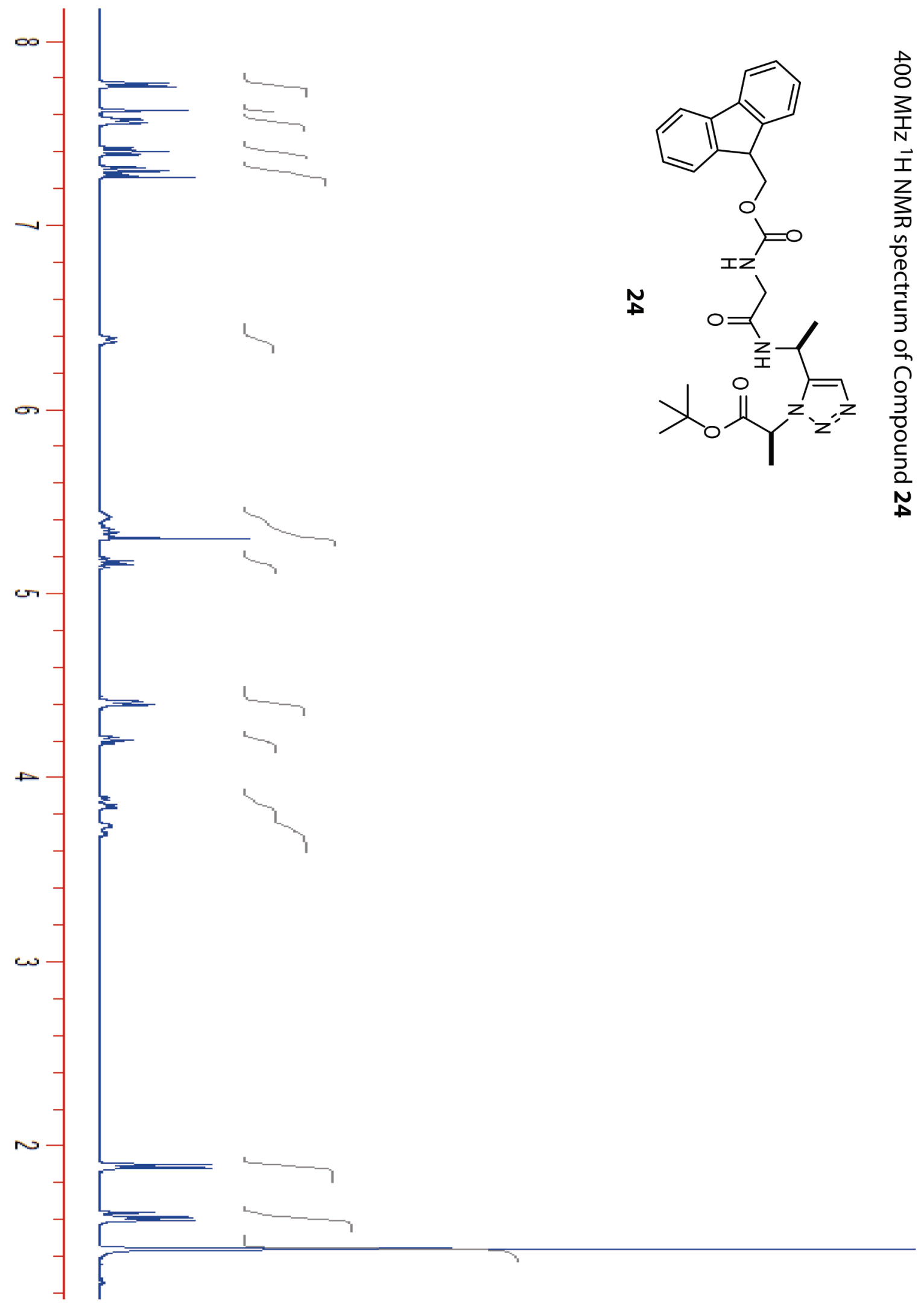




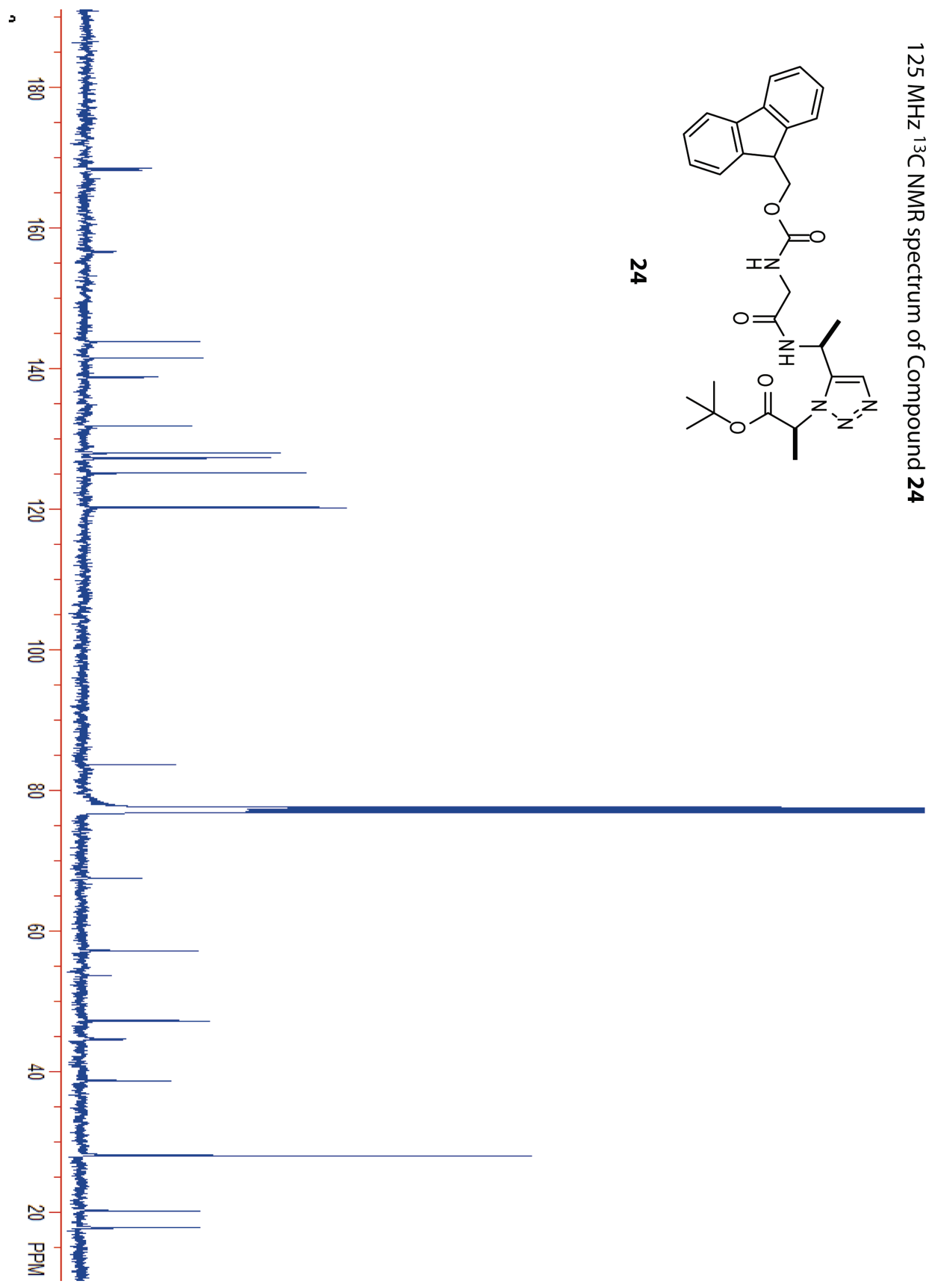




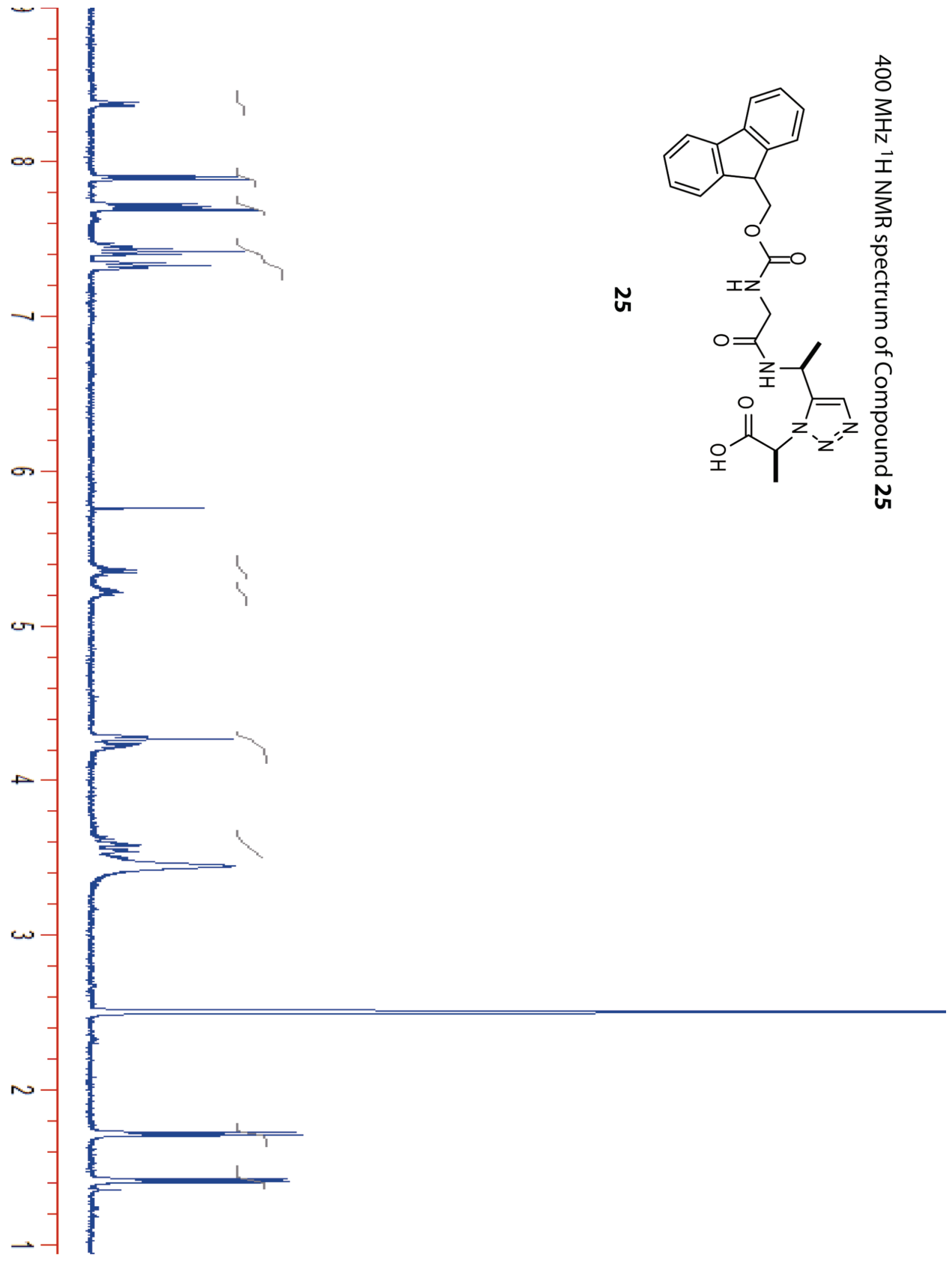




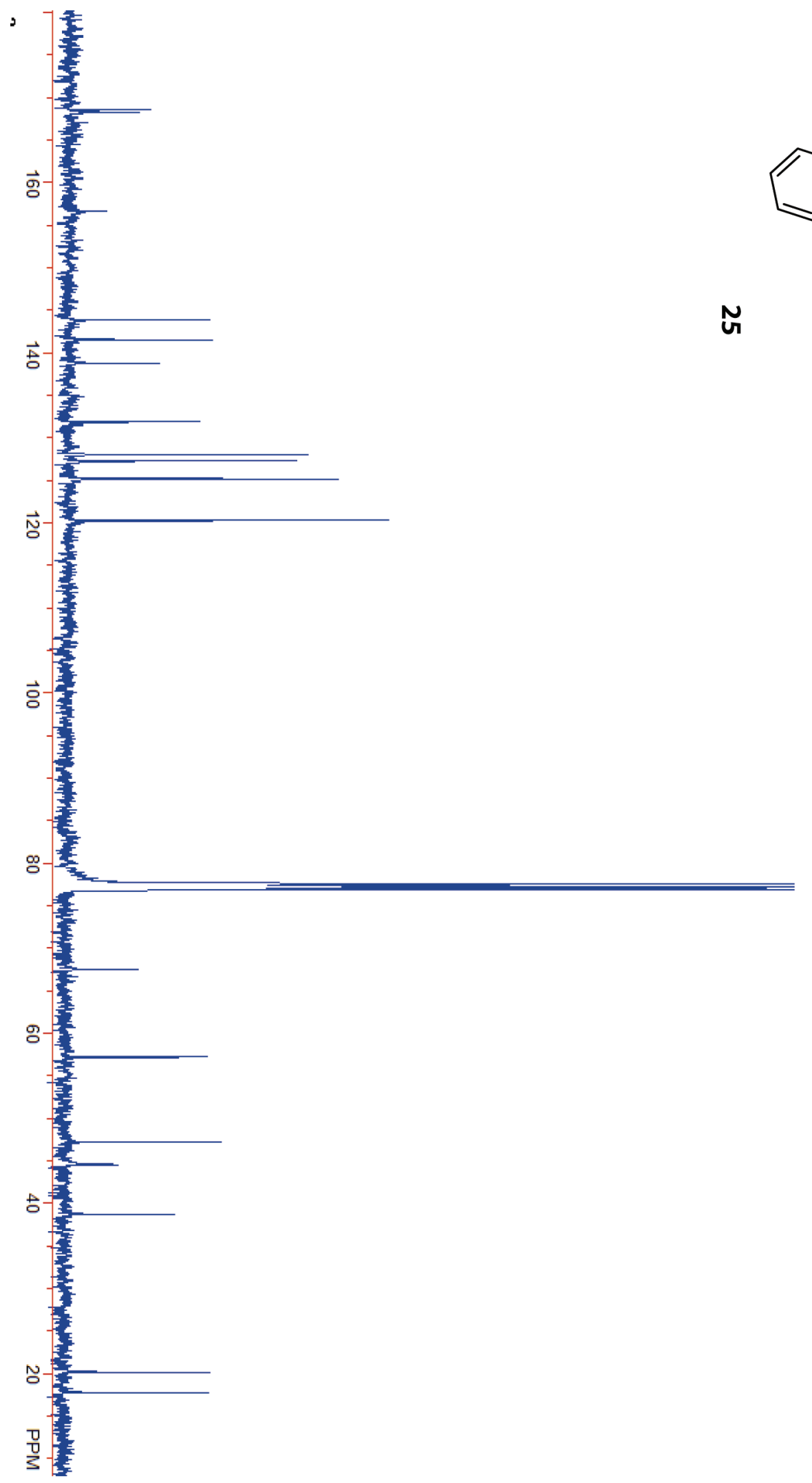

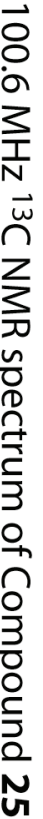




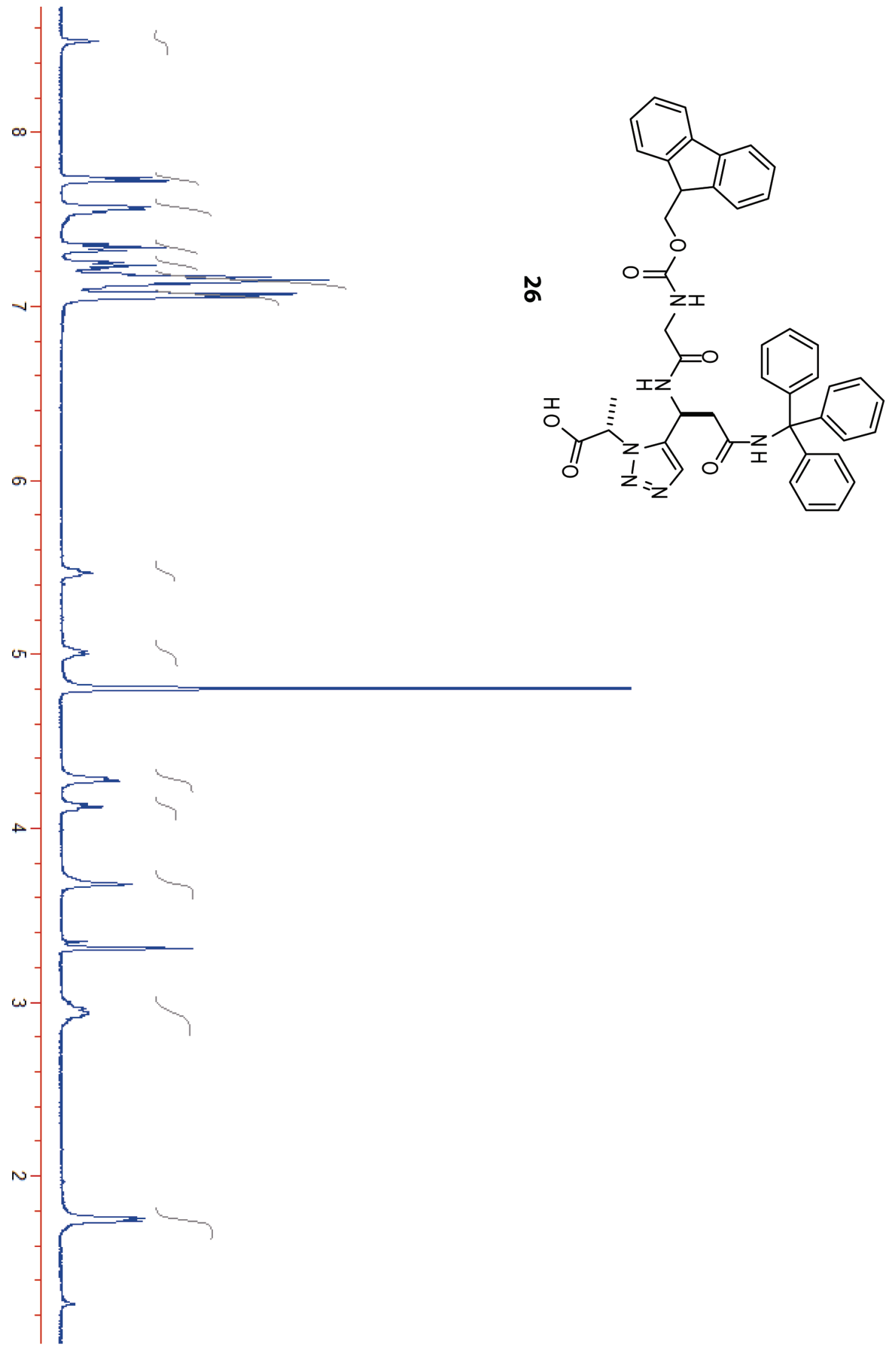

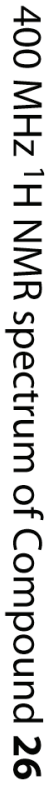




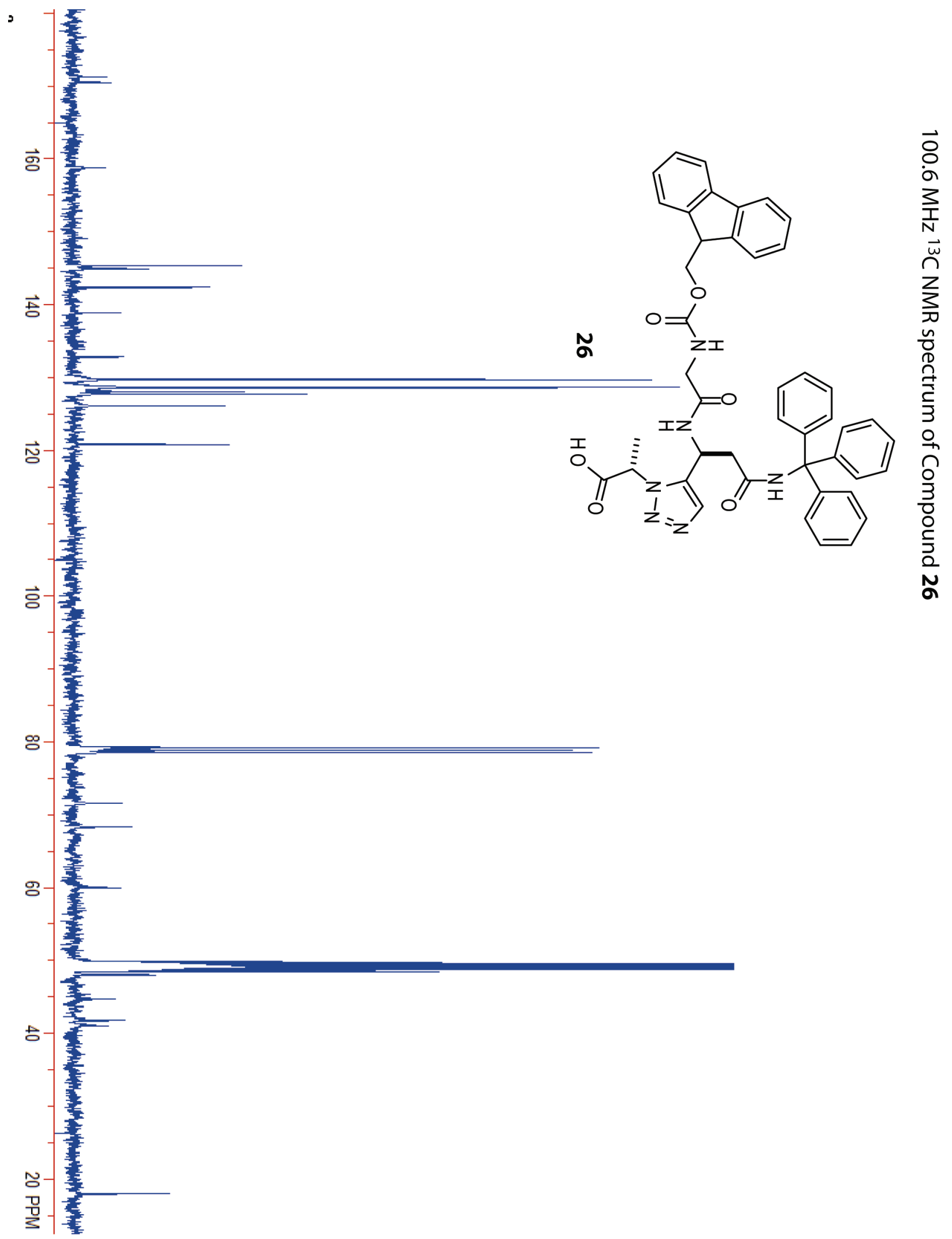




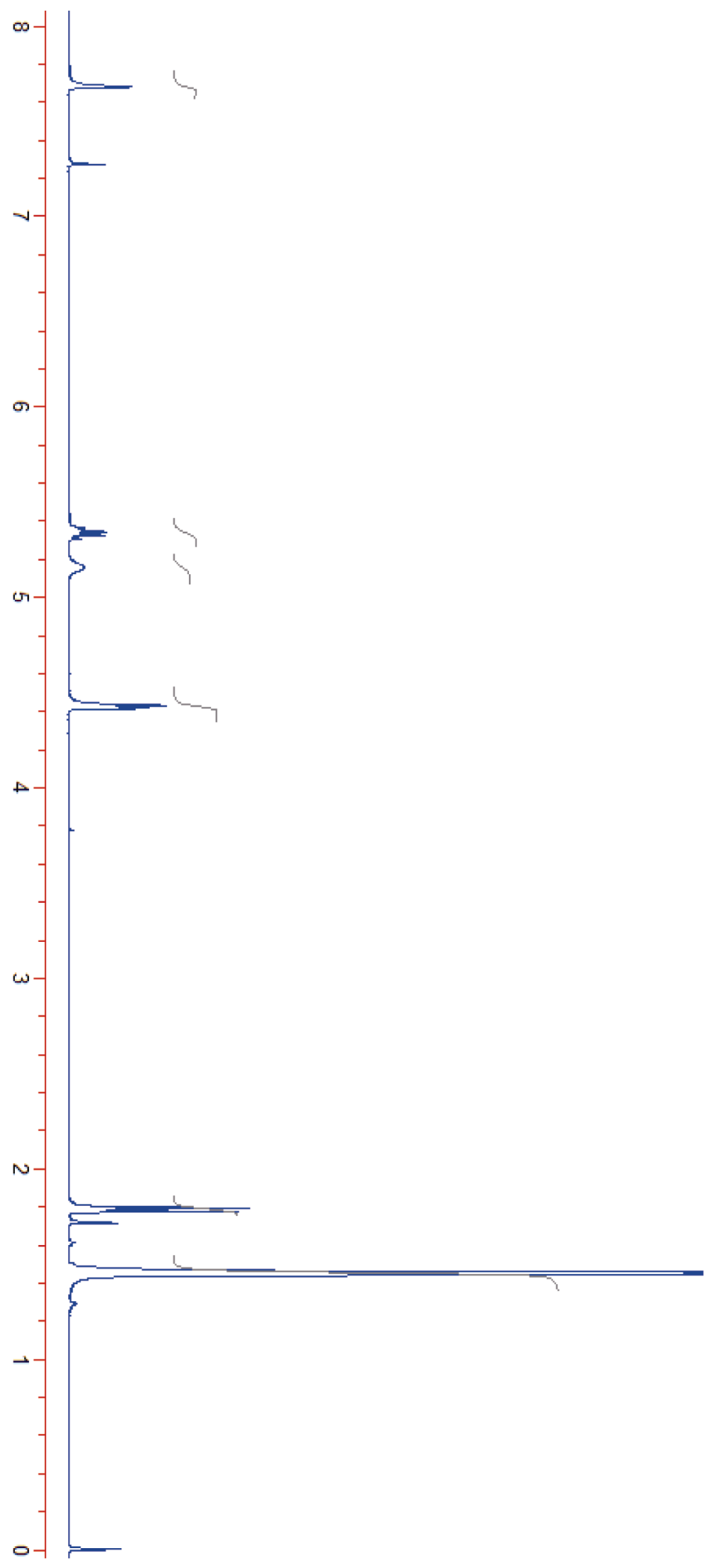




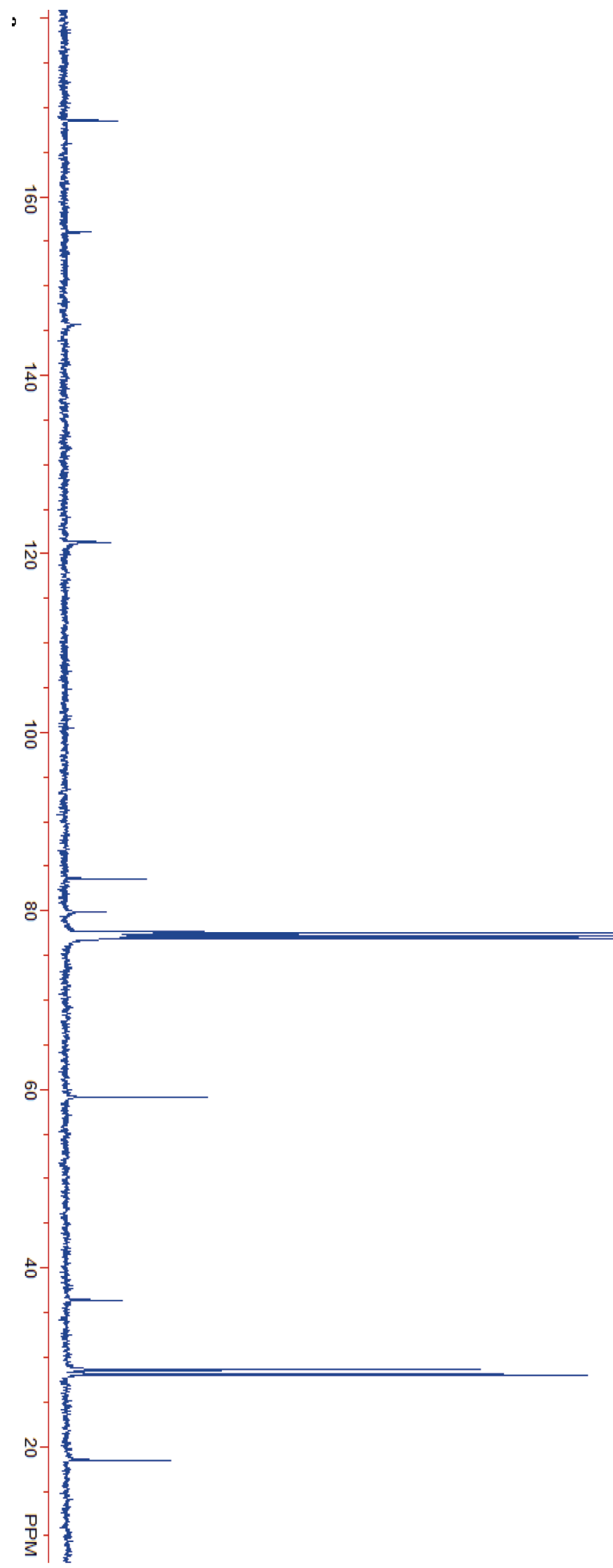



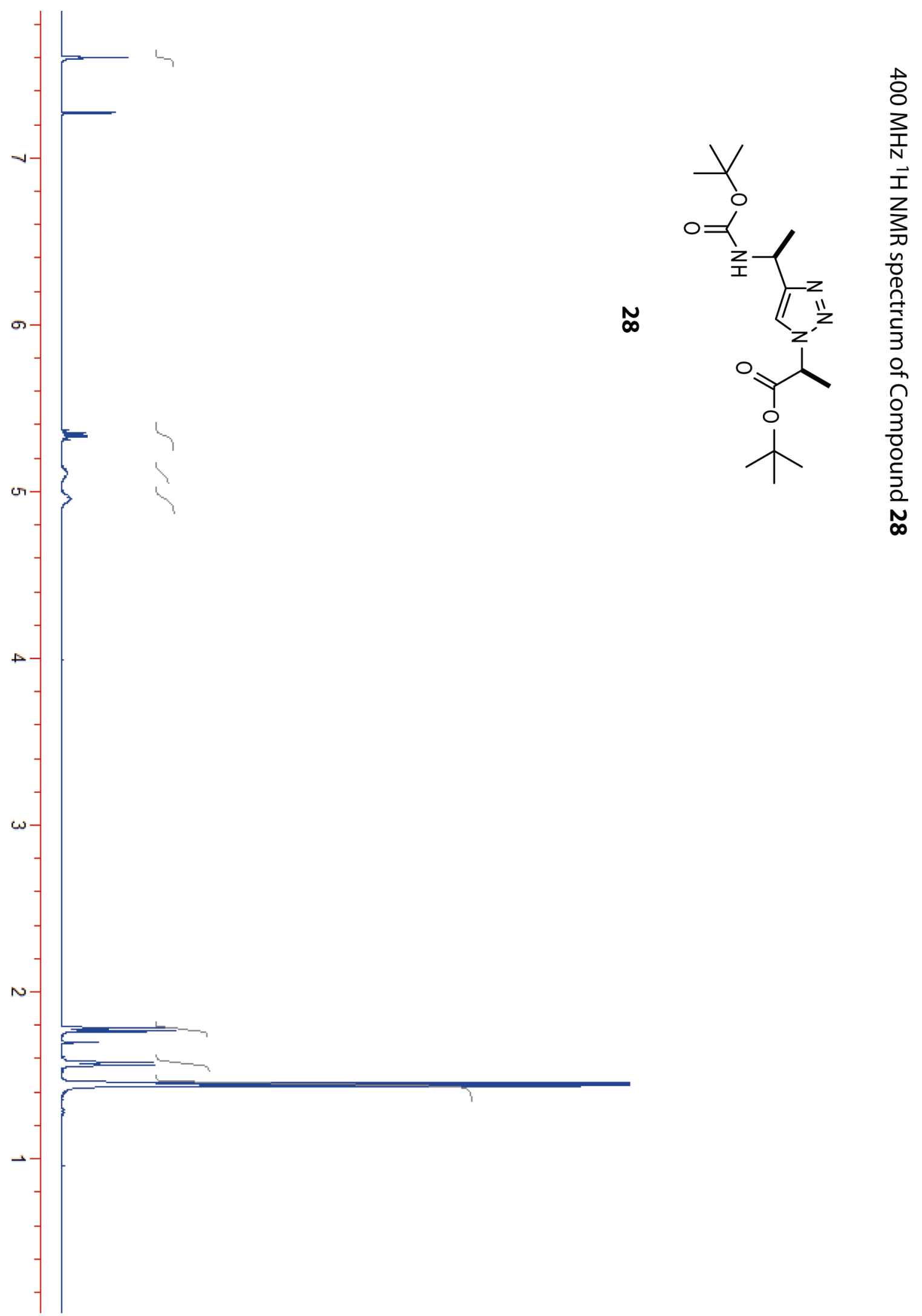


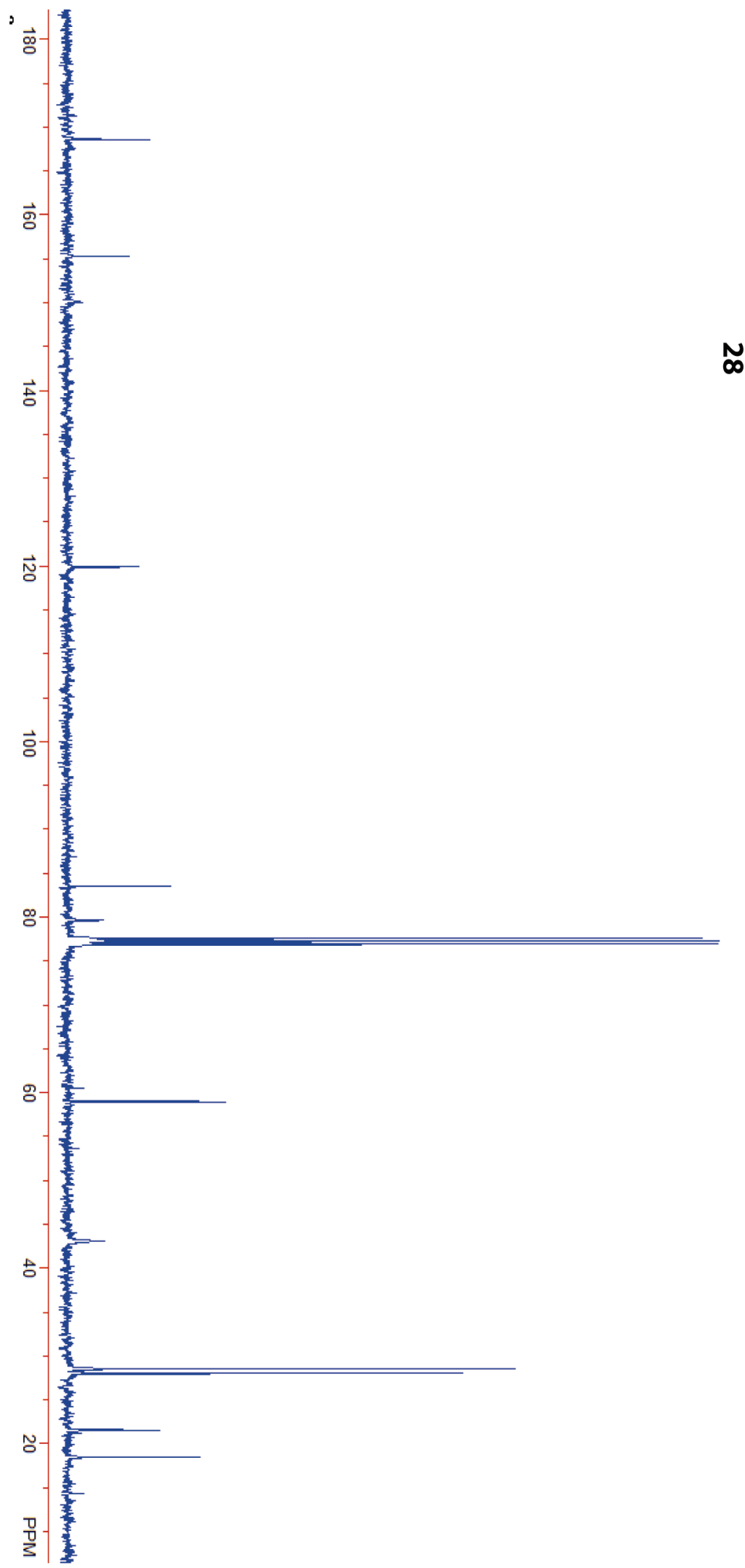

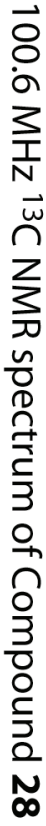




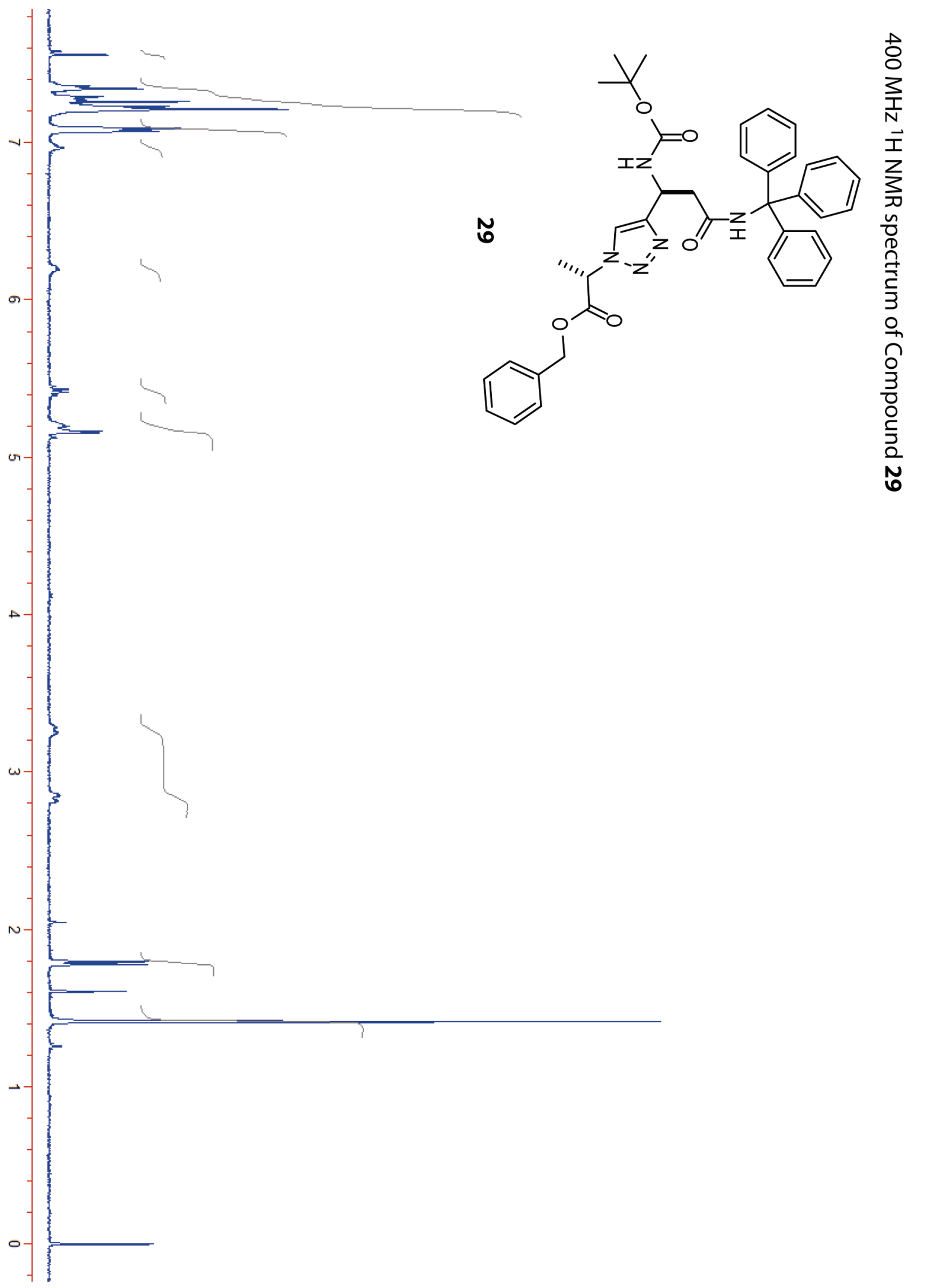




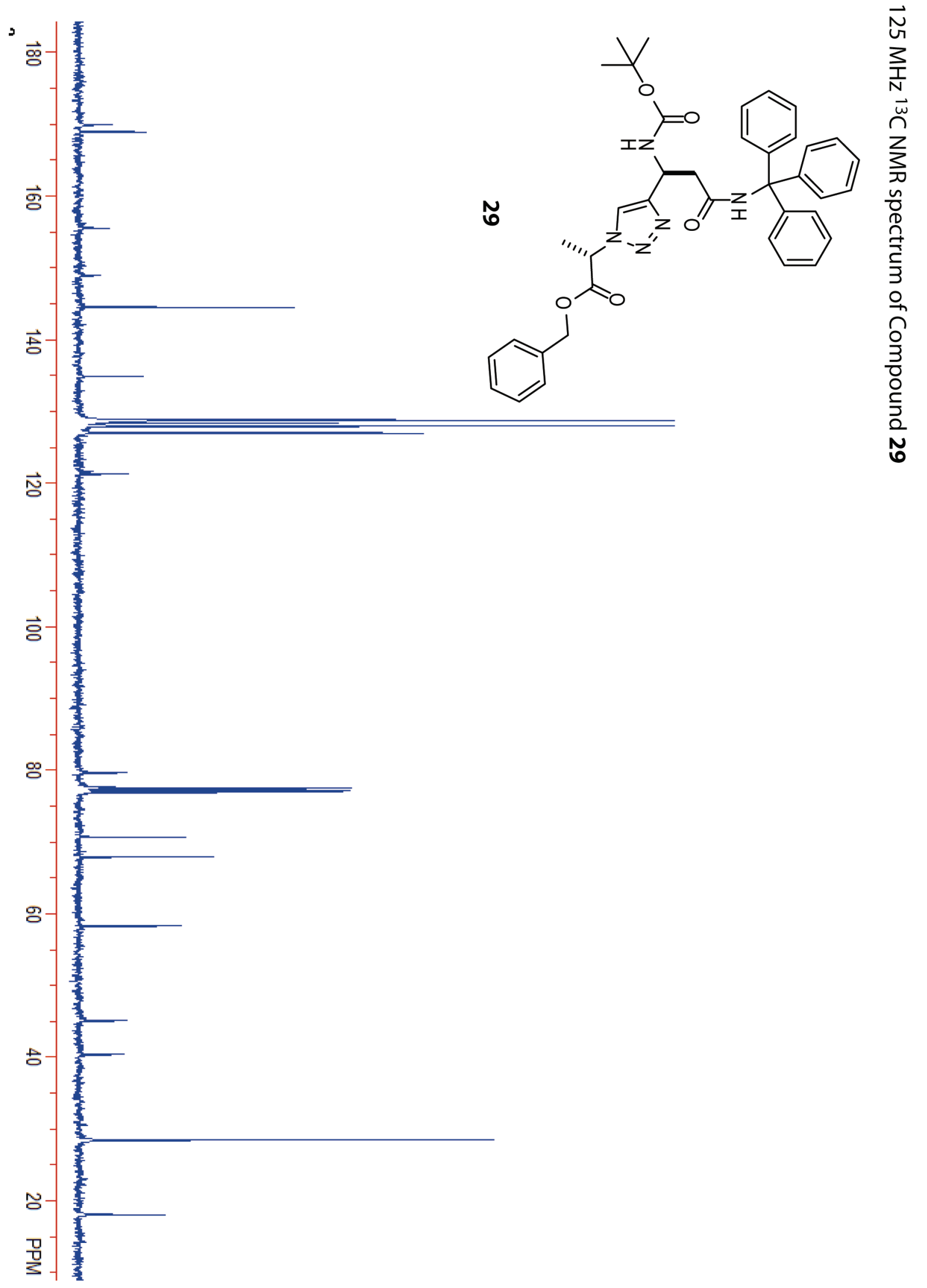




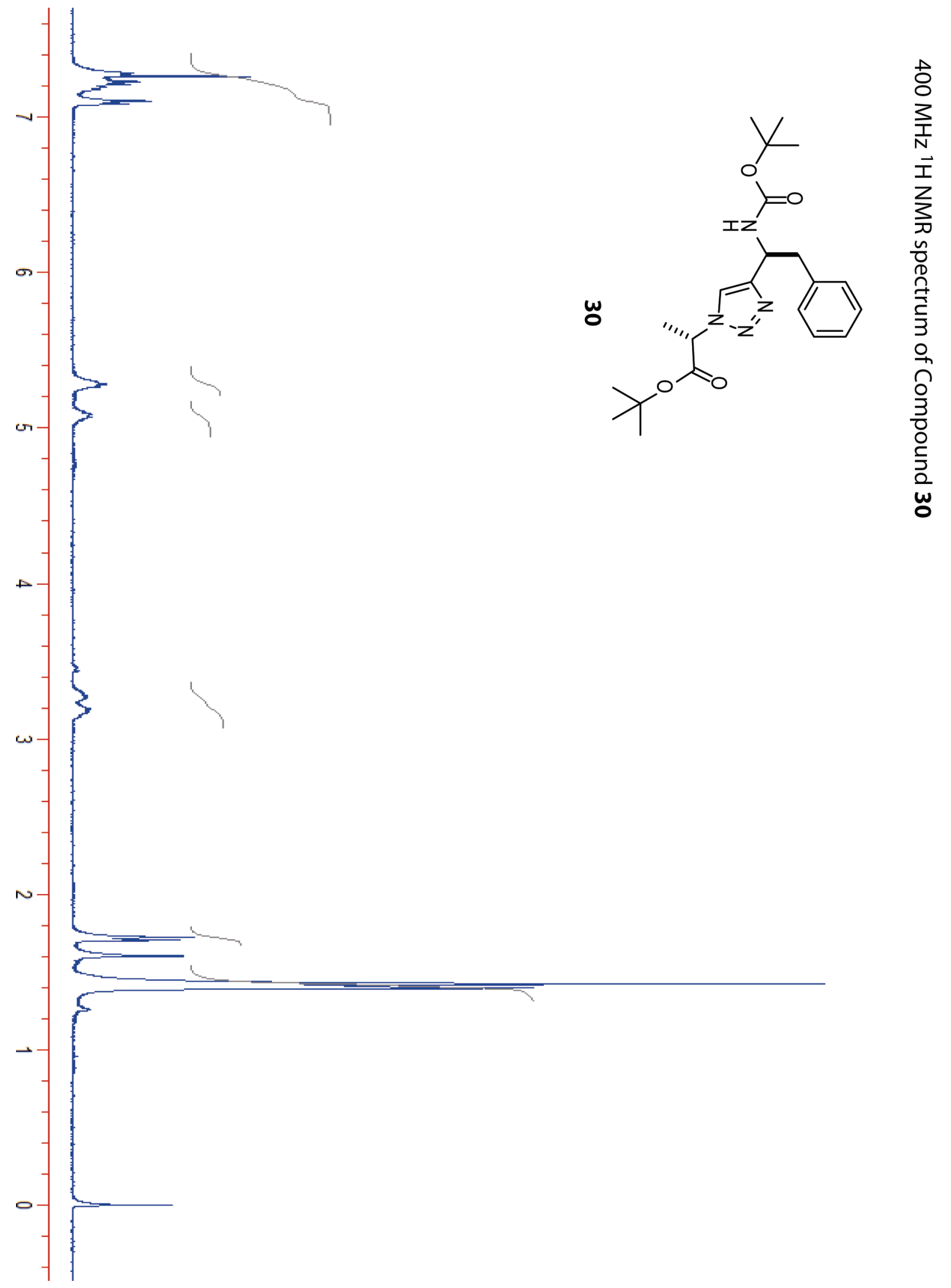


Tam, Arnold, Soellner, and Raines

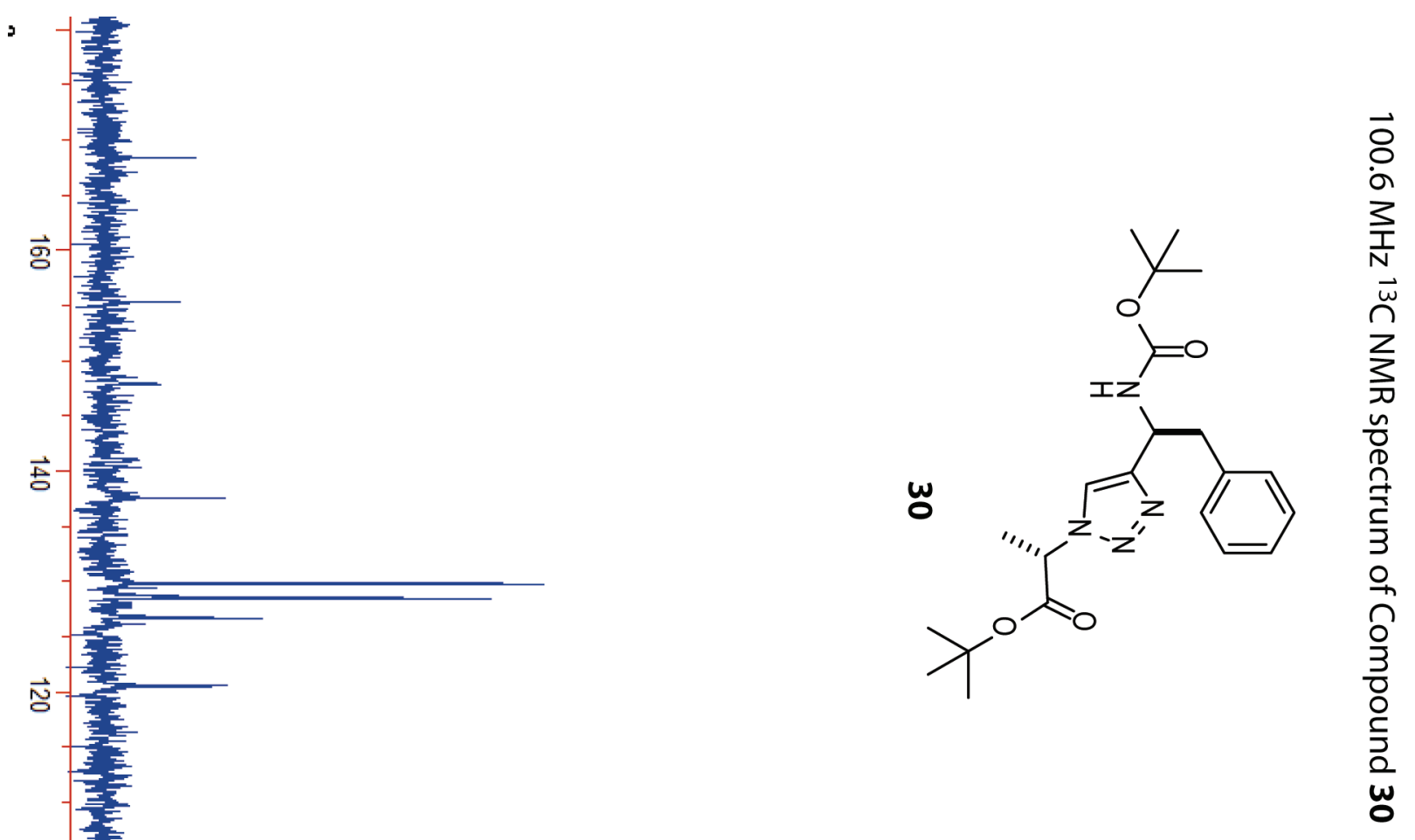

Supporting Information

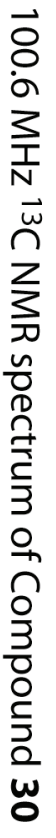

-S66- 


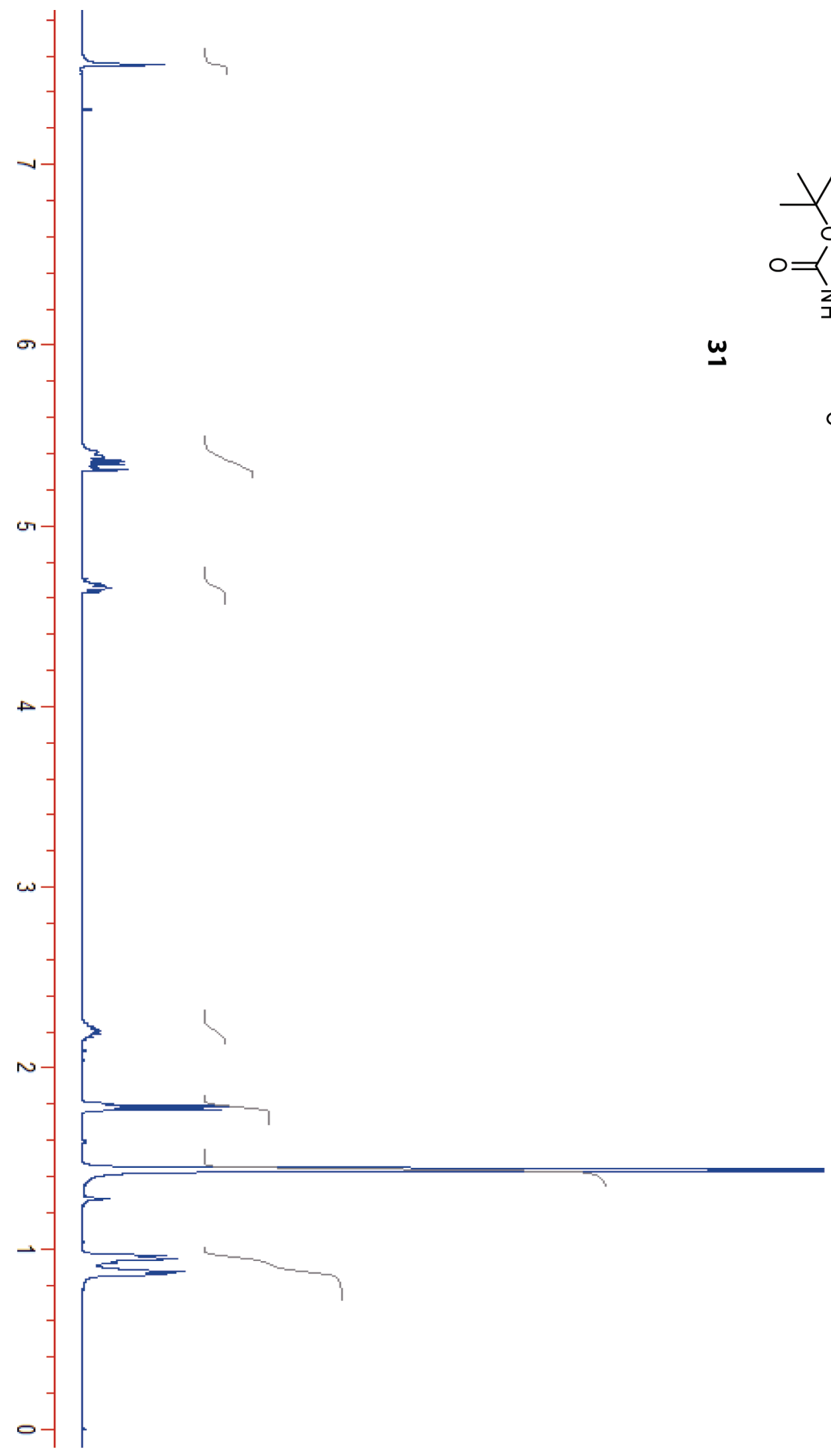




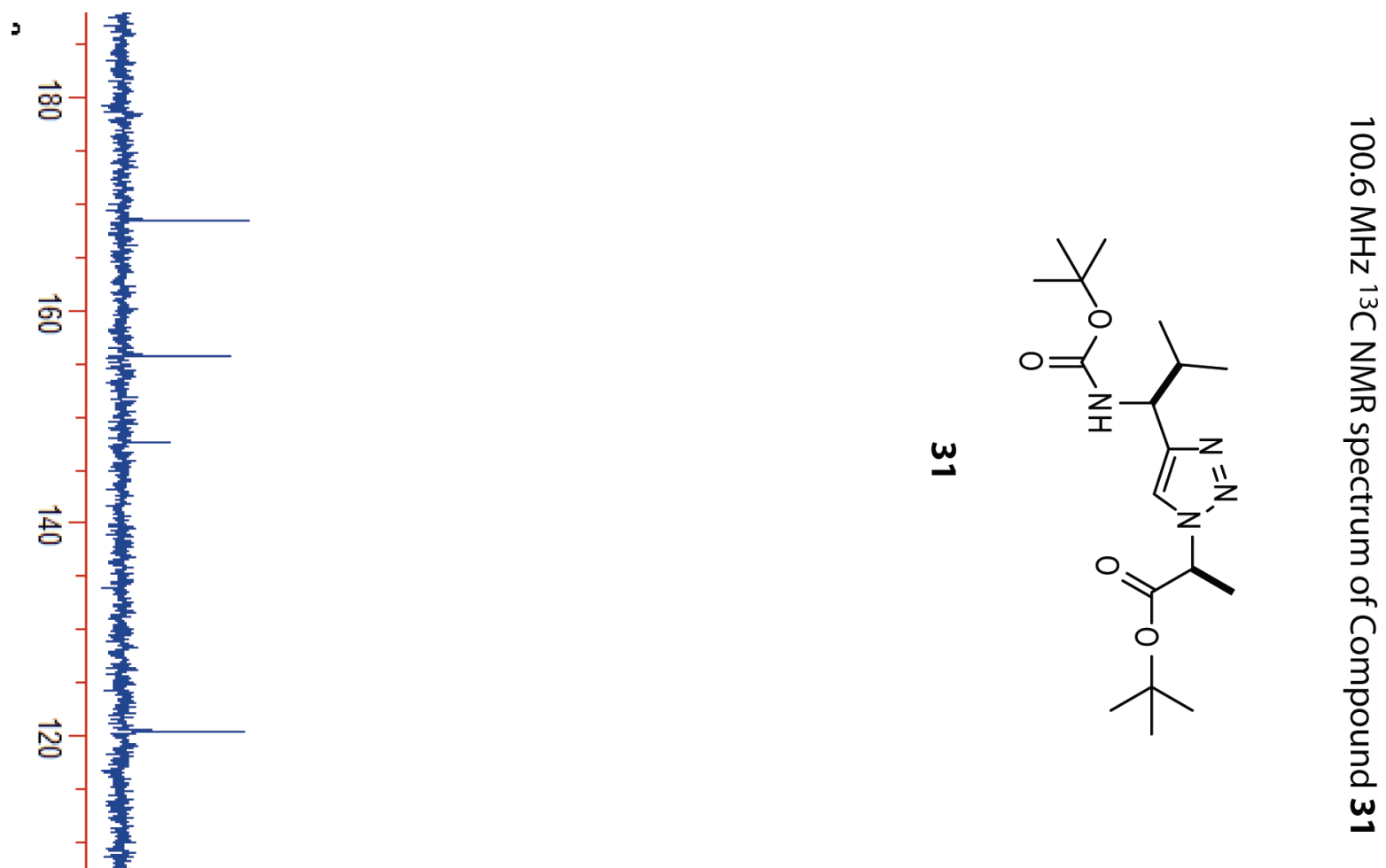

홍

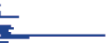

g용

政

몸

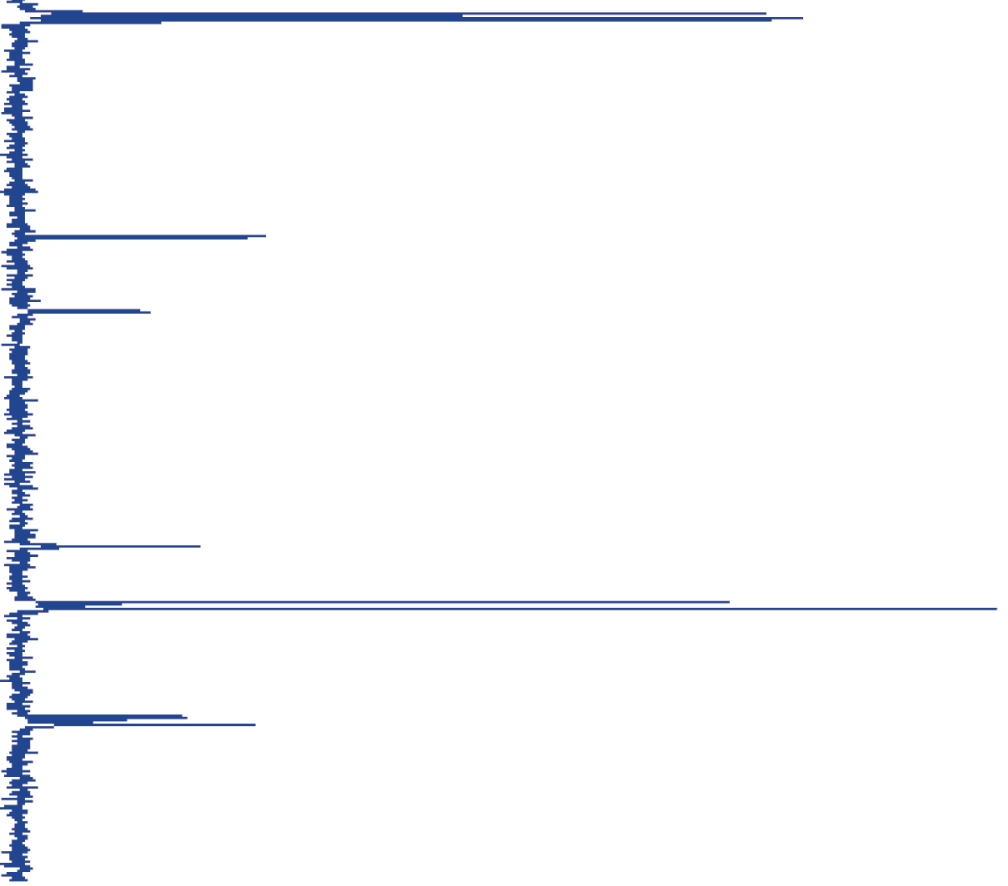



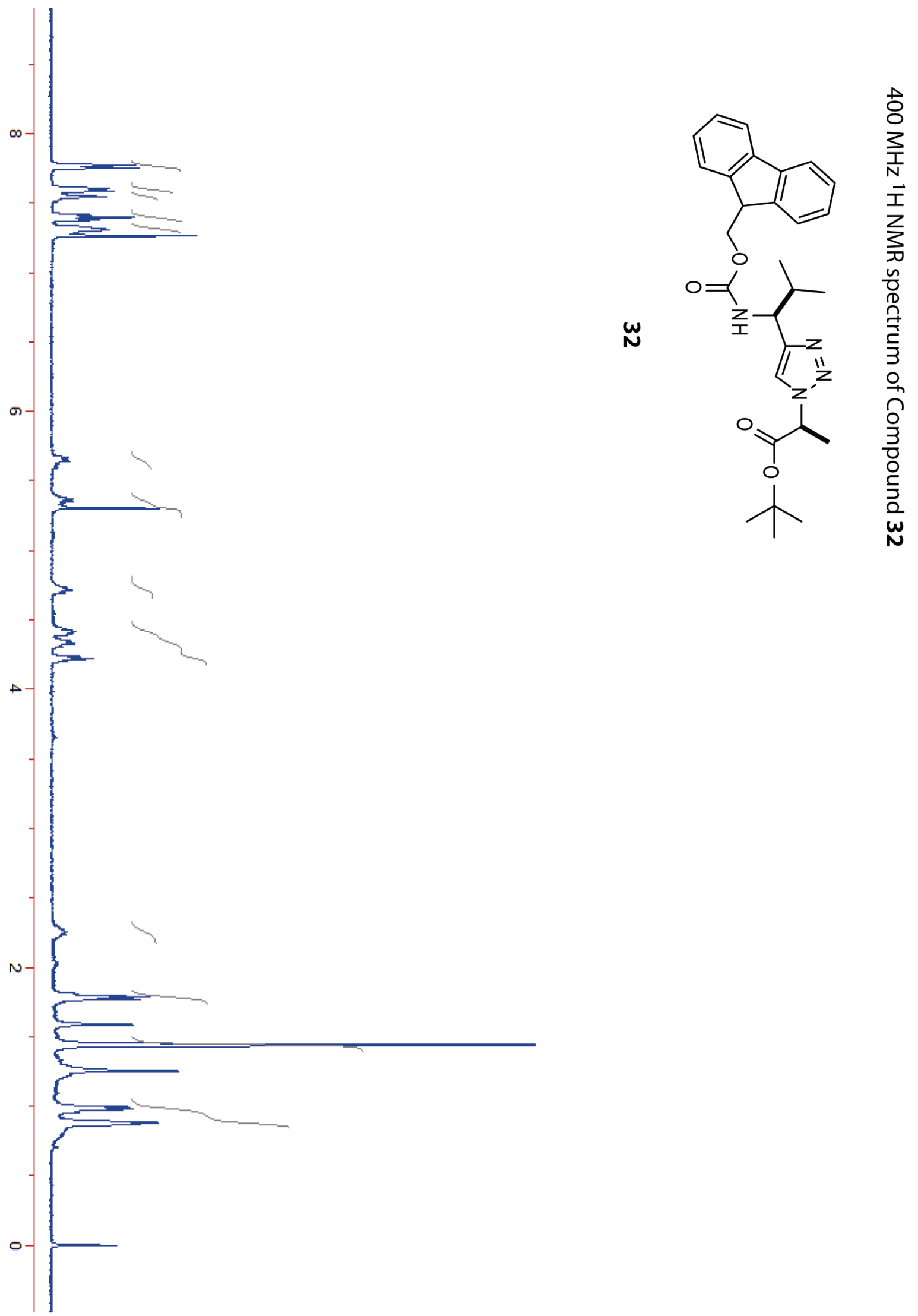
工

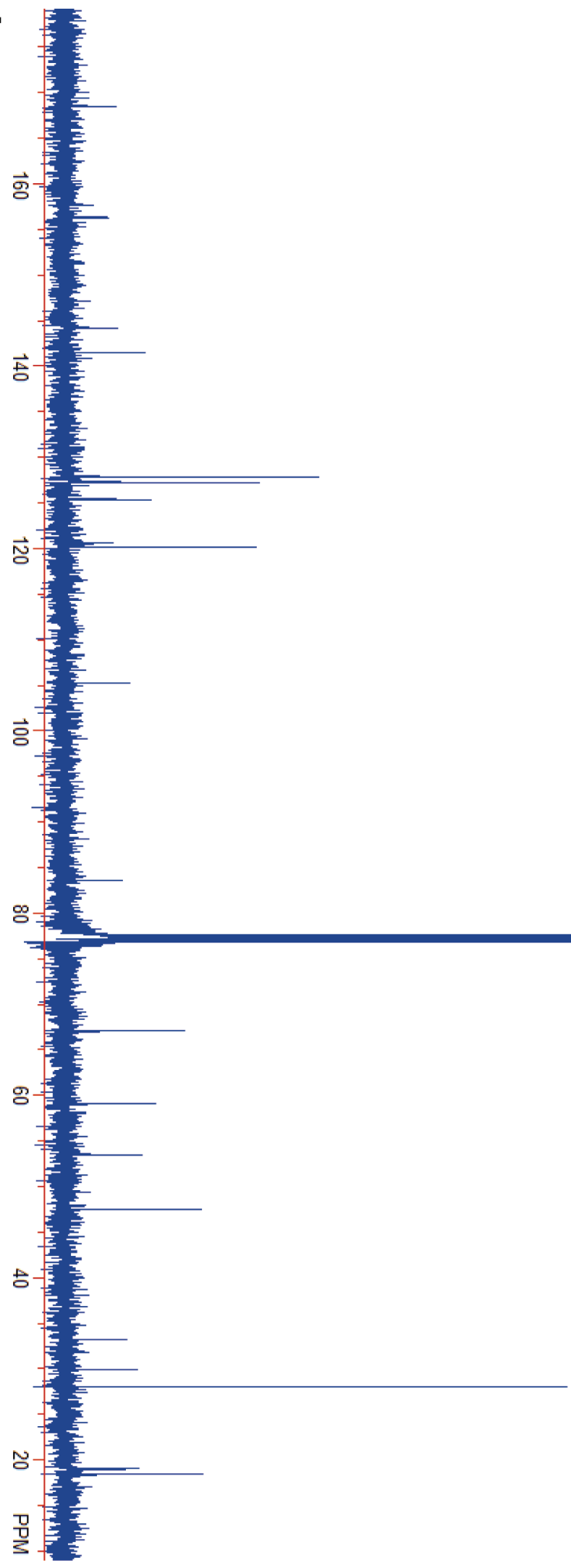

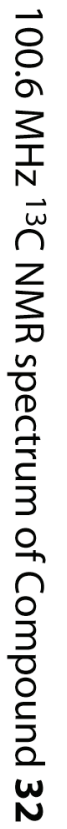




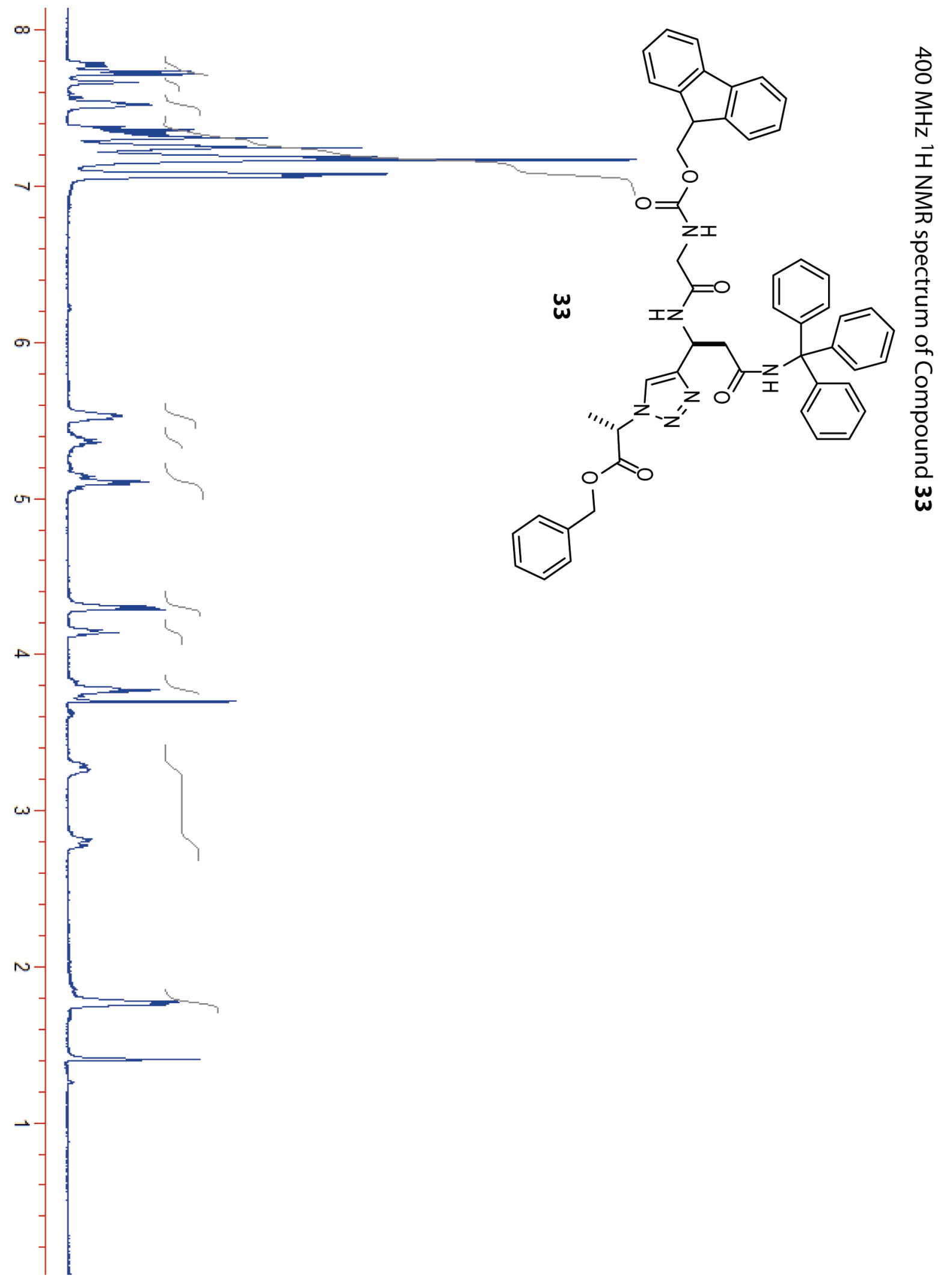




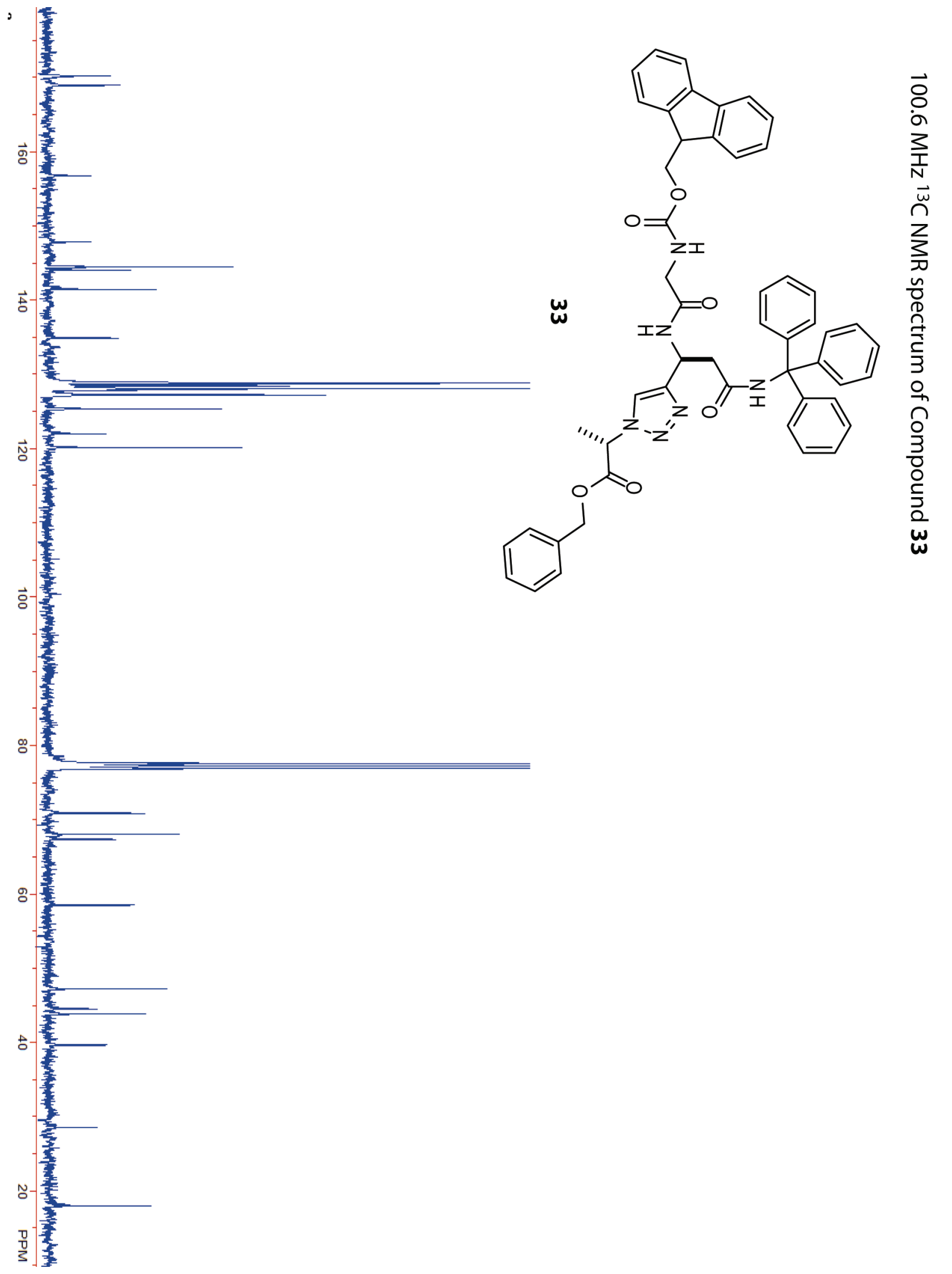




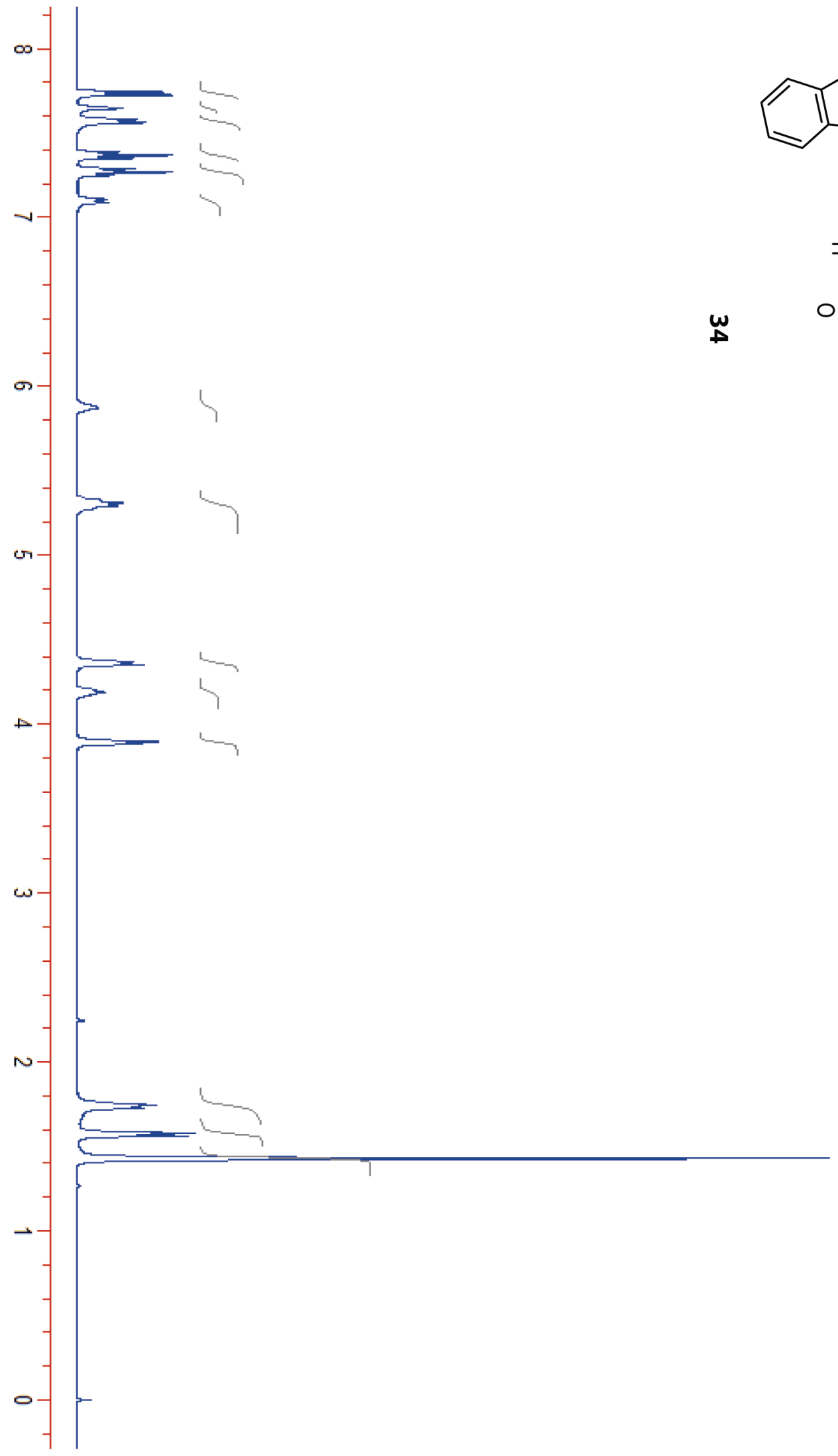



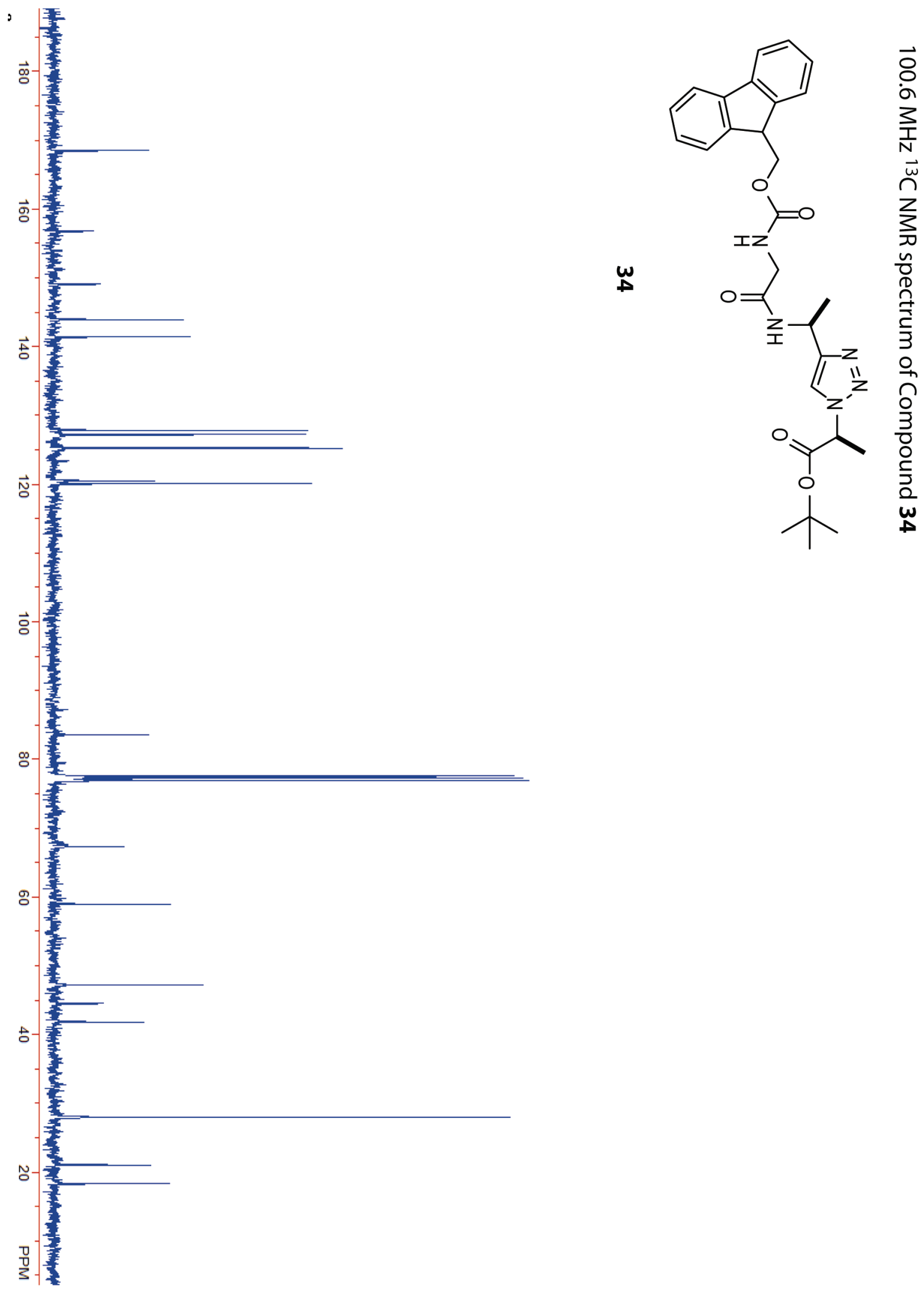

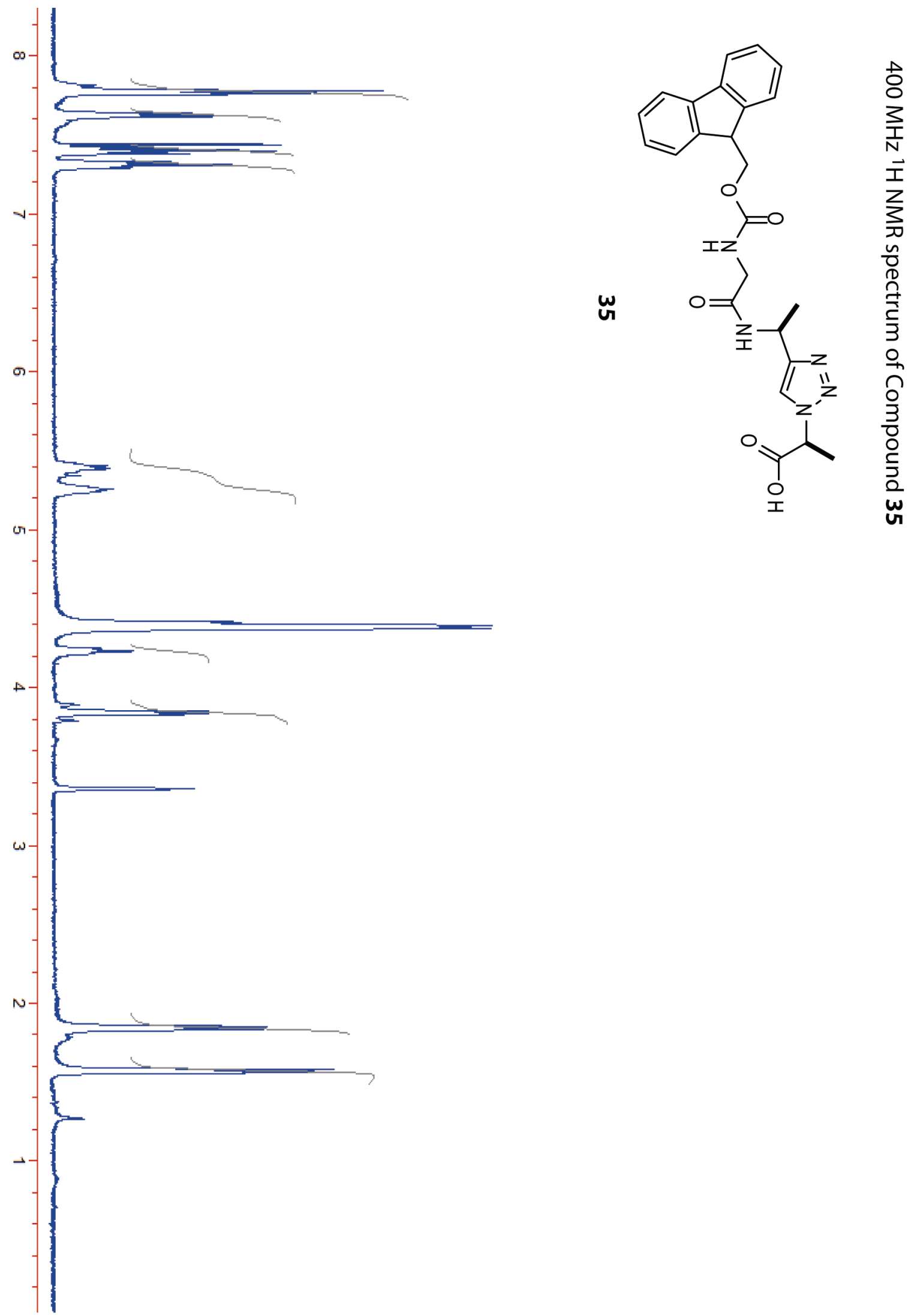

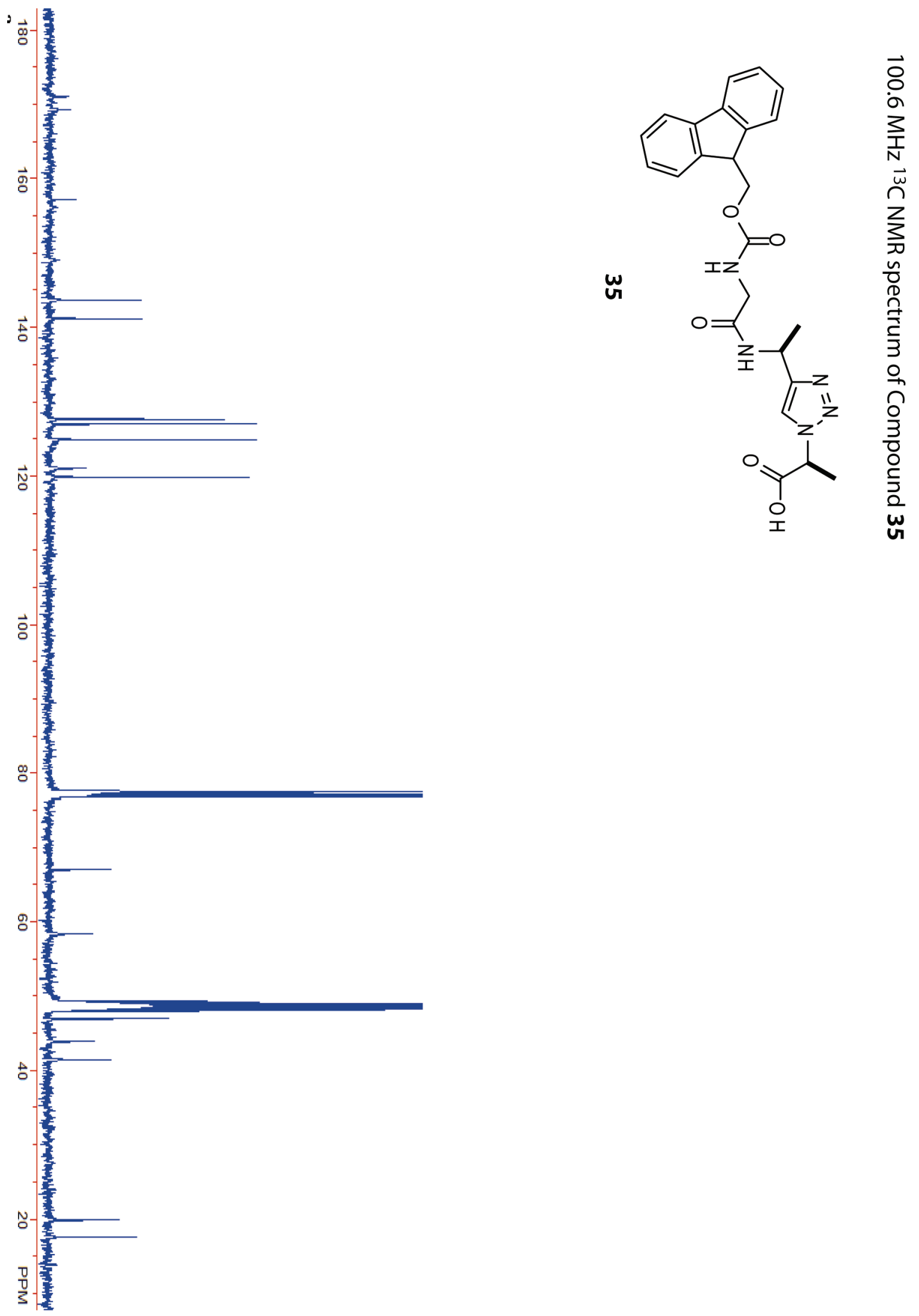


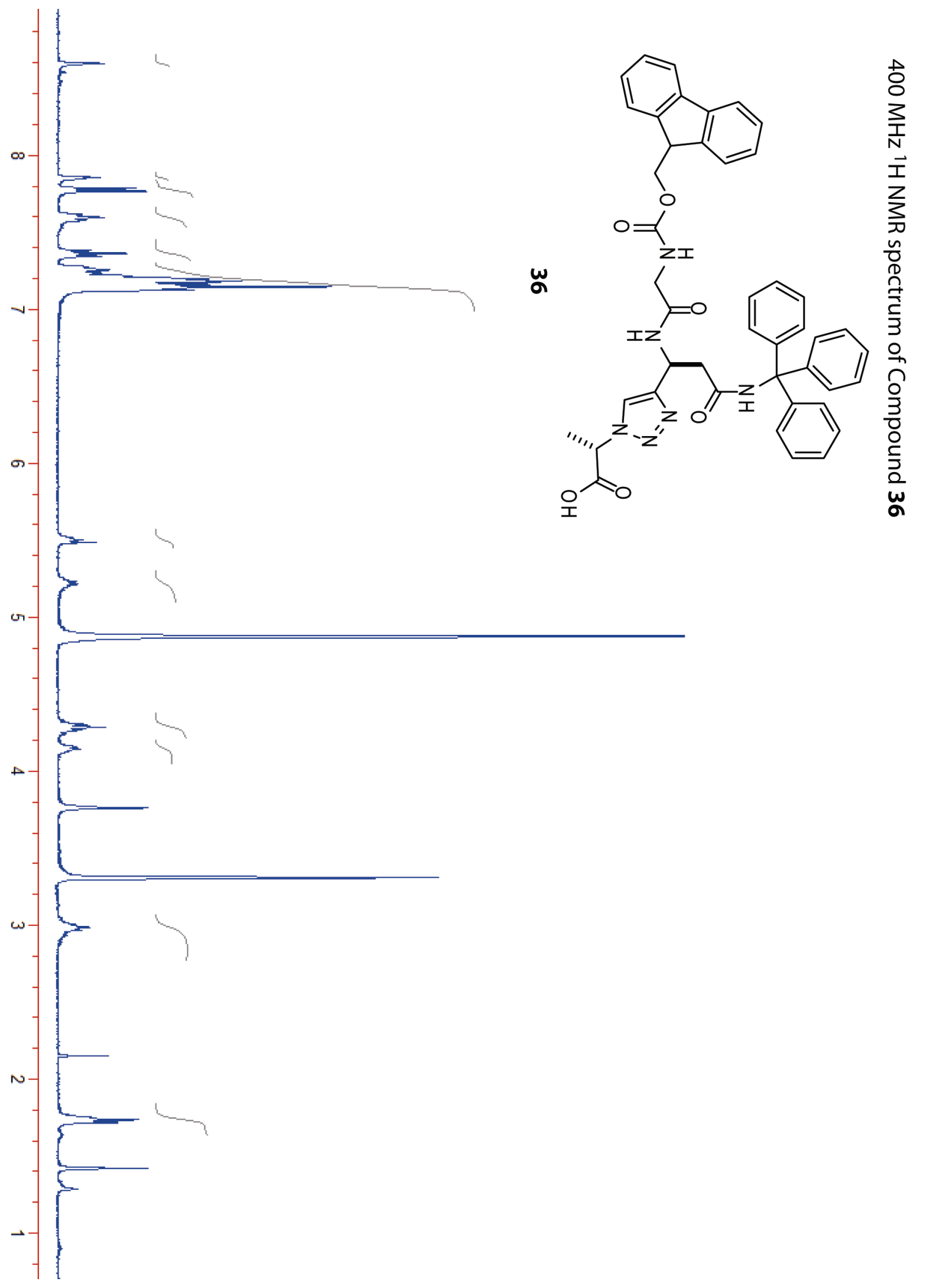




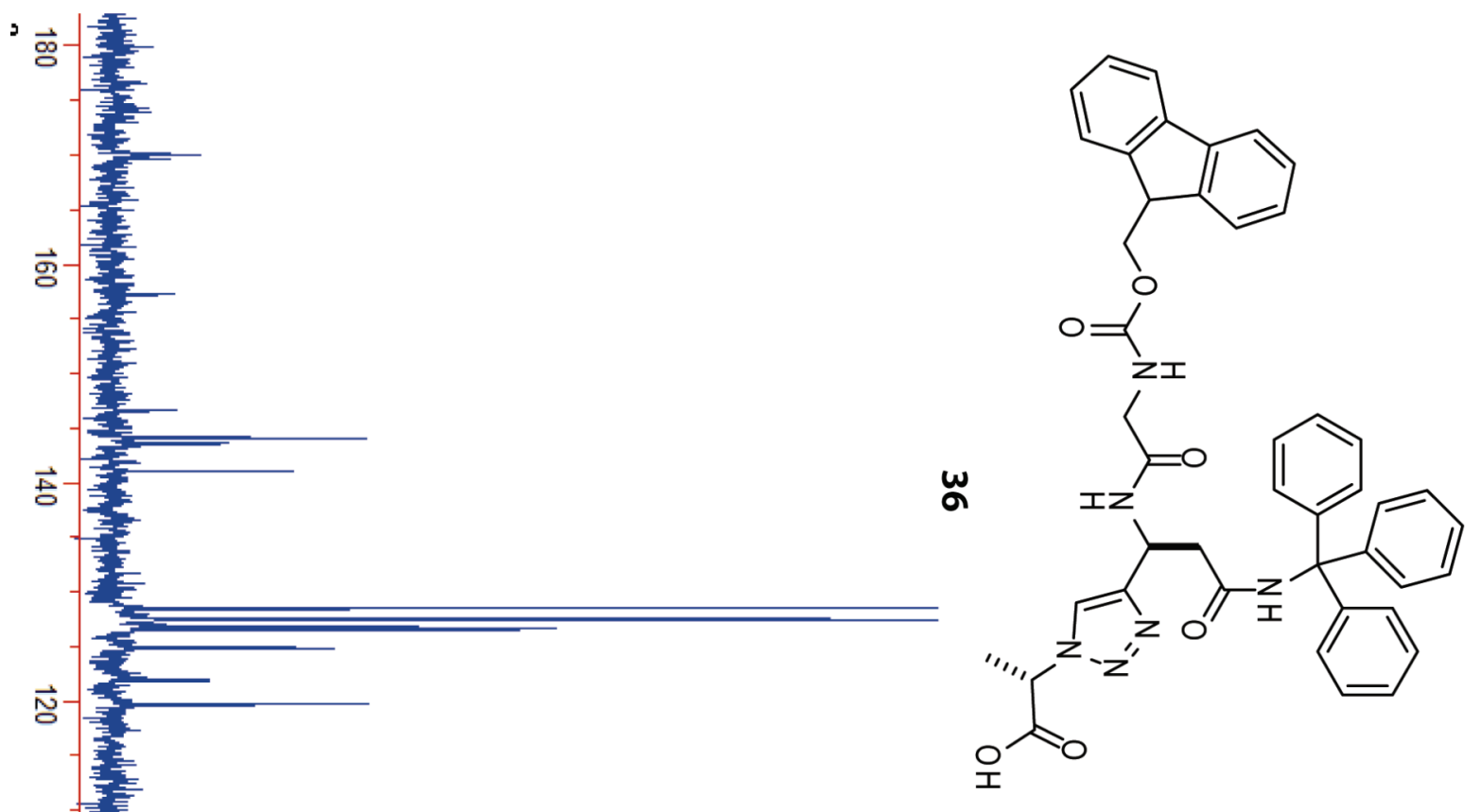

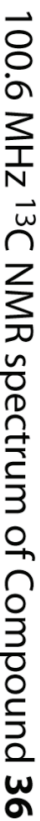

号-

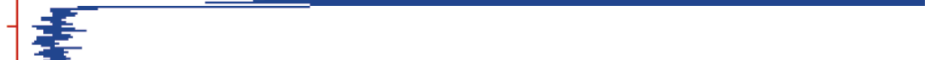

홍

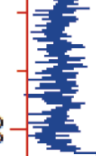

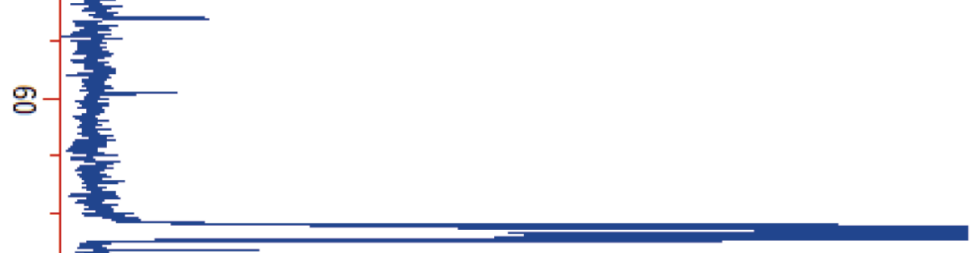

E
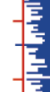

용

s

跣 